Florida International University FIU Digital Commons

\title{
Thermodynamic Evaluation and Modeling of Grade 91 Alloy and its Secondary Phases through CALPHAD Approach
}

Andrew Logan Smith Mr.

Florida International University, asmit297@fiu.edu

DOI: $10.25148 /$ etd.FIDC006862

Follow this and additional works at: https://digitalcommons.fiu.edu/etd

Part of the Computational Engineering Commons, and the Structural Materials Commons

\section{Recommended Citation}

Smith, Andrew Logan Mr., "Thermodynamic Evaluation and Modeling of Grade 91 Alloy and its Secondary Phases through CALPHAD Approach" (2018). FIU Electronic Theses and Dissertations. 3773.

https://digitalcommons.fiu.edu/etd/3773 


\section{FLORIDA INTERNATIONAL UNIVERSITY}

Miami, Florida

THE THERMODYNAMIC EVALUATION AND MODELING OF GRADE 91

ALLOY AND ITS SECONDARY PHASES THROUGH CALPHAD APPROACH

A thesis submitted in partial fulfillment of

the requirements for the degree of

MASTER OF SCIENCE

in

MATERIALS SCIENCE AND ENGINEERING

by

Andrew Logan Smith

2018 
To: Dean John Volakis

College of Engineering and Computing

This thesis, written by Andrew Logan Smith, and entitled The Thermodynamic Evaluation and Modeling of Grade 91 Alloy and its Secondary Phases through CALPHAD Approach, having been approved in respect to style and intellectual content, is referred to you for judgment.

We have read this thesis and recommend that it be approved.

\begin{tabular}{l} 
Zhe Cheng \\
\hline Jichua Chen
\end{tabular}

Yu Zhong, Major Professor

Date of Defense: May 7, 2018

The thesis of Andrew Logan Smith is approved.

Dean John Volakis College of Engineering and Computing

Andrés G. Gil Vice President for Research and Economic Development and Dean of the University Graduate School

Florida International University, 2018 


\section{DEDICATION}

I dedicate this thesis to my family. Without their patience, understanding, support, and most of all love, the completion of this work would not have been possible. 


\section{ACKNOWLEDGMENTS}

I wish to thank the members of my committee for their support, patience, and understanding throughout my studies. A special thanks to Hooman Sabarou, Mohammad Asadikiya, and Shadi Darvish and to the Department of Energy (DOE) for giving their opportunity and support to me and our group. Finally, I would like to thank my major

professor, Dr. Yu Zhong. Your mentorship and ability to challenge me has added tremendously to my education in computational thermodynamics.

I have found my coursework throughout the program to be stimulating and thoughtful, providing me with the tools with which to explore both past and present ideas and issues. 


\title{
ABSTRACT OF THE THESIS \\ THE THERMODYNAMIC EVALUATION AND MODELING OF GRADE 91 \\ ALLOY AND ITS SECONDARY PHASES THROUGH CALPHAD APPROACH
}

\author{
by \\ Andrew Logan Smith \\ Florida International University, 2018 \\ Miami, Florida \\ Professor Yu Zhong, Major Professor
}

Grade 91 (Gr.91) is a common structural material used in boiler applications and is favored due to its high temperature creep strength and oxidation resistance. Under cyclic stresses, the material will experience creep deformation eventually causing the propagation of type IV cracks within its heat-affected-zone (HAZ) which can be a major problem under short-term and long-term applications. In this study, we aim to improve this premature failure by performing a computational thermodynamic study through the Calculation of Phase Diagram (CALPHAD) approach. Under this approach, we have provided a baseline study as well as simulations based on additional alloying elements such as manganese (Mn), nickel (Ni), and titanium (Ti). Our simulation results have concluded that high concentrations of $\mathrm{Mn}$ and $\mathrm{Ni}$ had destabilized $\mathrm{M}_{23} \mathrm{C}_{6}$ for short-term creep failure, while Ti had increased the beneficial MX phase, and low concentrations of nitrogen $(\mathrm{N})$ had successfully destabilized Z-phase formation for long-term creep failure. 


\section{TABLE OF CONTENT}

CHAPTER

PAGE

CHAPTER 1 INTRODUCTION 1

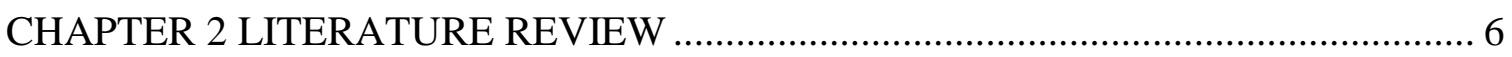

2.1 High Chromium Martensitic-Ferritic Grade 91 Alloy .............................................. 6

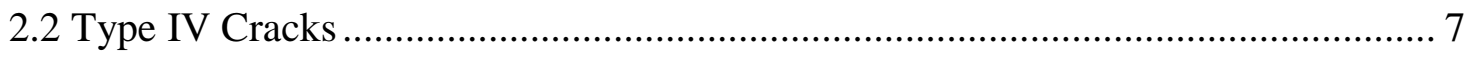

2.3 Heat-Treatment and Welding Parameters ........................................................... 8

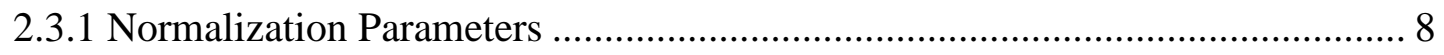

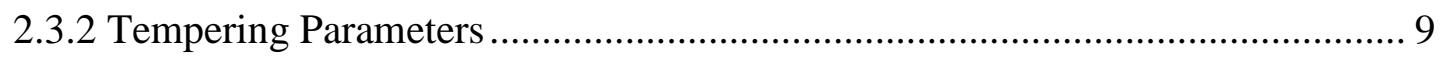

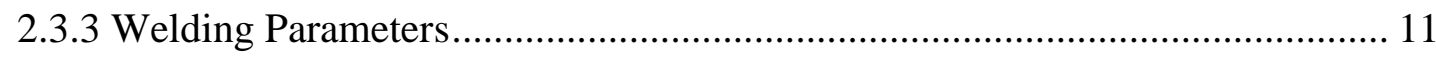

2.3.4 Post-Weld-Heat-Treatment (PWHT) Parameters .............................................. 12

2.4 Microstructural Change During Welding of Grade 91 ........................................... 12

2.4.1 Ac1 and Ac3 Temperatures ..................................................................... 13

2.4.1 Coarse-Grain HAZ (CGHAZ) ………………........................................ 15

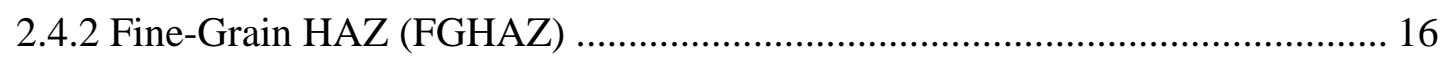

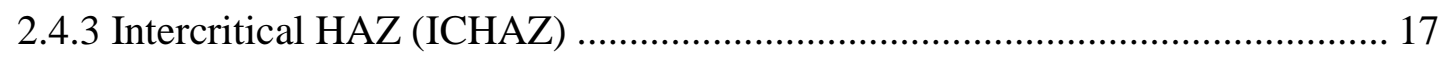

2.5 Secondary Phases that Influence Type IV Cracks .............................................. 18

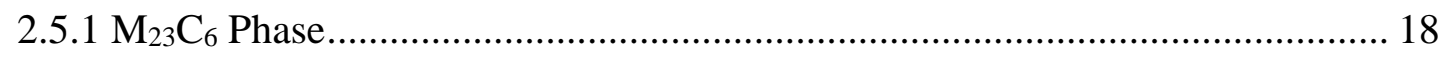

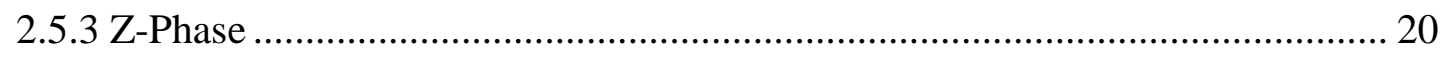

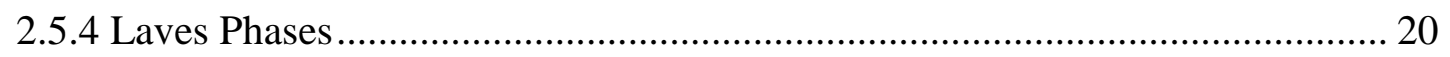

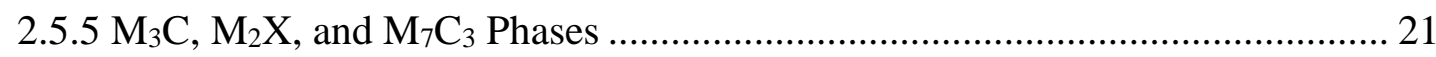

2.6 Elements and their roles in the formation of secondary phases............................. 22

2.6.1 Austenite $(\gamma-\mathrm{Fe})$ and Ferrite $(\alpha-\mathrm{Fe})$ Stabilizers.............................................. 22

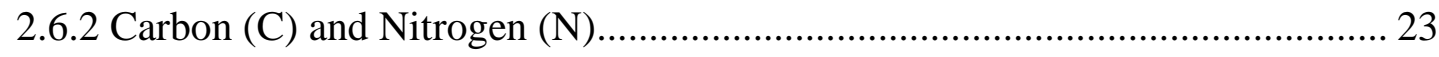

2.6.3 Chromium (Cr) and Molybdenum (Mo)...................................................... 23

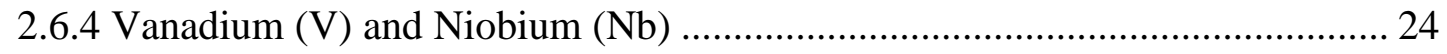

2.6.5 Nickel (Ni) and Manganese (Mn) .......................................................... 24

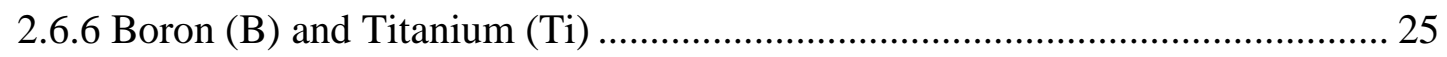

2.7 Observed Mechanisms Causing Type IV Failure …….......................................... 28

2.7.1 Long-Term Creep Failure ………………………................................. 28

2.7.2 Short-Term Creep Failure........................................................................ 28

2.8 CALPHAD (Calculation of Phase Diagrams) ....................................................... 30 
CHAPTER 3 OBJECTIVES AND CREEP THEORY 31

3.1 Objectives ...................................................................................................... 31

3.2 Theory of Improving Creep Life of Grade 91 ........................................................ 31

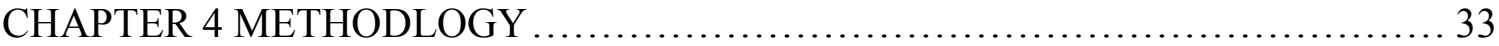

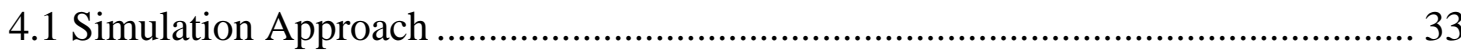

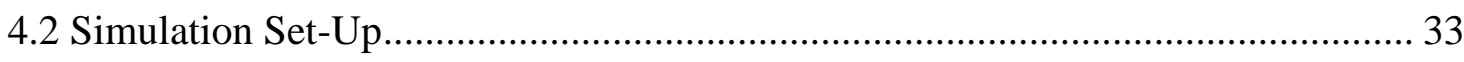

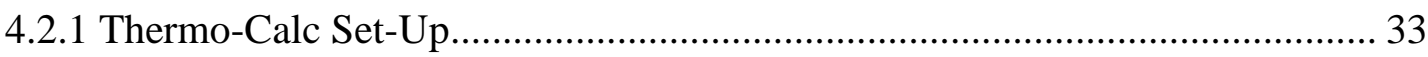

4.2.2 Composition of Grade 91 Baseline Study ....................................................... 34

4.2.3 Simulated Compositional Changes of Gr.91 .................................................. 34

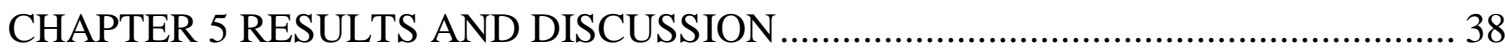

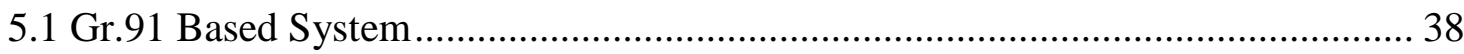

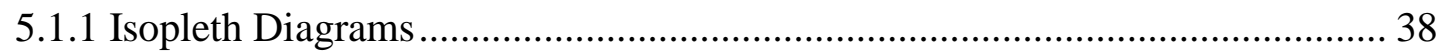

5.1.2 Ac1 and Ac3 Temperature Change ............................................................. 41

5.1.3 Gibbs Energy of FCC Structure ( $\gamma$ phase and MX phase)................................ 43

5.1.4 Mole Fraction of Secondary Phases under Equilibrium Condition ................... 44

5.1.5 Site Fraction of MX Phase under Equilibrium Condition ................................ 45

5.1.6 Equilibrium Cooling and Scheil Simulations ................................................... 48

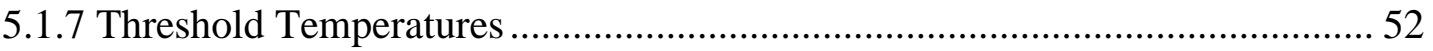

5.2 Modified Gr.91 System................................................................................ 54

5.2.1 Effects of Manganese (Mn) and Nickle (Ni) with Stability of $\mathrm{M}_{23} \mathrm{C}_{6}$ Phase ... 54

5.2.2 Mole and Composition Change of Titanium (Ti) with of MX1 Phase............. 56

5.2.3 Scheil Simulations for $\mathrm{M}_{23} \mathrm{C}_{6}$ and MX1 Phases for S-1, S-2, and S-3 ............ 59

5.2.4 Mole Fraction and Composition of New MX3 Phase under S-3 Simulation ... 61

5.2.5 Z-phase Stability Changes Under Different Compositions ............................... 63

5.2.6 Mole Fraction and Threshold Temperatures of the new modified Gr.91 ......... 64

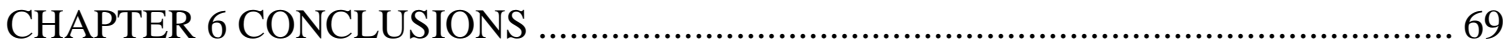

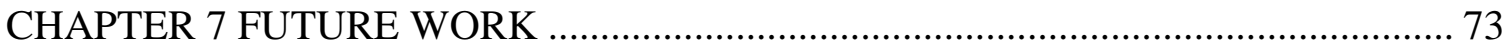

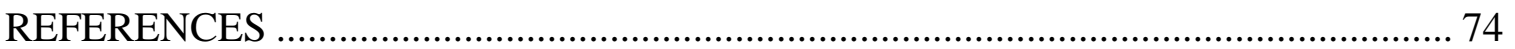




\section{LIST OF TABLES}

TABLE

PAGE

Table 1. Chemical compositions and heat treatment conditions of $9 \mathrm{Cr}-2 \mathrm{~W}-\mathrm{VNb}-$ $0.13 \mathrm{C}$ steels with and without $0.05 \mathrm{wt} . \% \mathrm{Ti}$ (adapted from [34])

Table 2. Chemical composition from the ASME standard[23] and simulation of Gr.91 base system.

Table 3. Compositional changes to Gr.91 base system. Here, concentrations of manganese $(\mathrm{Mn})$, nickel (Ni), and titanium (Ti) are added separately to the system.

Table 4. Compositional alloy changes to the Gr.91 base system under different niobium $(\mathrm{Nb})$, vanadium $(\mathrm{V})$, and nitrogen $(\mathrm{N})$ concentrations which excludes the additional $\mathrm{Mn}, \mathrm{Ni}$, and $\mathrm{Ti}$ concentrations made in Table 3.

Table 5. Modified version of Gr.91 under the combined elements of Mn, Ni, and $\mathrm{Ti}$ while also optimizing the $\mathrm{V}, \mathrm{Nb}$, and $\mathrm{N}$ concentrations. 


\section{LIST OF FIGURES}

FIGURE

PAGE

Figure 1. Microstructure of $9 \mathrm{Cr}-1 \mathrm{MoVNb}$ that consists of coarse prior-austenitic grain martensite, fine prior-austenitic grain martensite, intercritical, and overtempered regions

[17].

Figure 2. Schematic representation of the types of cracks and their location along the weld metal and HAZ in Gr.91 alloy [16].

Figure 3. Schematic showing microstructure evolutions during welding and PWHT for the LTT and HTT conditions [8].

Figure 4. Results of strain vs. time to failure in hours at tempering temperatures between $600^{\circ} \mathrm{C}-800^{\circ} \mathrm{C}[9]$ 11

Figure 5. Schematic showing the locations of the CGAHZ, FGHAZ, and ICHAZ between the weld metal (WM) and base metal (BM) of Gr.91 while comparing it to a $\mathrm{Fe}-\mathrm{Fe} 3 \mathrm{C}$ phase diagram [28].

Figure 6. Thermo-Calc calculation of the Fe-C binary phase diagram which highlights the Ac1(blue) and Ac3(red) temperatures

Figure 7. Coarse-Grain-HAZ (CGHAZ) of Gr.91 taken at $400 \mu \mathrm{m}$

Figure 8. Fine-Grain HAZ (FGHAZ) of Gr.91 taken at $300 \mu \mathrm{m}$.

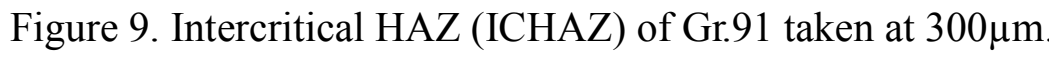

Figure 10. SEM image of $\mathrm{M}_{23} \mathrm{C}_{6}$ carbide after creep testing at $650^{\circ} \mathrm{C}$ for 10,872 hours [29]. 
Figure 11. Transmission Electron Microscope (TEM) image of a high titanium (Ti) MX phase after normalization at $1040^{\circ} \mathrm{C}$ for 2 hours [32].

Figure 12. A schematic of the Z-phase crystal structure. The lattice parameter for $\mathrm{CrNbN}$ is $\mathrm{a}=0.304 \mathrm{~nm}$ and $\mathrm{c}=0.739 \mathrm{~nm}$ while for $\mathrm{CrVN}$ it is $\mathrm{a}=0.286$ and $\mathrm{c}=$ $0.739[35]$.

Figure 13. A scanning transmission electron microscope-high angle Angular dark field (STEM-HAADF) image of Laves phase formation (dark arrows) next to $\mathrm{M}_{23} \mathrm{C}_{6}$ carbides (light arrows) after 10,200 hours of testing for $9 \mathrm{Cr}$ steel [43].

Figure 14. Graph of temperature $\left({ }^{\circ} \mathrm{C}\right)$ vs. weight $\%$ which represents the influence of alloying element additions on the eutectoid temperature within the $\mathrm{Fe}^{-} \mathrm{Fe}_{3} \mathrm{C}$ phase diagram [49]. An increase in eutectoid temperature represents an $\alpha-\mathrm{Fe}$ stabilizer, while a decrease represents $\gamma$-Fe stabilizer.

Figure 15. Comparison of predicted Ac1 and experimentally measured Ac1 temperatures for Gr.91 under $\mathrm{Mn}$ and $\mathrm{Ni}$ concentrations [56].

Figure 16. Electron backscatter diffraction pattern (EBSP) analysis results for 90 ppmB steel and P92 steel HAZ microstructures [58].

Figure 17. Log-log plot of creep rate versus time curves of the Ti series in Table 1 at $650^{\circ} \mathrm{C}$ under stress conditions of $80 \mathrm{MPa}$ [34].

Figure 18. Z-phase formation in Gr.91 steel after long-term creep exposure [63]. 28

Figure 19. TEM of $\mathrm{M}_{23} \mathrm{C}_{6}$ precipitates (black spots) under different working temperatures. A) Lower tempering temperatures (LTT) at $650{ }^{\circ} \mathrm{C}$ and B) high

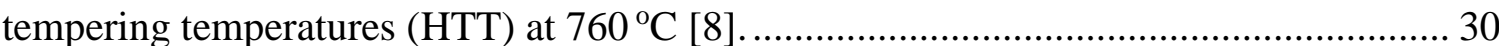

Figure 20. Overall isopleth diagram of Gr.91 based system for temperature ranges of $600^{\circ} \mathrm{C}-1600^{\circ} \mathrm{C}$ at a range of $0-0.2 \mathrm{wt} . \% \mathrm{C}[81]$. 
Figure 21. Close up of phase diagram at temperature ranges of $700^{\circ} \mathrm{C}-1000^{\circ} \mathrm{C}$ and $0-0.15$ wt.\%C [81]...

Figure 22. Ac1 temperature $\left({ }^{\circ} \mathrm{C}\right)$ vs. wt. $\%$ of $\mathrm{C}$ for $\mathrm{Gr} .91$ based system simulation (solid line) while comparing with the Fe-C binary system Ac temperatures (dash line) [81].

Figure 23. Ac3 temperature $\left({ }^{\circ} \mathrm{C}\right)$ vs. wt. $\%$ of $\mathrm{C}$ for Gr.91 based system simulation (solid line) while comparing with the Fe-C binary system Ac temperatures (dash line) $[81]$

Figure 24. The Gibbs energy of $\gamma$ phase, MX1 phase, and MX2 phase in the Gr.91 based system at $1000^{\circ} \mathrm{C}$ from $0 \mathrm{wt} . \%-0.20 \mathrm{wt} . \% \mathrm{C}$ [81]. 43

Figure 25. Mole fraction of secondary phases in Gr.91 based system [81]. 45

Figure 26. Site Fraction of MX1 for $\mathrm{Nb}$ and $\mathrm{V}$ concentrations under the first sublattice of the crystal [81] 46

Figure 27. Site Fraction of MX1 for $\mathrm{C}$ and $\mathrm{N}$ concentrations under the second sublattice of the crystal structure [81]. 46

Figure 28. Site Fraction of $\mathrm{MX} 2$ for $\mathrm{Nb}$ and $\mathrm{V}$ concentrations under the first sublattice of the crystal structure [81].

Figure 29. Site Fraction of MX2 for $\mathrm{C}$ and $\mathrm{N}$ concentrations under the second sublattice of the crystal structure [81]

Figure 30. Scheil (dash line) and equilibrium (solid line) cooling simulations results for molar fraction for $\mathrm{M}_{23} \mathrm{C}_{6}[81]$.

Figure 31.Scheil (dash line) and equilibrium (solid line) cooling simulations results for molar fraction for MX1 [81]. 50 
Figure 32. Equilibrium (solid line) simulations results for molar fraction for Zphase. No Scheil simulations were added due to its nature to being stable after longterm operational use [81].

Figure 33. Equilibrium (solid line) simulation results for molar fraction for MX2. No Scheil simulations were added due to a small amount that was simulated during equilibrium [81]. 52

Figure 34. Threshold temperatures of $\mathrm{M}_{23} \mathrm{C}_{6}$ (solid line), Z-phase (dotted line), Ac1 (blue), and Ac3 (red) temperatures under the Gr.91 base system [81]. 53

Figure 35. The effects of added concentrations of Mn and Ni to the Gr.91 Baseline System. S-1 represents the simulation for added $0.66 \mathrm{Wt} . \% \mathrm{Mn}$ and S-2 represents $0.43 \mathrm{wt} . \% \mathrm{Ni}$. Both are the maximum allowed wt.\% under ASME standards [23].

Figure 36. Added concentrations of Ti while compared to the Gr.91 Baseline System. S-3 represents the mole fraction of added $0.01 \mathrm{wt} . \% \mathrm{Ti}$ added to the baseline.

Figure 37. Site Fraction of MX1 for first sublattice under S-3 simulation which contains the alloying elements titanium $(\mathrm{Ti})$, niobium $(\mathrm{Nb})$, and vanadium $(\mathrm{V})$.

Figure 38. Site Fraction of MX1 for second sublattice under S-3 simulation which contains the alloying elements carbon $(\mathcal{C}$ and nitrogen $(\mathrm{N})$. 58

Figure 39. Scheil simulation results of $0.66 \mathrm{wt} . \% \mathrm{Mn} \mathrm{S}-1$ (dash line), $0.43 \mathrm{wt} . \% \mathrm{Ni}$ S2 (solid line), and Gr.91 baseline system (dotted line) for $\mathrm{M}_{23} \mathrm{C}_{6}$ phase.

Figure 40. Scheil simulation results of $0.01 \mathrm{wt} . \% \mathrm{Ti}$ (S-3) and $\mathrm{Gr} .91$ baseline system for MX1 phase. 
Figure 41. Results of mole fraction of a new MX phase under the S-3 simulation called MX3...

Figure 42. Composition of MX3 which contains results for the site fraction of the first sublattice results for vanadium $(\mathrm{V})$, niobium $(\mathrm{Nb})$, and titanium $(\mathrm{Ti})$

Figure 43. Composition of MX3 which contains results for the site fraction of the second sublattice results for carbon $(\mathrm{C})$, and nitrogen $(\mathrm{N})$.

Figure 44. Mole Fraction of Z-phase under three different simulations. S-4 represents the added concentrations of $0.27 \mathrm{wt} . \% \mathrm{~V}, \mathrm{~S}-5$ is for the added concentrations of $0.11 \mathrm{wt} . \% \mathrm{Nb}$, and S-6 is the lower concentrations of $0.025 \mathrm{wt} . \% \mathrm{~N}$ while compared with Gr.91 baseline.

Figure 45. Mole Fraction of secondary phases for the modified Gr.91 including

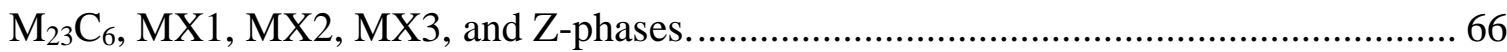

Figure 46. The new threshold temperatures of the modified Gr.91 including the Ac1 (blue), $\mathrm{Ac} 3$ (red), $\mathrm{M}_{23} \mathrm{C}_{6}$ (black solid line), and Z-phase (dash line)................................ 68 


\section{ABBREVIATIONS AND ACRONYMS}

$\begin{array}{ll}\text { HAZ } & \text { Heat-Affected-Zone } \\ \text { CGHAZ } & \text { Coarse-Grain HAZ } \\ \text { FGHAZ } & \text { Fine-Grain HAZ } \\ \text { ICHAZ } & \text { Intercritical HAZ } \\ \text { CALPHAD } & \text { Calculation of Phase Diagrams } \\ \text { PAGB } & \text { Prior Austenite Grain Boundaries } \\ \text { HJP } & \text { Holloman-Jaffe Parameter } \\ \text { GMAW } & \text { Gas Metal Arc Welding } \\ \text { GTAW } & \text { Gas Tungsten Arc Welding } \\ \text { SAW } & \text { Submerged Arc Welding } \\ \text { FCAW } & \text { Flux-Cored Arc Welding }\end{array}$




\section{CHAPTER 1}

\section{INTRODUCTION}

Grade 91 (Gr.91) alloy is a high chromium (Cr) creep strength enhanced ferriticmartensitic structural steel that was produced by Oak Ridge Laboratory in the 1970's and has been heavily utilized by the power industries, most notably for thick section boiler components [1]. With the evermore increasing issues of global warming and the constant push from power industries to produce higher energy outputs at higher efficiencies, it has become apparent that in order to accomplish the task of increasing the efficiency of Gr.91, increasing the maximum operating temperature of energy generators is necessary. Gr.91 has been an ideal candidate as the main alloy in production for new generation nuclear power reactors. Its basic properties include high-temperature creep resistance, thermal conductivity, and low thermal expansion coefficient coupled with its high amounts of $\mathrm{Cr}$, lets it have a low chance of corrosion cracking in aqueous and chloride environments and makes it an ideal alloy for most industrial operations [2]. However, the main concern for Gr.91 in high-temperature applications is its thermodynamic properties such as the stability of its secondary phases, which given under certain parameters could reduce the materials creep strength. More specifically, Ac1 and Ac3 temperatures coupled with peak temperatures during welding, factors into the microstructure of the Heat-Affected-Zone (HAZ) $[3,4]$, therefore creating three subzones: Coarse-Grain HAZ (CGHAZ), Fine-Grain HAZ (FGHAZ), and the Intercritical HAZ (ICHAZ). Ac1, in this case, is the temperature at which austenite begins to form, whereas Ac3 is the temperature at which austenite is fully formed and stable. 
It is well known that the most critical failure mechanism for Grade 91 is not in its weld metal nor the base alloy but in its HAZ under cyclic loading operations. The HAZ is created during welding and typical creep failure has been observed along its visible edge, i.e. the FGHAZ and the ICHAZ. These observed cracks are called type IV cracks and have been studied extensively over the past decades. While the exact mechanism behind type IV cracks are not yet known, they are influenced by multiple factors including the formation and coarsening of several precipitates, mainly $\mathrm{M}_{23} \mathrm{C}_{6}, \mathrm{MX}$, Laves-phase, and Z-phases. Most notably, the mechanism of failure for type IV cracks changes depending on both the stresses and temperatures during the alloys operational use. For example, $\mathrm{M}_{23} \mathrm{C}_{6}$ coarsening is the cause of short-term creep failures due to the loss of pinning forces to keep dislocations in place [5] while the formation of Z-phases is the cause of long-term failures primarily due to the dissolution of MX phases [6]. MX phases in both cases are beneficial to the steel because of its very low size and coarsening rate that are finely distributed throughout the grain matrix. Laves-phases, similar to the formation of Z-phases, "eat" away at $\mathrm{M}_{23} \mathrm{C}_{6}$ and can be a cause for concern to the degradation of the steel's creep resistance [7], however when compared, priority in this study was given to Z-phases.

Typically, what has been done in order to suppress type IV cracks is to add or adjust the composition of the steel or change the parameters of heat treatment/welding. For example, recent findings have indicated that changes to the tempering temperature during heat treatment has effectively increased the creep strength of the steel $[8,9]$. More specifically, the $\mathrm{M}_{23} \mathrm{C}_{6}$ precipitates during lower tempering temperatures (LTT) lowered in stability thus decreasing the necessary driving force for nucleation of new precipitates 
which resulted in lower volume concentrations. When this happens during the welding process, the smaller precipitates that have formed during the LTT process have now dissolved into the matrix of the steel. So, when post-weld-heat-treatment (PWHT) process begins after welding, the dissolved $\mathrm{M}_{23} \mathrm{C}_{6}$ carbides form within the grain boundaries and not within prior austenite grain boundaries (PAGB's) which has shown to lower the materials creep strength during high temperature applications. Overall, by lowering the stability of $\mathrm{M}_{23} \mathrm{C}_{6}$ during the heat-treatment process, one can control the amount of these precipitates to form and ultimately prolong the effect of coarsening. Unfortunately, the method above, while it has been observed to increase creep resistance in the alloy, have not been able to solve the issues with long-term exposure to high temperature use, or more specifically Z-phase, which forms at the expense of stable MX phase, can result in premature structural failure.

To achieve the task of increasing creep resistance in the Gr.91 alloy is to lower the stability of the secondary phases that form during both long and short-term use that cripple the materials creep strength. Under short-term, $\mathrm{M}_{23} \mathrm{C}_{6}$ carbides coarsening is the leading cause of failure, whereas Z-phase formation at the expense of the beneficial MX phase is the other cause of premature failure under long-term use. In order to increase the creep resistance of Gr.91, lowering the stability of $\mathrm{M}_{23} \mathrm{C}_{6}$ carbides and Z-phase stability should be the main priority. For this to be accomplished reducing the Ac1 and Ac3 temperatures, which in turn increases the materials austenite's stable temperature region, is necessary. Ac temperatures are directly related to the formation of the materials CGHAZ, FGHAZ, and ICHAZ, which is formed during welding. By adjusting the materials Ac temperatures, 
we can not only "tune" the materials $\mathrm{HAZ}$, but also destabilize the $\mathrm{M}_{23} \mathrm{C}_{6}$ and Z-phase stability, thereby increasing the materials creep strength.

In this study, various simulations were performed using the thermodynamic software Thermo-Calc alongside the TCFE8 database. Utilizing both this software and various Gr.91 literatures, the current study aims to model the effects of secondary phases under lower Ac1 and Ac3 temperatures in the alloy under the computational thermodynamic approach CALPHAD (Calculation of Phase Diagrams). The approach of this paper is broken into two major components. The first is the establishment of a baseline study of Gr.91 steels in order to investigate the relationship between various critical temperatures and the stability of the $\mathrm{M}_{23} \mathrm{C}_{6}, \mathrm{MX}$, and Z-phase within the HAZ. This can be used to predict and improve the creep resistance under both short-term and long-term applications, under which case Fe-Cr-Mo-V-Nb-C-N system was considered. The second is to establish and simulate the results of added/adjusting alloying elements from the baseline that can either reduce the Ac1 and Ac3 temperatures, decreasing the stability of $\mathrm{M}_{23} \mathrm{C}_{6}$ or $\mathrm{Z}$-phase, while in turn increasing the stability regions of $\mathrm{MX}$ phases. The elements considered in this case for lowering Ac temperatures are high concentrations of manganese (Mn) and nickel (Ni) while titanium (Ti) will be used to increase MX stability. In order to lower the stability of Z-phase within the steel, three different simulations were conducted: 1) Vanadium (V) concentration at $0.27 \mathrm{wt} . \%, 2$ ) niobium (Nb) concentration at 0.11wt.\%, and 3) $0.025 \mathrm{wt} . \%$ of nitrogen $(\mathrm{N})$ were performed. Lastly, a modified version of Gr.91 will be simulated, which combines all elements mentioned above, at their optimal 
concentrations. Hopefully, the simulations above will provide an effective model and tool in which to pave the way in increasing Gr.91 creep strength. 


\section{CHAPTER 2}

\section{LITERATURE REVIEW}

\subsection{High Chromium Martensitic-Ferritic Grade 91 Alloy}

Grade 91 (Gr.91) alloy is a high chromium (Cr) creep strength enhanced ferriticmartensitic structural steel that was produced by Oak Ridge Laboratory in the 1970's and has been heavily utilized by the power industries, most notably for thick section boiler components [1]. The alloy's high creep strength mainly comes from its tempered martensite substructure which contains a high-density dislocation lath-type morphology alongside finely dispersed secondary phases such as $\mathrm{M}_{23} \mathrm{C}_{6}$ and $\mathrm{MX}$ [10]. $\mathrm{M}_{23} \mathrm{C}_{6}$ carbides are mostly found along the lath boundaries and prior austenite grains during heat treatment, whereas MX nitrides (MN) and carbides (MC) are homogeneously distributed within the martensitic matrix [11-15]. Besides from the mentioned secondary phases, it is found that another secondary phase called Z-phase also stabilizes during long-term working operations. This phase can become detrimental to the long-term creep strength of the material which will be explained later.

Typically, a tempered martensitic microstructure is desired in standard industry practices. Specific heat treatment processes are done to Gr.91 so that the level of residual stresses is reduced and to improve the weld metal toughness [16]. This entire process generally varies depending on the chemical composition of Gr.91 and includes the following: Normalization, Tempering, Welding, and lastly Post-Weld-Heat-Treatment, respectively in that order. Though the ending result of the heat treatment process is mainly tempered martensite, a very small amount of ferrite BCC crystal structure is to be expected. 
Figure 1 shows the microstructure of Gr.91 after heat treatment and includes large martensite lath sub-grains and large prior austenite grains [2, 17].

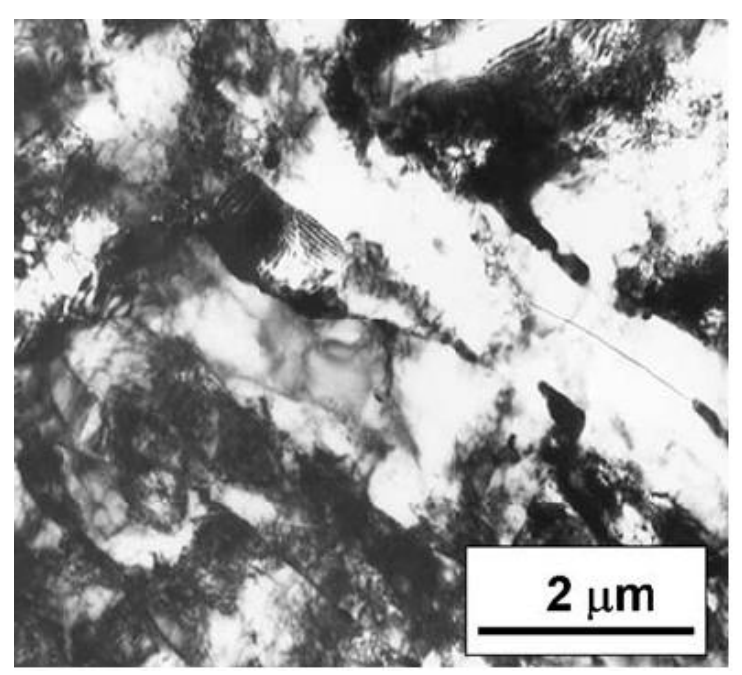

Figure 1. Microstructure of $9 \mathrm{Cr}-1 \mathrm{MoVNb}$ that consists of coarse prior-austenitic grain martensite, fine prior-austenitic grain martensite, intercritical, and over-tempered regions [17].

\subsection{Type IV Cracks}

Under repeated cyclic loading, Gr.91 has been observed to fail along the outer edge of the HAZ, or more specifically the Fine-Grain HAZ (FGHAZ) and Intercritical HAZ (ICHAZ), which are created during the welding process. These cracks are called type IV cracks and various works have been carried out to understand the formation mechanism and propose the suppression method of these cracks. However, the exact mechanism which leads to its critical failure along the HAZ is still unknown [18-22]. Figure 2 shows the different types of cracks and their location that have been observed along the HAZ [16]. 

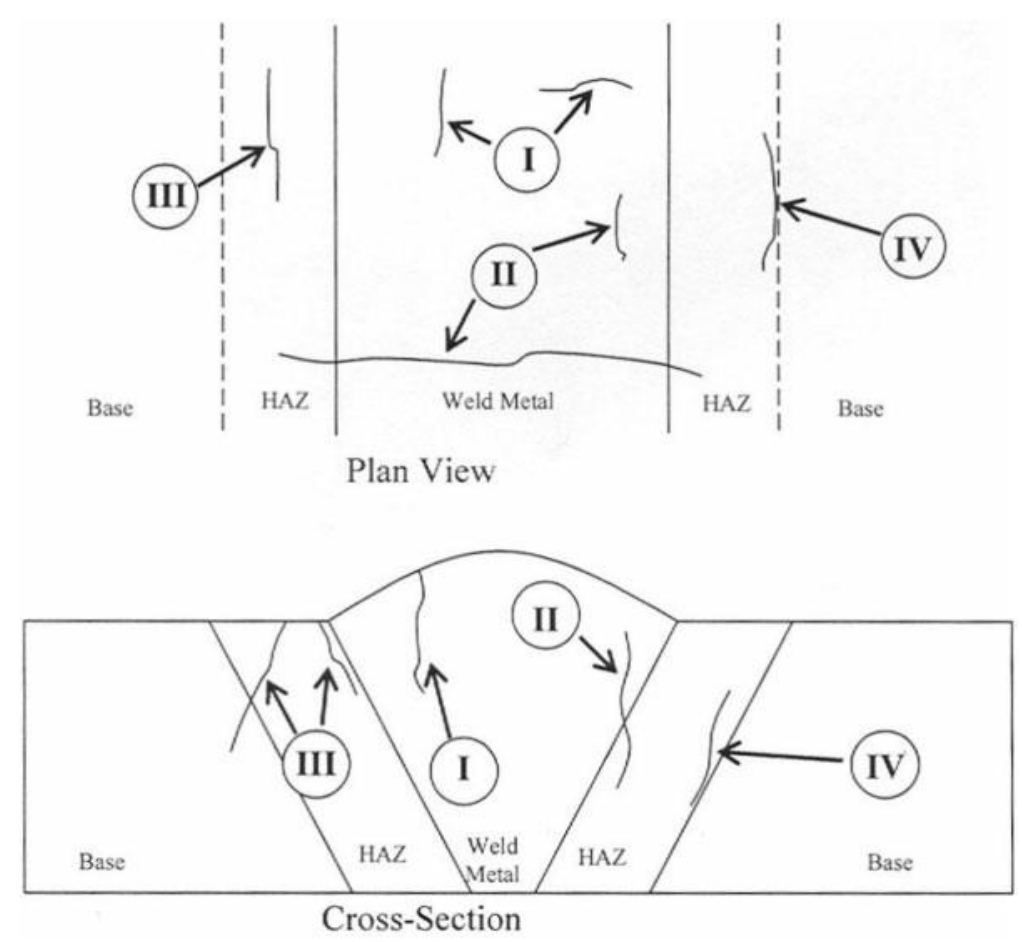

Figure 2. Schematic representation of the types of cracks and their location along the weld metal and HAZ in Gr.91 alloy [16].

\section{$\underline{2.3 \text { Heat-Treatment and Welding Parameters }}$}

Typically, the process of heat treating Gr.91 goes as following: 1) Normalization, 2) Tempering, 3) Welding, and 4) Post-Weld-Heat-Treatment. The entire process is to reduce the stresses and precipitate out as much $\mathrm{M}_{23} \mathrm{C}_{6}$ and $\mathrm{MX}$ phases as possible before working operations begin. Each process has their own set of temperatures and the result after heat treatment should contain a tempered martensitic microstructure.

\subsubsection{Normalization Parameters}

The parameters pertaining to the normalization process are usually seen by heating Gr.91 up to high temperature regions which include between $1050^{\circ} \mathrm{C}-1080^{\circ} \mathrm{C}$ and is held at that temperature for a minimum of 10 minutes [23]. However, this process has been 
observed to vary, including the holding time and temperatures depending on the objectives of the experiment and the chemical composition of the material being tested. The main function of this process is to precipitate out as much MX phase as possible before tempering begins.

\subsubsection{Tempering Parameters}

Tempering is the process of heating the alloy between $732^{\circ} \mathrm{C}-782^{\circ} \mathrm{C}$ for an extended period, typically longer than the normalization process [23]. One of the most common tempering parameters currently in use is the Holloman-Jaffe parameter (HJP) [24], as expressed in the follow equation:

$$
\begin{gathered}
\text { Equation 1: Holloman-Jaffe Parameter (HJP) [24] } \\
\qquad H J P=(T+460) X(C+\log 10 t) / 100
\end{gathered}
$$

Where: $\mathrm{T}$ is tempering temperature in ${ }^{\circ} \mathrm{F}, \mathrm{t}$ is holding time in hours and $\mathrm{C}$ is the HJP

constant. A common default value for $\mathrm{C}$ is 20 , however this can vary between 19-23 depending on the characteristics of a particular heat of material [23].

In the past decade, studies have shown that lower tempering temperatures (LTT) compared to the higher tempering temperatures (HTT) have a dramatic effect on the creep life of Gr.91 [8,9]. Figure 3 shows a schematic representation of the effect $\mathrm{M}_{23} \mathrm{C}_{6}$ carbides have on the different tempering temperatures within the microstructure [8]. 


\begin{tabular}{|c|c|c|c|c|}
\hline & Wre-weld temper \\
tempering \\
pre-weld \\
LTT
\end{tabular}

Figure 3. Schematic showing microstructure evolutions during welding and PWHT for the LTT and HTT conditions [8].

In summary:

- $\mathrm{M}_{23} \mathrm{C}_{6}$ (red) precipitates coarsen much more quickly under the HTT parameters when compared to the LTT. The fine MX phase (blue dots) has very low coarsening rate and is unaffected by either the LTT or HTT conditions.

- Under HTT for welding, the smaller $\mathrm{M}_{23} \mathrm{C}_{6}$ completely dissolve within the matrix during welding while larger $\mathrm{M}_{23} \mathrm{C}_{6}$ carbides remained behind. During PWHT, the larger $\mathrm{M}_{23} \mathrm{C}_{6}$ nucleate at prior austenite grain boundaries (PAGB) which results in $\mathrm{M}_{23} \mathrm{C}_{6}$ to coarsen within the grain matrix and continue to do so during working operations.

- Under LTT during welding, all $\mathrm{M}_{23} \mathrm{C}_{6}$ carbides are dissolved within the matrix due to a lower driving force. During PWHT, the completely dissolved $\mathrm{M}_{23} \mathrm{C}_{6}$ carbides stabilize and continue to coarsen within the grain boundaries and not within the PAGB's. 


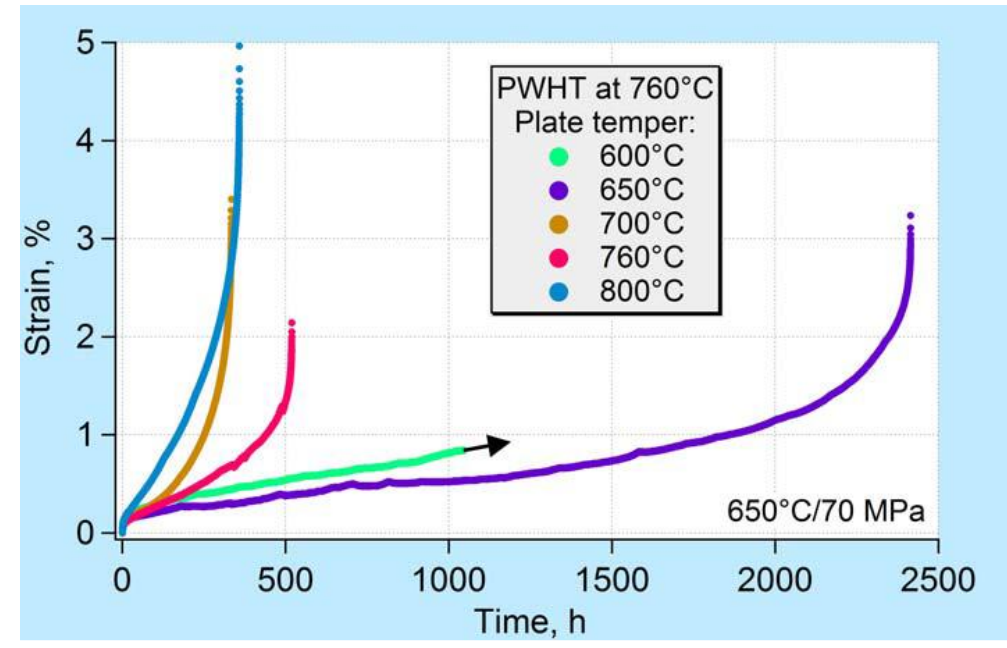

Figure 4. Results of strain vs. time to failure in hours at tempering temperatures between $600^{\circ} \mathrm{C}-800^{\circ} \mathrm{C}[9]$.

Figure 4 shows the results of Gr.91 strain vs. time to failure in hours at tempering temperatures between $600^{\circ} \mathrm{C}-800^{\circ} \mathrm{C}$ [9]. The results show that at LTT conditions such as at $650^{\circ} \mathrm{C}$, an increase in creep life is observed while the $\mathrm{HTT}$ at $800^{\circ} \mathrm{C}$ is much lower.

\subsubsection{Welding Parameters}

Welding of Gr.91 can be done though many processes including methods such as Gas Metal Arc Welding (GMAW), Gas Tungsten Arc Welding (GTAW), Submerged Arc Welding (SAW), and Flux-Cored Arc Welding (FCAW). Filler material used for the weld metal must be similar to the chemical composition of Gr.91 in order to avoid premature creep failure [25]. Matching and overmatching the filler material can increase the creep life of the alloy only at high stress levels, while undermatching the weld material at lower stresses under creep conditions can shift the location of type IV cracks to the FGHAZ [25].

Pre-heating the material and interpass temperatures during welding are also important to the creep strength of Gr.91. For pre-heating, temperatures must be between $150^{\circ} \mathrm{C}-205^{\circ} \mathrm{C}$ as to avoid cold cracking, whereas the interpass temperatures must be under 
$370^{\circ} \mathrm{C}[23]$. This is to avoid unnecessary phases such as delta $(\delta-\mathrm{Fe})$ to stabilize as this can lower the toughness and reduce the creep strength of the alloy [26].

\subsubsection{Post-Weld-Heat-Treatment (PWHT) Parameters}

The main purpose for PWHT is to reduce the level of residual stresses, improve the weld metal toughness after welding, and increase the volume amount of secondary phases into the microstructure [16]. Temperatures for PWHT can vary between $730^{\circ} \mathrm{C}-770^{\circ} \mathrm{C}$ [23]. The holding time can vary depending on what you want to view, in terms of secondary phases, in experiments. However, it is typically seen to be anywhere between $2-6$ hours.

\subsection{Microstructural Change During Welding of Grade 91}

A HAZ is created during the welding process of the material. This is due primarily to three main factors: 1.) Peak welding temperatures, 2.) Ac1 and Ac3 temperatures, and 3.) the formation and dissolution of $\mathrm{M}_{23} \mathrm{C}_{6}$ carbides. In this case, $\mathrm{MX}$ phase is not considered during the formation of the HAZ because they do not dissolve or destabilize during welding [8]. This is due to the fact that in studies MX have high thermal stability, small coarsening, and fine distribution within the microstructure[8,27]. Because of this, phase stability and the coarsening of $\mathrm{M}_{23} \mathrm{C}_{6}$ are the primary focus for the $\mathrm{HAZ}$ formation in most studies.

The HAZ has three subzones within it: 1) Coarse-Grain HAZ (CGHAZ), 2) FineGrain HAZ (FGHAZ), and 3) Intercritical HAZ (ICHAZ). Depending on the location of the weld metal (WM), the base metal (BM), and peak temperatures which can change creating a thermal gradient across the joint, can result in a dramatic difference in the 
microstructure. Figure 5 shows the locations of the CGAHZ, FGHAZ, and ICHAZ between the $\mathrm{WM}$ and $\mathrm{BM}$ while comparing it to a $\mathrm{Fe}-\mathrm{Fe} 3 \mathrm{C}$ phase diagram [28].

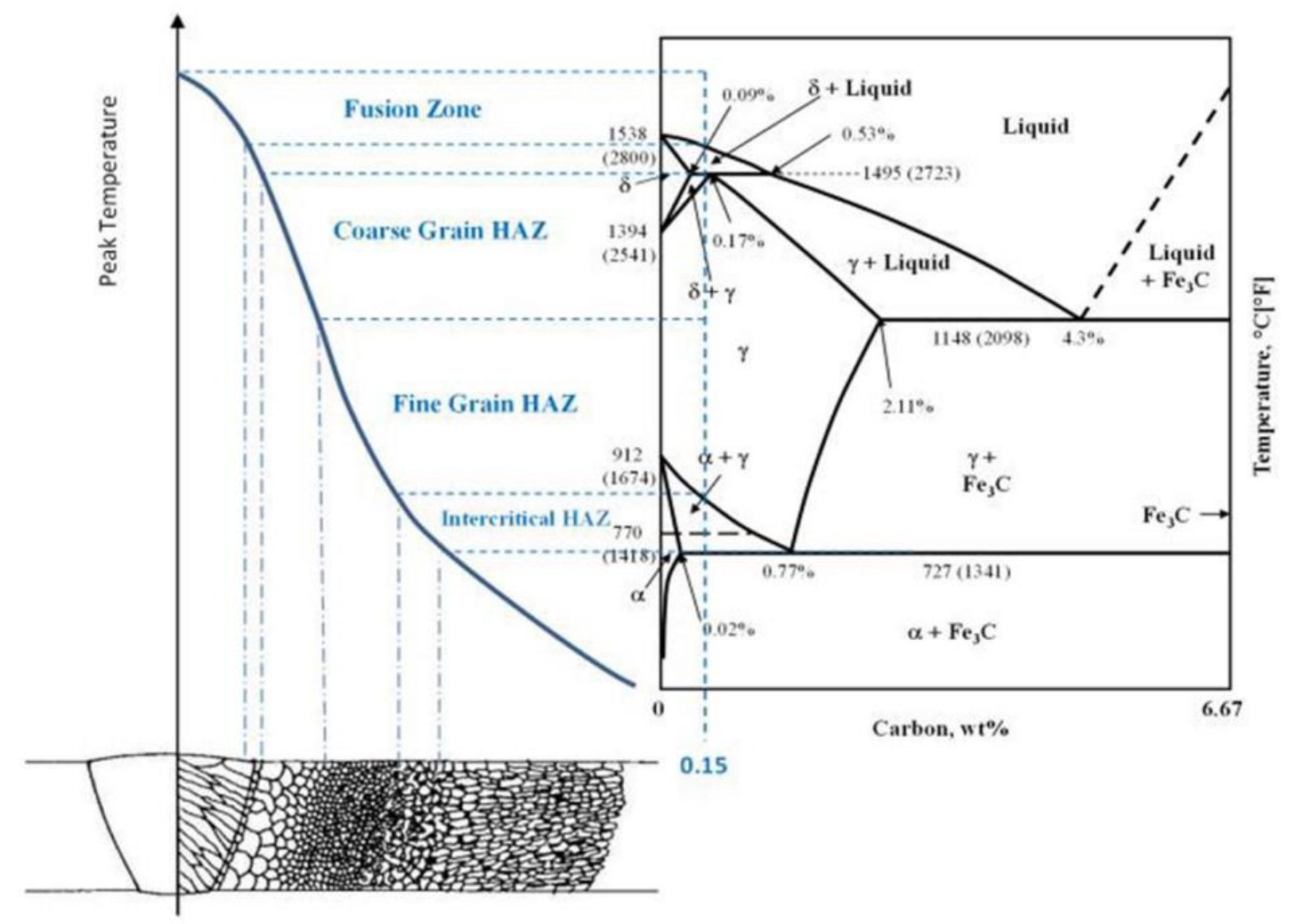

Figure 5. Schematic showing the locations of the CGAHZ, FGHAZ, and ICHAZ between the weld metal (WM) and base metal (BM) of Gr.91 while comparing it to a $\mathrm{Fe}-\mathrm{Fe} 3 \mathrm{C}$ phase diagram [28].

\subsubsection{Acl and Ac3 Temperatures}

Ac1 and Ac3 temperatures are important to the formation of the HAZ because they determine the stability of $\mathrm{M}_{23} \mathrm{C}_{6}$ carbides. Ac1 temperature can be defined as the temperature at which austenite $(\gamma-\mathrm{Fe})$ begins to form, whereas Ac3 is the temperature at which ferrite $(\alpha-\mathrm{Fe})$ is fully transformed to austenite. An example of this can be seen in Figure 6 below, which highlights the Ac1 and Ac3 temperature thresholds for a binary FeC phase diagram. 


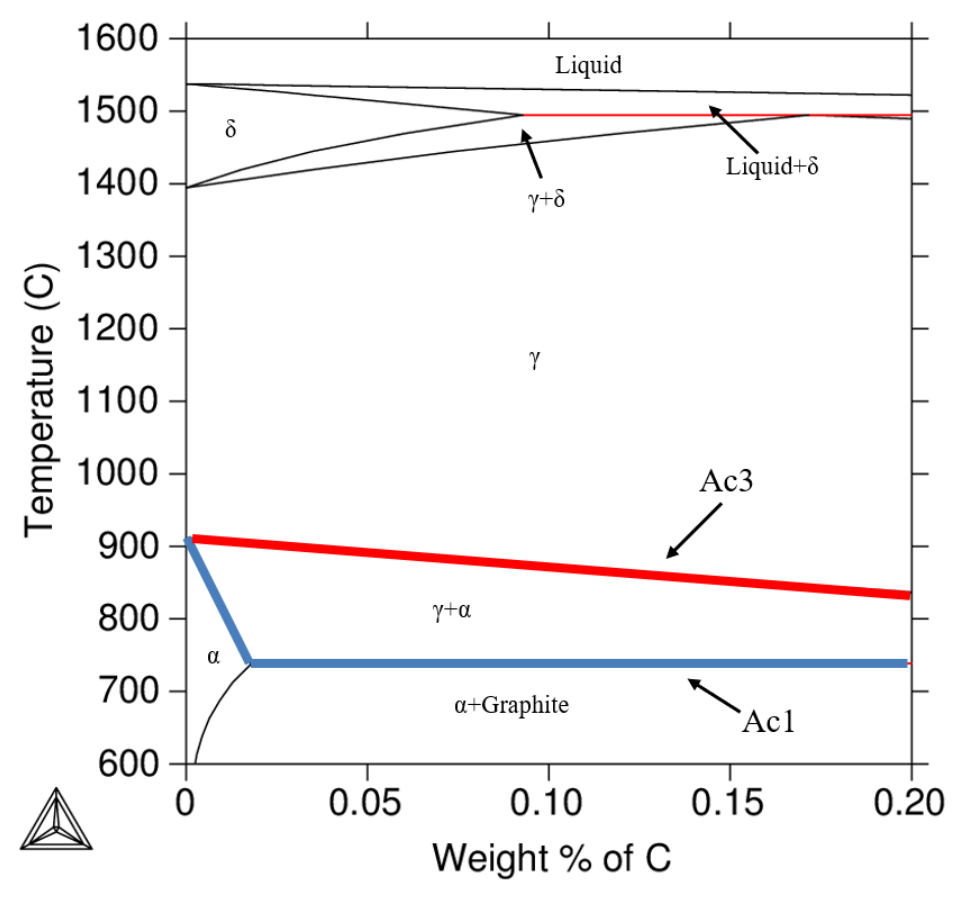

Figure 6. Thermo-Calc calculation of the Fe-C binary phase diagram which highlights the Ac1(blue) and Ac3(red) temperatures. 


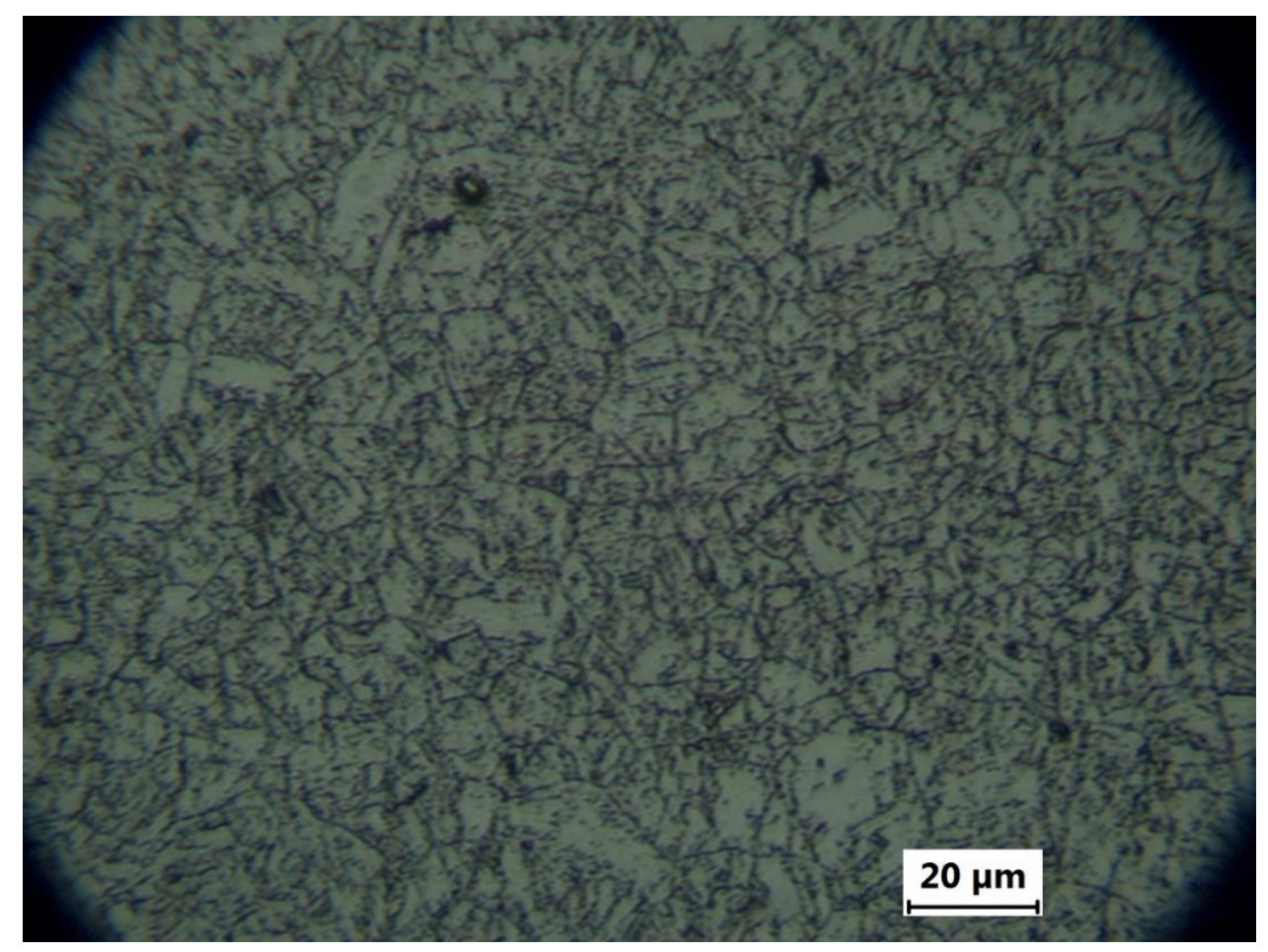

Figure 7. Coarse-Grain-HAZ (CGHAZ) of Gr.91 taken at $400 \mu \mathrm{m}$

The CGHAZ is the first zone to appear next to the WM, after the fusion line. Here, its peak temperature is above $\mathrm{Ac} 3$ and higher than the $\mathrm{M}_{23} \mathrm{C}_{6}$ threshold temperature. Due to these peak temperatures, the $\mathrm{M}_{23} \mathrm{C}_{6}$ particles dissolve into the grain matrix, which leads to a loss of pinning forces along the grain boundaries, resulting in coarser gains. 


\subsubsection{Fine-Grain HAZ (FGHAZ)}

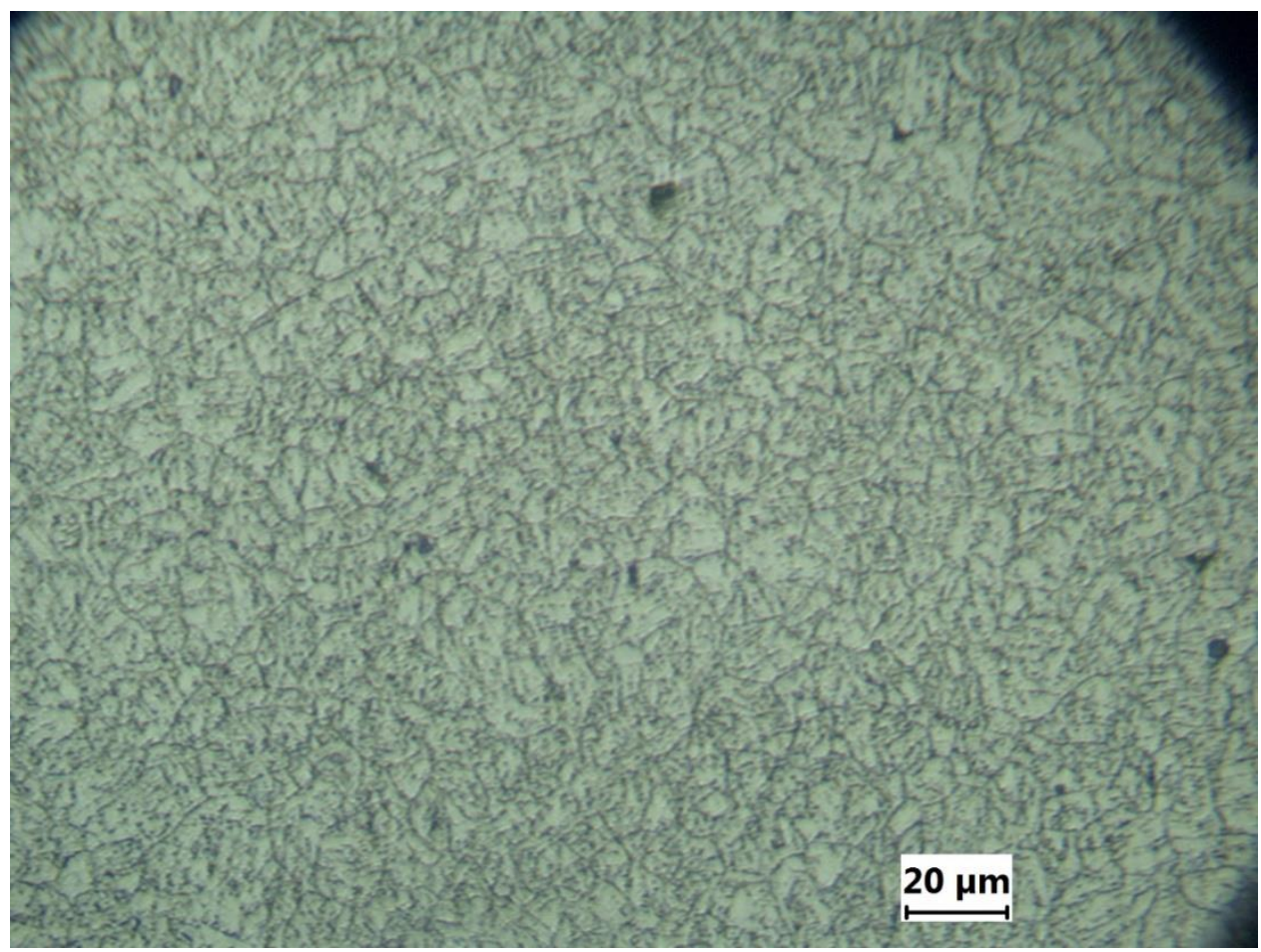

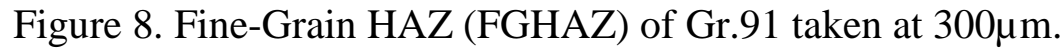

The FGHAZ is located next to the CGHAZ. Here, like in the CGHAZ, the peak temperatures are above $\mathrm{Ac} 3$, but within the $\mathrm{M}_{23} \mathrm{C}_{6}$ stability region. This results in partial dissolution of $\mathrm{M}_{23} \mathrm{C}_{6}$ particles which results in very fine grain sizes due to the grain boundary pinning effect from $\mathrm{M}_{23} \mathrm{C}_{6}$. 


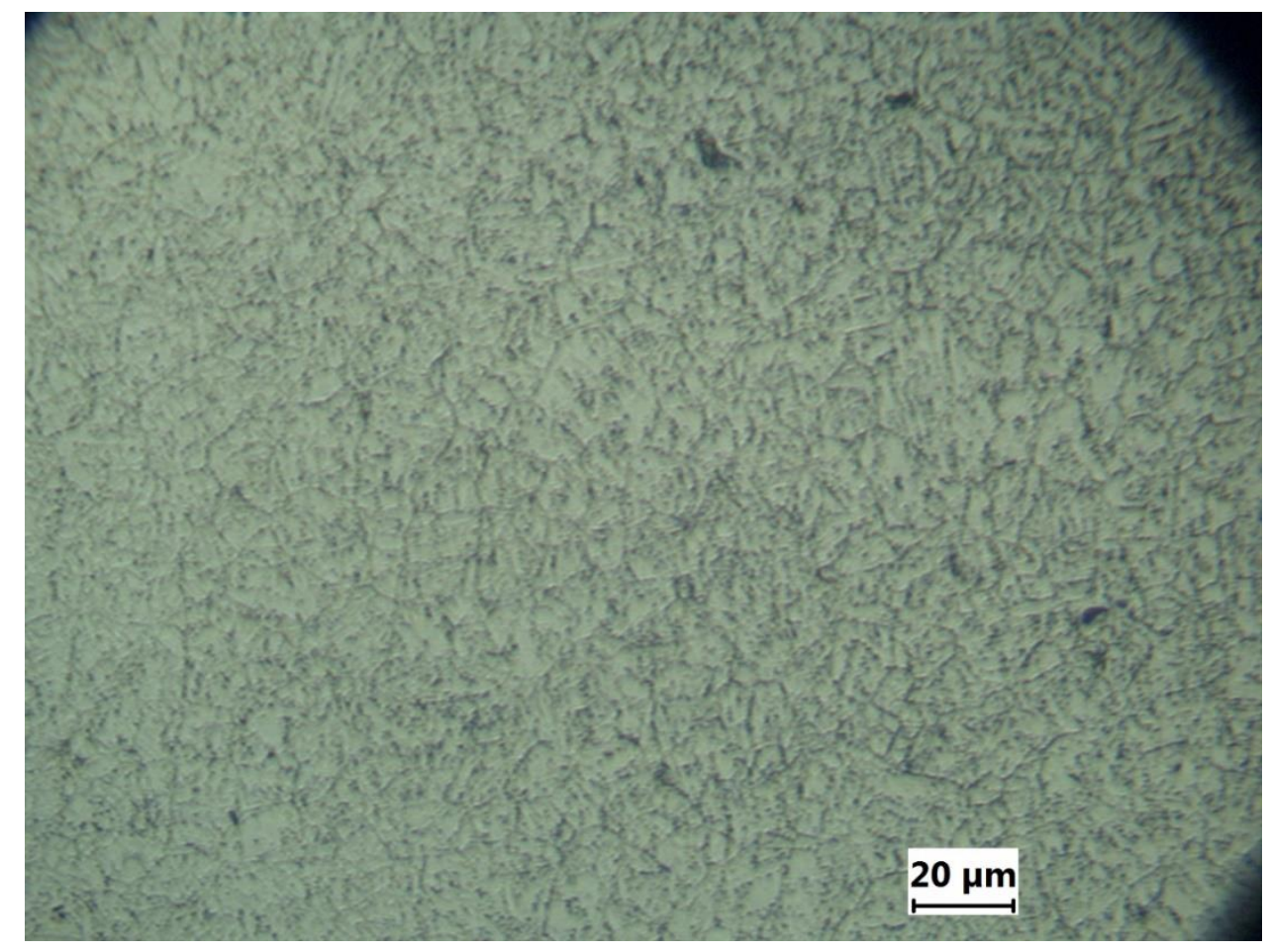

Figure 9. Intercritical HAZ (ICHAZ) of Gr.91 taken at 300 $\mu$ m.

The last zone to be observed as well as the smallest of the three is the ICHAZ. The peak temperatures here are between Ac1 and Ac3. This zone is different from the other two since upon cooling, a mixture of fresh martensite and ferrite will be formed whereas the CGHAZ and the FGHAZ will contain mostly martensite upon cooling. 


\section{$\underline{2.5 \text { Secondary Phases that Influence Type IV Cracks }}$}

\subsection{1 $\mathrm{M}_{23} \mathrm{C}_{6}$ Phase}

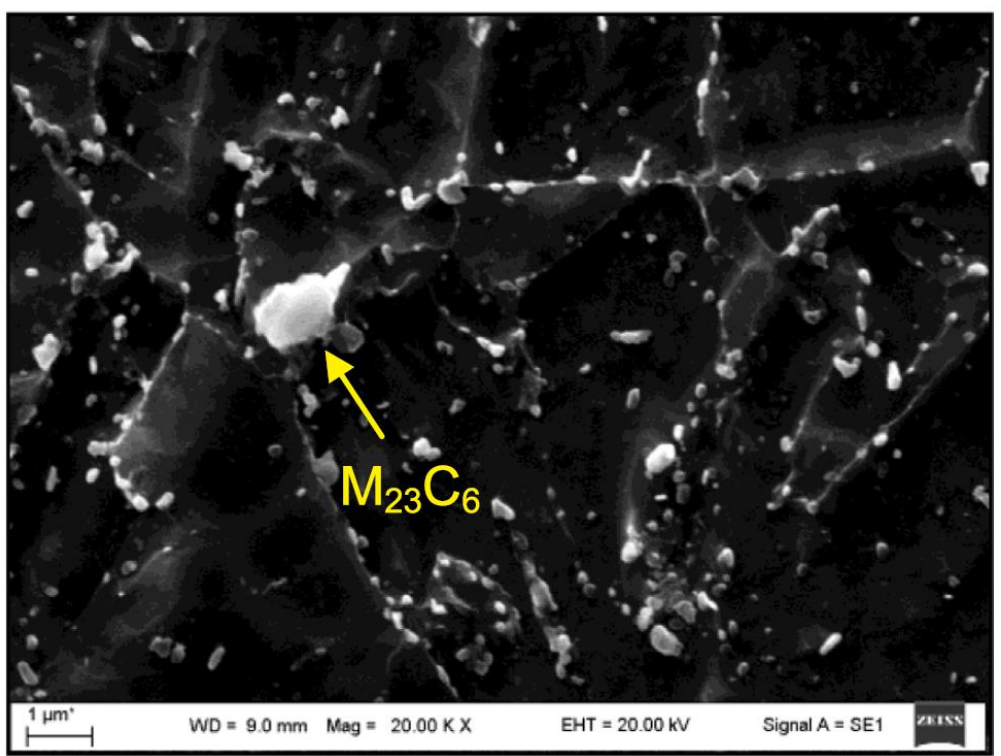

Figure 10. SEM image of $\mathrm{M}_{23} \mathrm{C}_{6}$ carbide after creep testing at $650^{\circ} \mathrm{C}$ for 10,872 hours [29].

$\mathrm{M}_{23} \mathrm{C}_{6}$ phase is a crystal structure that contains three sublattices. It is widely written as a two sublattice structure and is considered an important phase during the initial stages of creep. The first sublattice noted as "M" can contain either chromium $(\mathrm{Cr})$, iron $(\mathrm{Fe})$, or molybdenum (Mo) depending on the concentrations of these elements within the material, while the second sublattice contains only carbon $(\mathrm{C})$. They form and coarsen mostly along the prior austenite grain boundaries (PAGB's), or more specifically, at martensite lath boundaries [30, 31]. In terms of volume amount, $\mathrm{M}_{23} \mathrm{C}_{6}$ carbides, depending on the composition of the material, can be observed most often. 


\subsubsection{Secondary Phase}

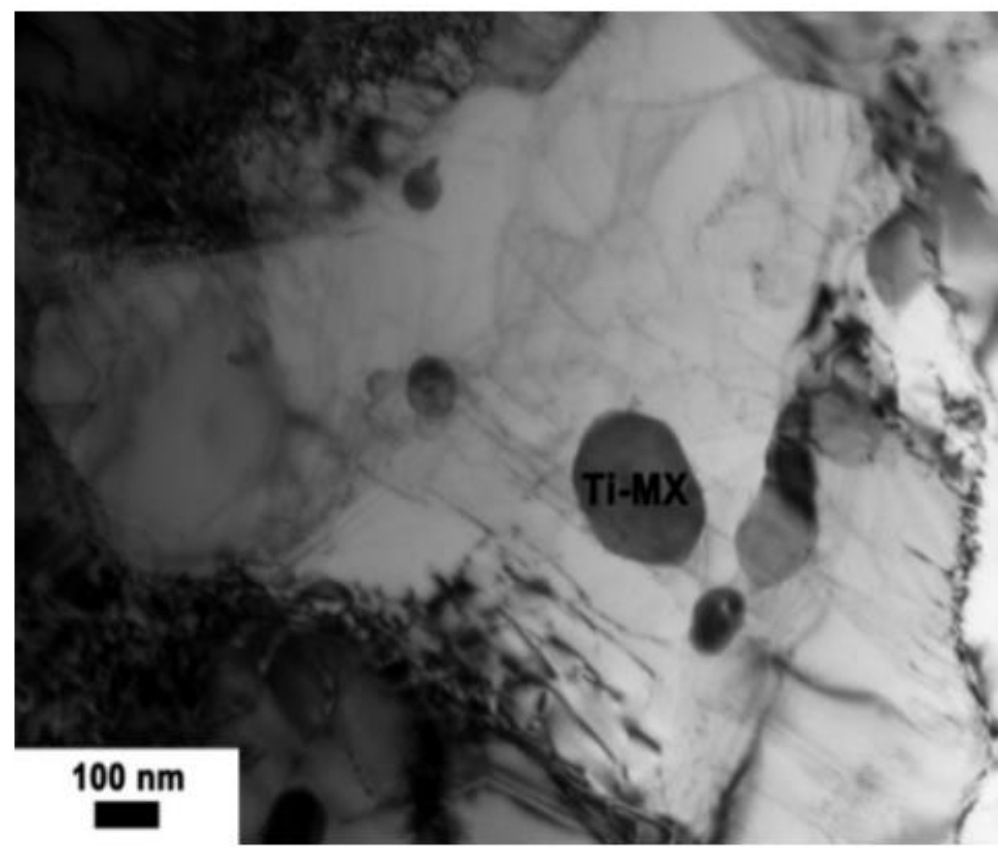

Figure 11. Transmission Electron Microscope (TEM) image of a high titanium (Ti) MX phase after normalization at $1040^{\circ} \mathrm{C}$ for 2 hours [32].

The MX phase is a FCC crystal structure and like the $\mathrm{M}_{23} \mathrm{C}_{6}$ phase, is important to the creep strength of the material throughout its entire life cycle. The MX phase is a two sublattice structure where "M" can contain vanadium $(\mathrm{V})$, niobium $(\mathrm{Nb})$, or titanium $(\mathrm{Ti})$ while " $\mathrm{X}$ " can contain carbon $(\mathrm{C})$ or nitrogen $(\mathrm{N})$ making these phases carbides $(\mathrm{MC})$, nitrides $(\mathrm{MN})$, or carbonitrides $(\mathrm{M},(\mathrm{C}, \mathrm{N}))[33]$. This is also the smallest phase that is observed within this material which can be between 5-20nm[34]. 


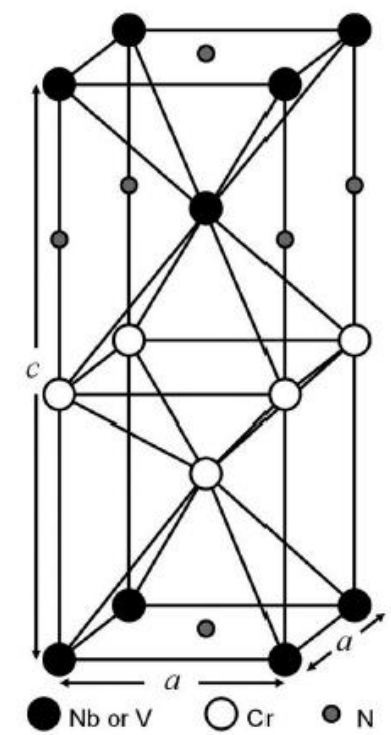

Figure 12. A schematic of the Z-phase crystal structure. The lattice parameter for $\mathrm{CrNbN}$ is $\mathrm{a}=0.304 \mathrm{~nm}$ and $\mathrm{c}=0.739 \mathrm{~nm}$ while for $\mathrm{CrVN}$ it is $\mathrm{a}=0.286$ and $\mathrm{c}=0.739$ [35].

Z-phase is a tetragonal crystal structure that contains three sublattices and is considered a detrimental phase under long-term creep. It has been observed as the most stable nitride in $9-12 \% \mathrm{Cr}$ steels and has an empiric formula of $\mathrm{CrXN}$, where $\mathrm{X}$ can contain $\mathrm{Nb}, \mathrm{V}$, or Ta [36]. This phase appears under low temperature and low stress operations [16, 37-39], and can form at the expense of MX particles.

\subsubsection{Laves Phases}

Much like the Z-phase that form under long-term creep, Laves phases have also been observed to appear after long-term aging or creep at $600^{\circ} \mathrm{C}$ and $650^{\circ} \mathrm{C}$ [40]. The phases empirical formula can be written as $\mathrm{M}_{2} \mathrm{X}$ where $\mathrm{M}$ can contain $\mathrm{Fe}$ and $\mathrm{Cr}$, whereas $\mathrm{X}$ can have Mo and $\mathrm{W}$. This intermetallic phase can significantly influence the microstructure of Gr.91 as well as its mechanical properties [7] due to the removal of W 
and Mo from solid solution. This can be detrimental to the creep resistance of the alloy however, others have noted that the formation of Lazes phases within the sub-grain boundaries and grain boundaries retards the recovery of sub-grains, which has been observed to improve creep rate [41]. In either case, a strict control of high temperature exposure to the alloy must be maintained in order to fully control the growth of Laves phases [42].

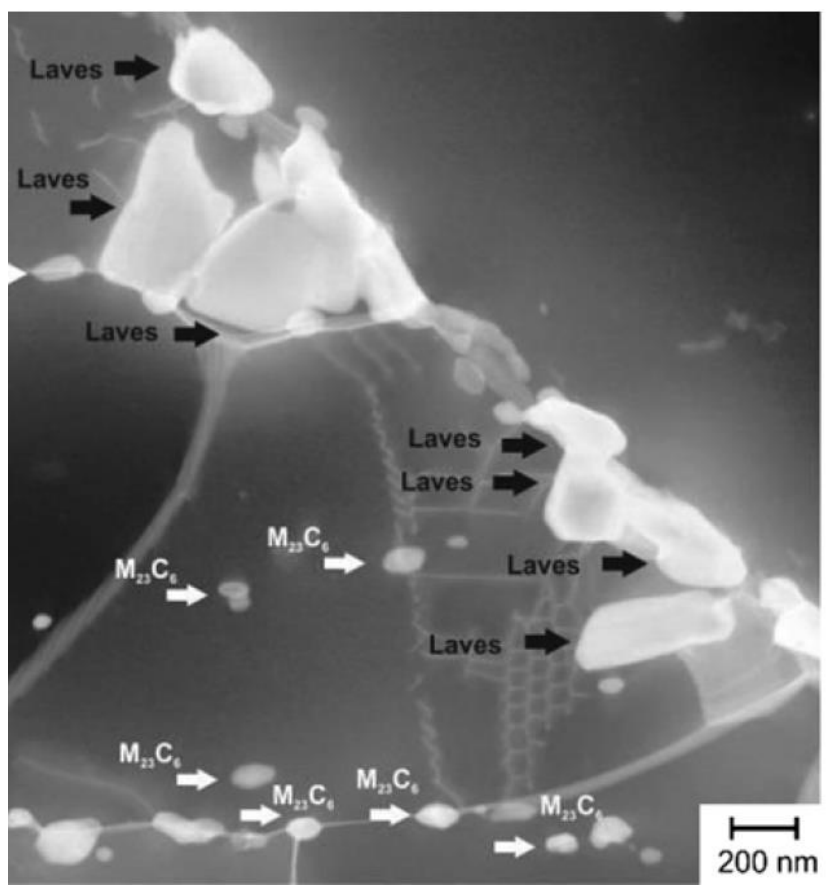

Figure 13. A scanning transmission electron microscope-high angle Angular dark field (STEM-HAADF) image of Laves phase formation (dark arrows) next to $\mathrm{M}_{23} \mathrm{C}_{6}$ carbides (light arrows) after 10,200 hours of testing for 9Cr steel [43].

\subsection{5 $M_{3} C, M_{2} X$, and $M_{7} C_{3}$ Phases}

Many precipitates such as $\mathrm{M}_{3} \mathrm{C}, \mathrm{M}_{2} \mathrm{X}$, and $\mathrm{M}_{7} \mathrm{C}_{3}$ where $\mathrm{M}$ is most often $\mathrm{Fe}$ and $\mathrm{Cr}$, especially in $\mathrm{Cr}$ concentrations between $9-12 \% \mathrm{Cr}$, can be considered as metastable [36]. This of course can vary depending on the concentration of $\mathrm{Cr}$, for example $\mathrm{M}_{7} \mathrm{C}_{3}$ can only form under concentrations where $\mathrm{Cr} \leq 7 \%$ [44], however even still it has been observed that 
$\mathrm{M}_{23} \mathrm{C}_{6}$ carbides will still form under prolong heat exposure. Under high concentrations of $\mathrm{N}$ and $\mathrm{Cr}$ content, the hexagonal crystal structure $\mathrm{M}_{2} \mathrm{X}$ phase can become stable even after thousands of hours of annealing $[26,36]$. Normally, $\mathrm{M}_{2} \mathrm{X}$ can be harmful to the creep resistance of the alloy due to them being stable at sites where MX are usually precipitate therefore, interfere with the $\mathrm{MX}$ precipitation [36, 41]. As for $\mathrm{M}_{3} \mathrm{C}$, this precipitate, depending on the amount of $\mathrm{Cr}$ and heat treatment applied to the alloy, could be the first to appear. The transformation from $\mathrm{M}_{3} \mathrm{C} \rightarrow \mathrm{M}_{7} \mathrm{C}_{3}$ has been observed to happen in two stages: 1) an increase in $\mathrm{Cr}$ content to the $\mathrm{M}_{3} \mathrm{C}$ then 2) the in-situ transformation of $\mathrm{M}_{3} \mathrm{C}$ into $\mathrm{M}_{7} \mathrm{C}_{3}$ [45-47]. It has also been simulated that $\mathrm{M}_{3} \mathrm{~B}$ can form under high concentrations of $\mathrm{B}$ [48]. An example of a typical precipitation sequence in Gr.91 alloy could be can be seen below [36]:

$$
\mathrm{M}_{3} \mathrm{C} \rightarrow \mathrm{M}_{7} \mathrm{C}_{3}+\mathrm{M}_{2} \mathrm{X} \rightarrow \mathrm{M}_{23} \mathrm{C}_{6}+\mathrm{MX} \rightarrow \mathrm{M}_{23} \mathrm{C}_{6}+\mathrm{Z} \text {-phase }
$$

\subsection{Elements and their roles in the formation of secondary phases}

\subsubsection{Austenite $(\gamma-F e)$ and Ferrite $(\alpha-F e)$ Stabilizers}

The entire system of elements contained within the Gr.91 can be grouped into two categories: ferrite $(\alpha-\mathrm{Fe})$ or austenite $(\gamma-\mathrm{Fe})$ stabilizers which affects both the Ac temperatures and the stability of certain secondary phase, such as $\mathrm{M}_{23} \mathrm{C}_{6}$. For $\alpha-\mathrm{Fe}$ stabilizers, when added to the system, have a large solubility in $\alpha$-Fe phase, therefore increasing the alloy's Ac temperatures. Under $\gamma$-Fe stabilizers, they have a large solubility in $\gamma$-Fe, therefore decreasing the Ac temperatures. 


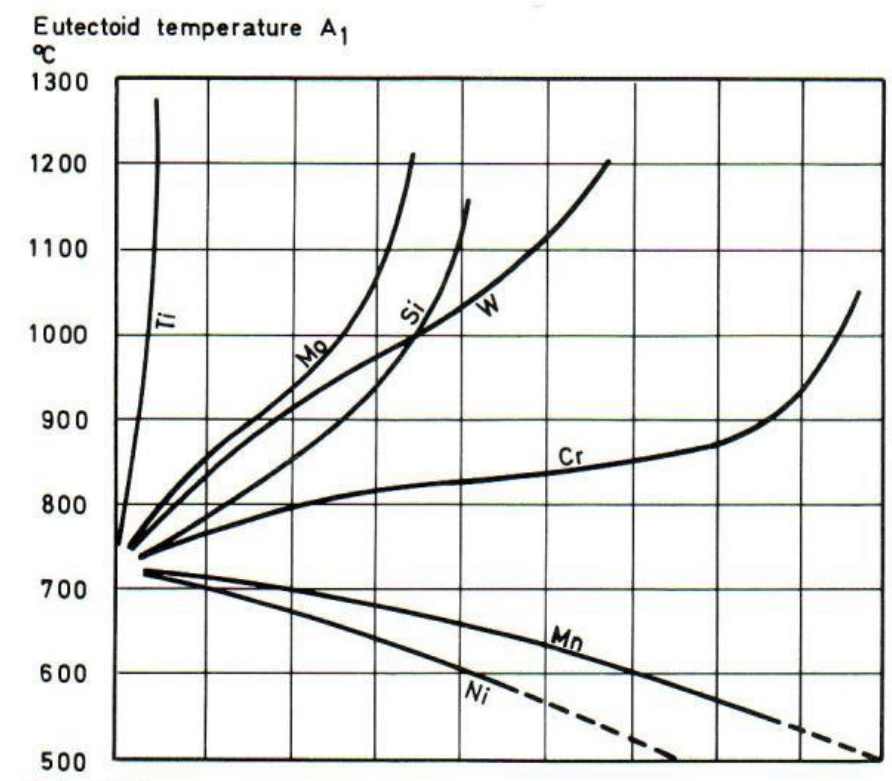

Figure 14. Graph of temperature $\left({ }^{\circ} \mathrm{C}\right)$ vs. weight $\%$ which represents the influence of alloying element additions on the eutectoid temperature within the $\mathrm{Fe}-\mathrm{Fe}_{3} \mathrm{C}$ phase diagram [49]. An increase in eutectoid temperature represents an $\alpha$-Fe stabilizer, while a decrease represents $\gamma$-Fe stabilizer.

\subsubsection{Carbon $(C)$ and Nitrogen $(N)$}

Carbon (C) and nitrogen (N) are both $\gamma$-Fe stabilizers [26] and are both essential to the stabilities of $\mathrm{MX}$ and $\mathrm{M}_{23} \mathrm{C}_{6}$ precipitates that are formed and coarsen during the normalization and tempering process of the heat treatment. A typical amount of $\mathrm{C}$ and $\mathrm{N}$ within Gr.91 can range anywhere between $0.06-0.15 w t . \%$ and $0.025-0.080 w t . \%$ respectively [23].

\subsubsection{Chromium (Cr) and Molybdenum (Mo)}

Chromium (Cr) and Molybdenum (Mo) are both $\alpha$-Fe stabilizers [26]. $\mathrm{Cr}$ is considered the most important element in this material since it can prevent oxidation and corrosion under aqueous situations. $\mathrm{Cr}$ is also a critical element in the stabilization and creation of $\mathrm{M}_{23} \mathrm{C}_{6}$ carbides which make up most of the secondary phases that form during 
the beginning stages of heat treatment. Other precipitates form as well, such as the $\mathrm{M}_{7} \mathrm{C}_{3}$ $\left(\mathrm{Cr}_{7} \mathrm{C}_{3}\right)$ and $\mathrm{M}_{2} \mathrm{X}\left(\mathrm{Cr}_{2} \mathrm{~N}\right)$ if changes are made to the composition [26, 44]. Mo provides additional stabilization to the solid solution of $\mathrm{M}_{23} \mathrm{C}_{6}\left(\mathrm{Mo}_{23} \mathrm{C}_{6}\right)$ [26]. A limited amount needs to be added in order to prevent both an abundance of Laves phase $(\mathrm{Fe}, \mathrm{Cr})_{2}(\mathrm{Mo}, \mathrm{W})$ and $\delta$-phase formation [33]. At low amounts of $\mathrm{Cr}, \mathrm{M}_{2} \mathrm{X}\left(\mathrm{Mo}_{2} \mathrm{C}\right)$ can form [44]. A typical amount of $\mathrm{Cr}$ and Mo within Gr.91 can range anywhere between $7.90-9.60$ wt.\% and 0.80$1.10 \mathrm{wt} . \%$ respectively [23].

\subsubsection{Vanadium $(\mathrm{V})$ and Niobium $(\mathrm{Nb})$}

Similar to carbon $(\mathrm{C})$ and nitrogen $(\mathrm{N})$, both vanadium $(\mathrm{V})$ and niobium $(\mathrm{Nb})$ are $\gamma$-Fe stabilizers [26] and are strong suppliers to the formation of MX, especially in Gr.91 steel. $\mathrm{V}$ and $\mathrm{Nb}$ mainly form bonds with $\mathrm{C}$ and $\mathrm{N}$, thus forming carbides (MC), nitrides $(\mathrm{MN})$, or carbonitrides, $\mathrm{M}(\mathrm{C}, \mathrm{N})$ depending on the temperature region during heat treatment [33]. The standard amount of $\mathrm{V}$ and $\mathrm{Nb}$ can be between $0.16-0.27 \mathrm{wt} . \%$ and $0.05-0.11 \mathrm{wt} . \%$ respectively [23].

\subsubsection{Nickel (Ni) and Manganese (Mn)}

Nickel (Ni) and Manganese (Mn) are both considered $\gamma$-Fe stabilizers [26]. Under the family of high $\mathrm{Cr}$ steel, the main use of using $\mathrm{Ni}$ and $\mathrm{Mn}$ is to ensure $100 \% \gamma$-Fe, with no indications of delta $(\delta$-Fe) phase, so that upon cooling, would transform into $100 \%$ martensite $[50,51]$. Ni has been known to increase the toughness of ferritic/ martensitic steels [52], as well as accelerate precipitate coarsening [53], and promote the formation of $\mathrm{M}_{6} \mathrm{C}$ [54] which can destabilize $\mathrm{M}_{23} \mathrm{C}_{6}$. Similar effects for $\mathrm{Mn}$ in terms of an increase in

precipitate coarsening have been observed [55]. A typical amount of Ni and Mn within 
Gr.91 can range anywhere between $0.0-0.43 w t . \%$ and $0.25-0.66 w t . \%$ respectively [23].

Figure 15 below shows the effects of lowering Ac temperatures under an increase concentration of Mn and Ni in Gr.91 [56].

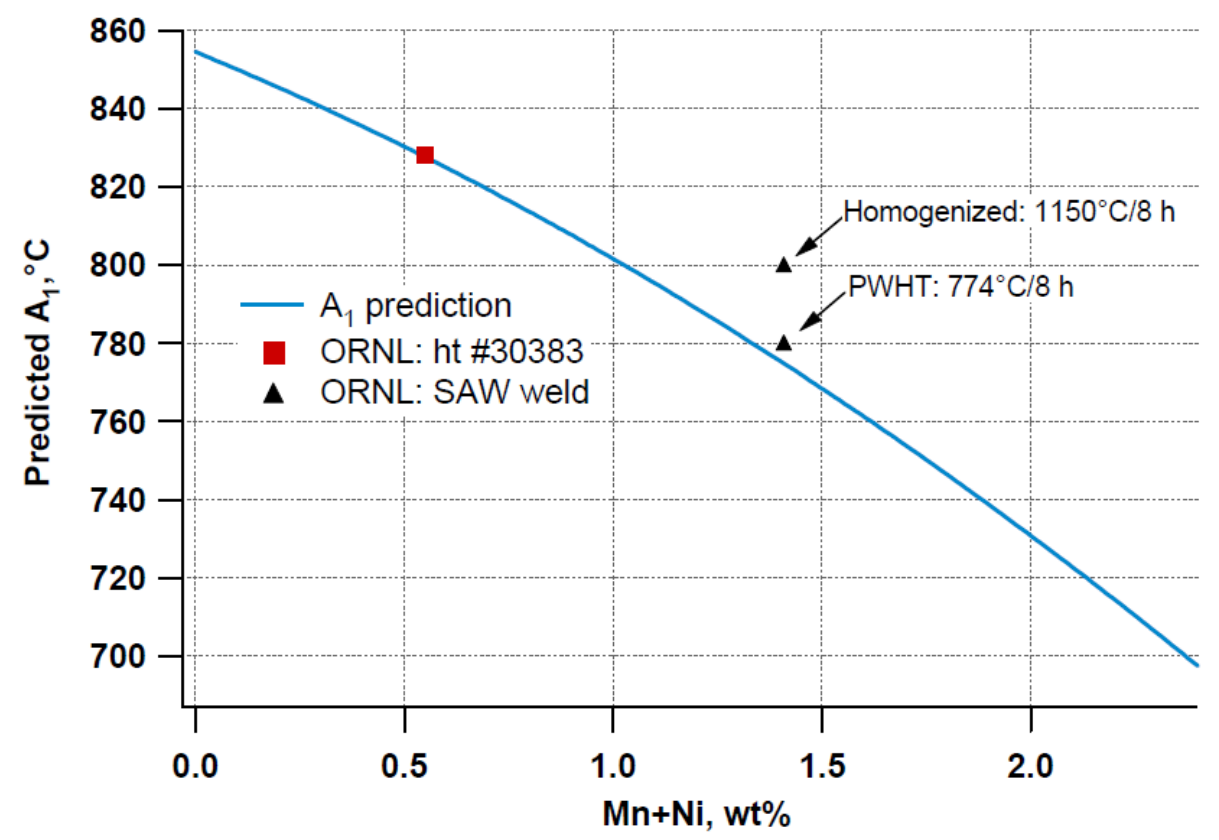

Figure 15. Comparison of predicted Ac1 and experimentally measured Ac1 temperatures for Gr.91 under Mn and Ni concentrations [56].

\subsubsection{Boron (B) and Titanium (Ti)}

Boron (B) has low solubility in $\alpha$-Fe, and is used primary to increase hardenability within the system [26]. In recent studies, B has been added in small concentrations, about $0.005-0.01 w t . \% B$, in $9 \%-12 \% \mathrm{Cr}$ steels. The effects of this surface activated element have been observed to be incorporated to the stability of $\mathrm{M}_{23} \mathrm{C}_{6}$ and decrease the rate at which the carbide can coarsen, thus stabilizing the microstructure $[48,57,58]$. An example of this can be found at Kondo et al. [58] in Figure 16, where the additional 90ppm of B added to Gr.92 showed that larger grain sizes were found within the FGHAZ. This reduced the effect 
of type IV cracks to a point where failure occurred within the weld metal (WM) and not within the HAZ.

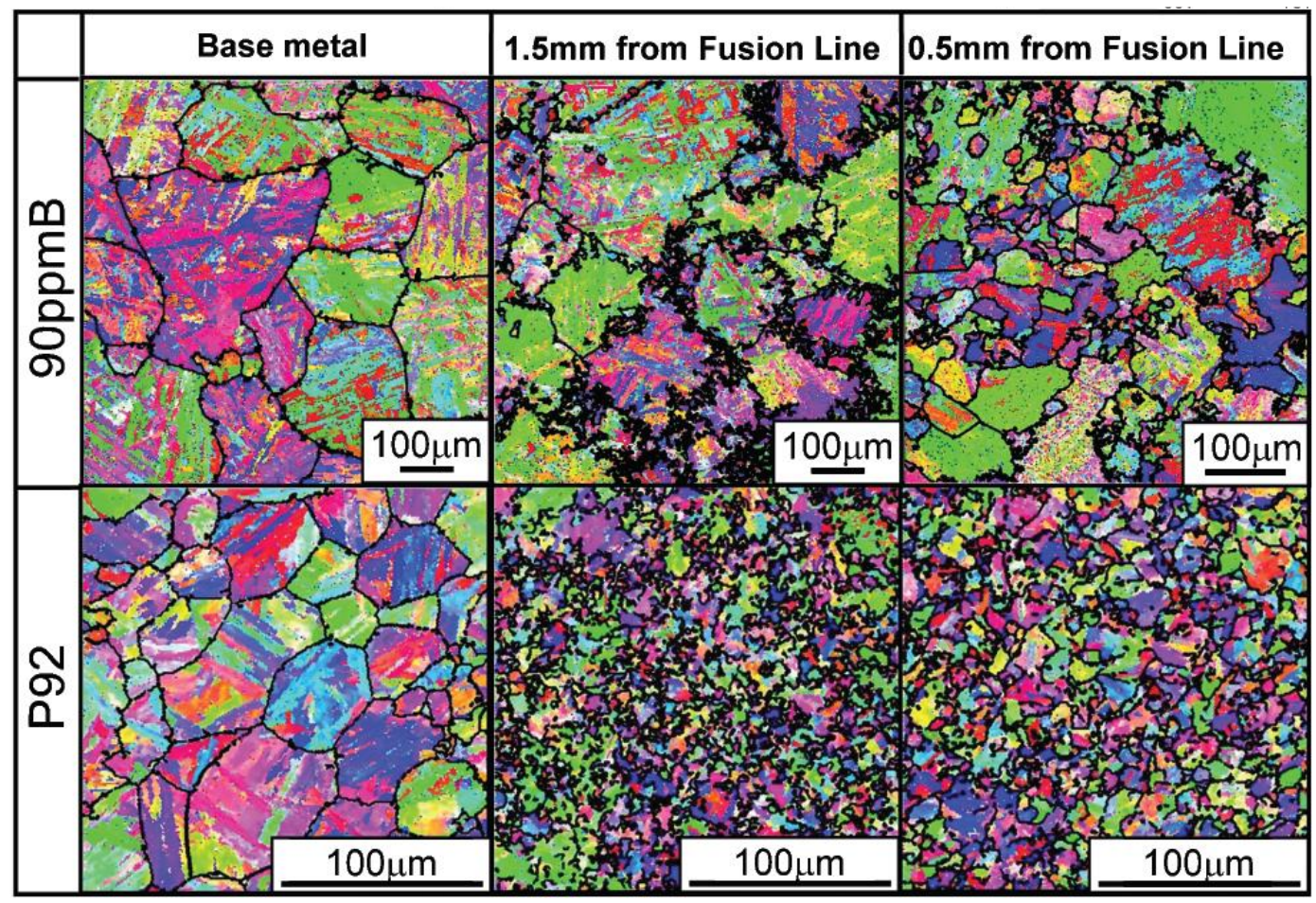

Figure 16. Electron backscatter diffraction pattern (EBSP) analysis results for $90 \mathrm{ppmB}$ steel and P92 steel HAZ microstructures [58].

Titanium (Ti) is an $\alpha$-Fe stabilizer [49] and its concentration in Gr.91 steel can range anywhere between $0.0-0.01 w t . \%$ [23]. The primary function of $\mathrm{Ti}$ is to greatly increase the stability of MX phase by promoting MC (TiC) carbides and MN (TiN) nitrides [59]. A downside of using Ti to enhance the creep strength of Gr.91 is the required high solution temperatures during the steel's heat treatment process which can result in higher costs to the steelmaker. Table 1 and Figure 17 below shows the heat treatment and creep results of three different $9 \mathrm{Cr}-2 \mathrm{~W}-\mathrm{VNb}-0.13 \mathrm{C}$ steels with and without $0.05 \mathrm{wt} . \% \mathrm{Ti}$ [34]. 
The results show that an increase in heat treatment temperatures, such as in the normalization temperatures, promotes Ti-rich MX phase which lead to higher creep life.

Table 1. Chemical compositions and heat treatment conditions of $9 \mathrm{Cr}-2 \mathrm{~W}-\mathrm{VNb}-0.13 \mathrm{C}$ steels with and without $0.05 w t . \%$ Ti (adapted from [34])

\begin{tabular}{|c|c|c|c|c|c|c|c|c|c|c|}
\hline $\begin{array}{c}\text { Elements } \\
(\text { wt. } \%)\end{array}$ & $C$ & $S i$ & $C r$ & $W$ & $V$ & $N b$ & $C o$ & $N$ (mass \%) & Normalizing & Tempering \\
\hline OTi & 0.13 & 0.51 & 8.49 & 1.93 & 0.195 & 0.045 & $<0.001$ & 0.006 & $1100^{\circ} \mathrm{C} \times 1 \mathrm{~h}$ & $760^{\circ} \mathrm{C} \times 1 \mathrm{~h}$ \\
\hline $0.05 T i-\mathrm{S}$ & 0.13 & 0.50 & 8.42 & 1.91 & 0.192 & 0.044 & 0.047 & 0.006 & $1100^{\circ} \mathrm{C} \times 1 \mathrm{~h}$ & $760^{\circ} \mathrm{C} \times 1 \mathrm{~h}$ \\
\hline $0.05 T i-\mathrm{H}$ & 0.13 & 0.50 & 8.42 & 1.91 & 0.192 & 0.044 & 0.047 & 0.006 & $1300^{\circ} \mathrm{Cx} 1 \mathrm{~h}$ & $770^{\circ} \mathrm{Cx} 1 \mathrm{~h}$ \\
\hline
\end{tabular}

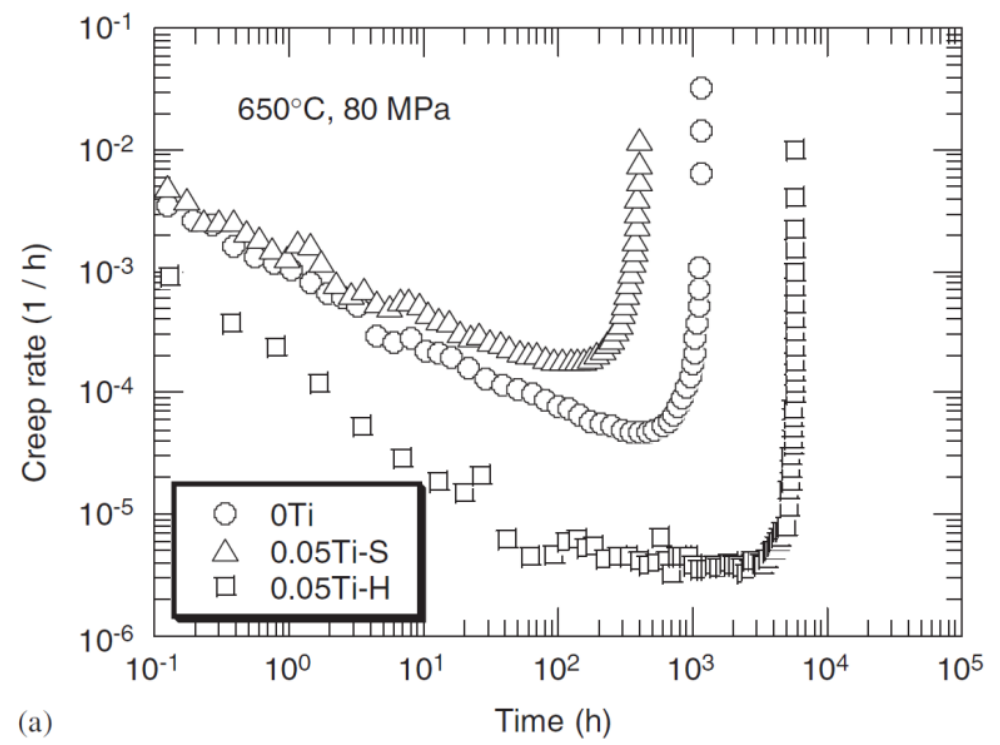

Figure 17. Log-log plot of creep rate versus time curves of the Ti series in Table 1 at $650^{\circ} \mathrm{C}$ under stress conditions of $80 \mathrm{MPa}$ [34]. 


\subsection{Observed Mechanisms Causing Type IV Failure}

\subsubsection{Long-Term Creep Failure}

Under long-term creep tests for Gr.91, life expectancy for the material can be up to 100,000 hours or above with preferred stresses for testing to be below $100 \mathrm{MPa}[27,37,39$, $60,61]$ and testing temperatures as low as $550^{\circ} \mathrm{C}[37,39]$. In this case, premature creep failure comes from the stabilization of Z-phase [62]. Experimental observations have shown that the precipitation and rapid coarsening of Z-phase leads to a decrease of the fine MX carbonitrides $(\mathrm{M}(\mathrm{C}, \mathrm{N}))$ and disappearance of $\mathrm{Nb}$ rich $(\mathrm{NbX}) \mathrm{MX}$ phases [6]. Figure 18 shows an TEM image of Z-phase formation after long-term testing.

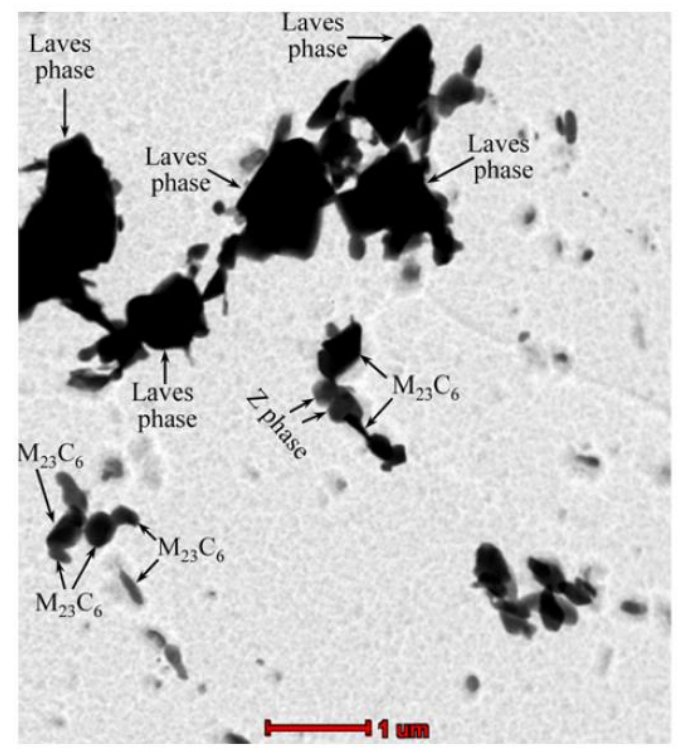

Figure 18. Z-phase formation in Gr.91 steel after long-term creep exposure [63].

\subsubsection{Short-Term Creep Failure}

The main objective behind short-term creep testing is to speed up failure in order to observe the effects of $\mathrm{M}_{23} \mathrm{C}_{6}$. For example, the total creep life lending to short-term 
failure can vary from 100 to 1,000 hours at temperatures between $575^{\circ} \mathrm{C}-650^{\circ} \mathrm{C}$ [64] with high stresses ranging between $100 \mathrm{MPa}-200 \mathrm{MPa}$, depending on heat-treatment conditions prior to tests $[16,64]$. The main observation that has been consistent throughout these experiments is both the volume and coarsening of $\mathrm{M}_{23} \mathrm{C}_{6}$ particles which influences the microstructure in the HAZ and can result in lowering the creep resistance of the material. Many factors can contribute to the coarsening of $\mathrm{M}_{23} \mathrm{C}_{6}$, including the presence of creep voids in the HAZ [65-67] and neutron irradiation [68-72]. However, the main observed mechanism behind the coarsening of $\mathrm{M}_{23} \mathrm{C}_{6}$ has been described as the Ostwald ripening effect $[2,5,61,73,74]$ which is considered to be the last stage of precipitation and is mainly dependent on the working temperature of the material. Higher working temperatures lead to higher coarsening rates. More specifically, at martensite lath boundaries, it has been observed to contain larger $\mathrm{M}_{23} \mathrm{C}_{6}$ particles [30, 31]. Martensite laths, under normalized and tempered conditions, are known to have high density dislocations and are primarily contained within prior austenite grain boundaries (PAGB). Under increasing temperatures, the dislocation structure contained by laths recovers resulting in elongated equiaxed subgrains under which can cause a decrease in creep strength leading to premature failure. Figure 19 shows TEM images of $\mathrm{M}_{23} \mathrm{C}_{6}$ precipitates (black spots) by comparing both lower and higher tempering temperatures [8] which shows the coarsening effect under two different conditions. 


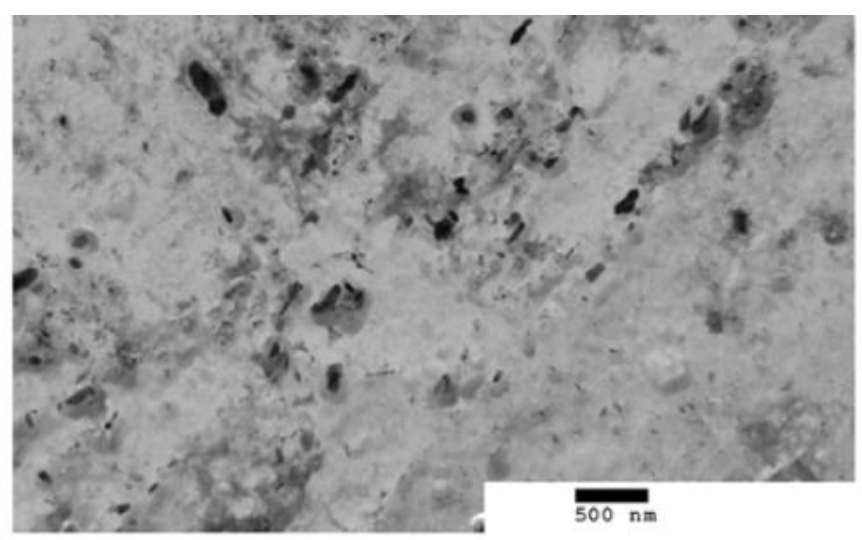

(A)

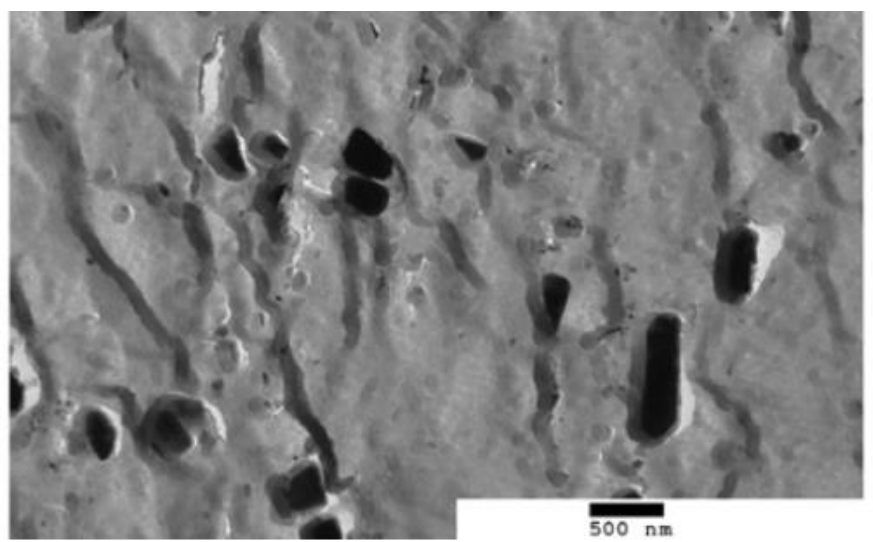

(B)

Figure 19. TEM of $\mathrm{M}_{23} \mathrm{C}_{6}$ precipitates (black spots) under different working temperatures. A) Lower tempering temperatures (LTT) at $650{ }^{\circ} \mathrm{C}$ and B) high tempering temperatures (HTT) at $760^{\circ} \mathrm{C}[8]$.

\subsection{CALPHAD (Calculation of Phase Diagrams)}

The CALculation of PHAse Diagram (CALPHAD) approach was first developed by Kaufman [75] to model complex multi-component materials and their corresponding equilibrium phases. The basic concept of this approach is to gather and analyze thermodynamic data from individual phases and use this data to predict properties of the material under a wide range of temperatures, pressures, and compositional conditions [7680]. 


\section{CHAPTER 3}

\section{OBJECTIVES AND CREEP THEORY}

\section{$\underline{3.1 \text { Objectives }}$}

The main objective under this thesis is to investigate the Gr. 91 base alloy and weldment under the CALculation of PHAse Diagram (CALPHAD) approach. By investigating the fundamental creep cracking mechanisms of Gr.91 during the operation conditions in advanced technologies FE power plants, we can provide and build a link among Composition - Processing Parameters - Phase Stability - Microstructure - Creep Resistance. By utilizing CALPAHD approach, we will be able to provide guidance on how to improve creep resistance under Gr.91 alloys. Both short-term and long-term goals are listed below:

1) Predict the phase stability and microstructure of Gr.91 base alloy and weldment with the computational thermodynamics and kinetics (CALPHAD) approach.

2) Develop a model which has excellent match with the experimental data from the current work and also from the previous existing work.

3) Predict how to improve the long-term creep resistance for the Gr.91 family alloys.

\subsection{Theory of Improving Creep Life of Grade 91}

To improve the creep resistance of Gr.91 based steels, it is imperative that the understanding of the stability of secondary phases including the mentioned $\mathrm{MX}, \mathrm{M}_{23} \mathrm{C}_{6}$, and Z-phase is critical. As mentioned before, MX is considered a beneficial phase while $\mathrm{M}_{23} \mathrm{C}_{6}$ and Z-phase are detrimental to the creep resistance in high temperature and high stress conditions and in low temperature and low stress conditions respectively. Under 
short-term operations, coarsening of $\mathrm{M}_{23} \mathrm{C}_{6}$ is the main cause of premature creep failure while the formation of Z-phase, which dissolve MX, are considered under long-term operations. However, under both short-term and long-term operations for Gr.91 steels, MX phase is the beneficial phase. It is expected that better creep resistance will be achieved by increasing its stability which can be resolved in two ways: 1.) Increase the MX phase stability temperature range; 2.) Increase the concentration of MX phase in the steel. One way of achieving this is to lower both Ac1 and Ac3 temperatures, which in turn can reduce the threshold temperatures and stability of both $\mathrm{M}_{23} \mathrm{C}_{6}$ and Z-phase at higher temperatures. This can have three main advantages: 1.) It can possibly reduce the coarsening of the $\mathrm{M}_{23} \mathrm{C}_{6}$ precipitates since lowering the $\mathrm{M}_{23} \mathrm{C}_{6}$ threshold temperature will lower the stability of $\mathrm{M}_{23} \mathrm{C}_{6}$; 2.) It could reduce the likelihood of Z-phase formation; (3) It can possibly increase the MX stability over long-term use since Z-phase formation would take $\mathrm{V}, \mathrm{Nb}$, and $\mathrm{N}$ elements from MX. In addition, Ac1 and Ac3 temperatures are directly linked with the local microstructure inside HAZ, especially the boundary of ICHAZ. By combining the prediction of the $\mathrm{Ac}$ temperatures and $\mathrm{M}_{23} \mathrm{C}_{6}$ and $\mathrm{Z}$ phase threshold temperatures with the temperature profile data during welding, it is possible to simulate the detail microstructure evolution of the HAZ subzones, which would pave the way to predict how to tune the welding parameters to form the desired local microstructure in HAZ. 


\section{CHAPTER 4}

\section{METHODOLOGY}

\subsection{Simulation Approach}

In this paper we will be utilizing the CALculation of Phase Diagram (CALPHAD) approach in order to characterize and simulate the stability of $\mathrm{M}_{23} \mathrm{C}_{6}, \mathrm{MX}$, and Z-phase within Gr.91 under different compositional changes. Here, the main priority is the destabilization of $\mathrm{M}_{23} \mathrm{C}_{6}$ and $\mathrm{Z}$-phase that are detrimental to the creep resistance under short-term and long-term operation respectively. The decrease in stability of $\mathrm{M}_{23} \mathrm{C}_{6}$ and Z-phase is likely to result in not only an increase in MX phase stability, but also a decrease in the coarsening effect caused by $\mathrm{M}_{23} \mathrm{C}_{6}$ which has been observed to induce premature creep failure in the material. To accomplish this, a baseline study of the system will need to be established to investigate the relationship between various critical temperatures and the stability of the $\mathrm{M}_{23} \mathrm{C}_{6}, \mathrm{MX}$, and Z-phase within the heat-affectedzone (HAZ). This will be followed by simulated changes to the composition of the material under lower Ac1 and Ac3 temperatures. By comparing the baseline study with the results given by lowering the Ac 1 and Ac3 temperatures, a model can be obtained in which to predict and improve the creep resistance under both short-term and long-term applications.

\subsection{Simulation Set-Up}

\subsubsection{Thermo-Calc Set-Up}

To determine the stability of $\mathrm{M}_{23} \mathrm{C}_{6}, \mathrm{MX}$, and Z-phase, the CALPHAD (CALculation of PHAse Diagram) approach has been utilized by using Thermo-Calc and its corresponding TCFE8 database. 


\subsubsection{Composition of Grade 91 Baseline Study}

The chemical composition of the Gr.91 baseline system can be seen in Table 2 below. The weight percentage of each element under ASME standards[23] was shown on top in comparison with the composition chosen for the current simulations. Overall, the alloy consists of more than 13 elements however, under the direction of this study, only core elements that have major influence over the $\mathrm{M}_{23} \mathrm{C}_{6}, \mathrm{MX}$, and Z-Phase stability were chosen for the baseline. To reiterate, " $\mathrm{M}$ " in $\mathrm{M}_{23} \mathrm{C}_{6}$ represents $\mathrm{Cr}, \mathrm{Fe}$, and $\mathrm{Mo}$, the " $\mathrm{M}$ " in MX represents $\mathrm{V}$ and $\mathrm{Nb}$, while the $\mathrm{X}$ represents $\mathrm{C}$ and $\mathrm{N}$, and Z-Phase has a chemical notation and sublattice model of $\mathrm{Cr}(\mathrm{V}, \mathrm{Nb}) \mathrm{N}$. Therefore, a Fe-Cr-C-V-Nb-Mo-N (Gr.91 based system) alloy was chosen as the base material for investigation.

Table 2. Chemical composition from the ASME standard[23] and simulation of Gr.91 base system.

\begin{tabular}{|c|c|c|c|c|c|c|c|c|c|}
\hline $\begin{array}{c}\text { Elements } \\
\text { (wt.\%) }\end{array}$ & $C r$ & $C$ & $V$ & $N b$ & $M o$ & $N$ & $M n$ & $N i$ & $T i$ \\
\hline $\begin{array}{c}\text { ASME } \\
\text { standard }\end{array}$ & $\begin{array}{c}7.90- \\
9.60\end{array}$ & $\begin{array}{c}0.06- \\
0.15\end{array}$ & $\begin{array}{c}0.16- \\
0.27\end{array}$ & $\begin{array}{c}0.05- \\
0.11\end{array}$ & $\begin{array}{c}0.80- \\
1.10\end{array}$ & $\begin{array}{c}0.025- \\
0.080\end{array}$ & $\begin{array}{c}0.25- \\
0.66\end{array}$ & $\begin{array}{c}0.43 \\
(\max )\end{array}$ & $\begin{array}{c}0.01 \\
(\max )\end{array}$ \\
\hline $\begin{array}{c}\text { Gr.91 } \\
\text { Baseline }\end{array}$ & 8.75 & .10 & .215 & .08 & .95 & .05 & - & - & - \\
\hline
\end{tabular}

\subsubsection{Simulated Compositional Changes of Gr.91}

Table 3 below shows the various compositional simulation alloy changes to the Gr.91 base system. The primary elements focused on here are concentrations of manganese (Mn), nickel (Ni), and titanium (Ti) added to the system. Mn and Ni are both ferrite ( $\alpha$ - 
Fe) stabilizers and are the most effective elements in lowering Ac temperatures [56], while Ti have been observed to greatly increase the stabilization of MX phase [34, 59]. A maximum weight percent of $\mathrm{Mn}, \mathrm{Ni}$, and $\mathrm{Ti}$ are necessary in order to establish the greatest effect these elements have on both lowering Ac temperatures and destabilizing $\mathrm{M}_{23} \mathrm{C}_{6}$ and Z-Phase.

Table 3. Compositional changes to Gr.91 base system. Here, concentrations of manganese (Mn), nickel (Ni), and titanium (Ti) are added separately to the system.

\begin{tabular}{|c|c|c|c|c|c|c|c|c|c|}
\hline $\begin{array}{c}\text { Elements } \\
\text { (wt.\%) }\end{array}$ & $C r$ & $C$ & $V$ & $N b$ & $M o$ & $N$ & $M n$ & $N i$ & $T i$ \\
\hline $\begin{array}{c}\text { ASME } \\
\text { standard }\end{array}$ & $\begin{array}{c}7.90- \\
9.60\end{array}$ & $\begin{array}{c}0.06- \\
0.15\end{array}$ & $\begin{array}{c}0.16- \\
0.27\end{array}$ & $\begin{array}{c}0.05- \\
0.11\end{array}$ & $\begin{array}{c}0.80- \\
1.10\end{array}$ & $\begin{array}{c}0.025- \\
0.080\end{array}$ & $\begin{array}{c}0.25- \\
0.66\end{array}$ & $\begin{array}{c}0.43 \\
(\text { max })\end{array}$ & $\begin{array}{c}0.01 \\
(\text { max })\end{array}$ \\
\hline $\begin{array}{c}\text { Gr.91 } \\
\text { Baseline }\end{array}$ & 8.75 & .10 & .215 & .08 & .95 & .05 & - & - & - \\
\hline $\begin{array}{c}\text { Simulation 1 } \\
\text { (S-1) }\end{array}$ & 8.75 & .10 & .27 & .08 & .95 & .05 & .66 & - & - \\
\hline $\begin{array}{c}\text { Simulation 2 } \\
\text { (S-2) }\end{array}$ & 8.75 & .10 & .215 & .11 & .95 & .05 & - & .43 & - \\
\hline $\begin{array}{c}\text { Simulation 3 } \\
\text { (S-3) }\end{array}$ & 8.75 & .10 & .215 & .08 & .95 & .025 & - & - & .01 \\
\hline
\end{tabular}

Table 4 shows the compositional alloy changes to the Gr.91 base system under different niobium $(\mathrm{Nb})$, vanadium $(\mathrm{V})$, and nitrogen $(\mathrm{N})$ concentrations which excludes the additional $\mathrm{Mn}, \mathrm{Ni}$, and Ti concentrations made in Table 3. The reason for this is to reduce the stability of Z-phase in order to increase the creep life of the material under long-term 
operations. Recall that the main configuration for the modified Z-phase $((\mathrm{Cr}, \mathrm{Fe})(\mathrm{V}, \mathrm{Nb}) \mathrm{N})$ includes $\mathrm{V}, \mathrm{Nb}$, and $\mathrm{N}$.

Table 4. Compositional alloy changes to the Gr.91 base system under different niobium $(\mathrm{Nb})$, vanadium $(\mathrm{V})$, and nitrogen $(\mathrm{N})$ concentrations which excludes the additional Mn, $\mathrm{Ni}$, and Ti concentrations made in Table 3.

\begin{tabular}{|c|c|c|c|c|c|c|c|c|c|}
\hline $\begin{array}{c}\text { Elements } \\
\text { (wt.\%) }\end{array}$ & $\mathrm{Cr}$ & $\mathrm{C}$ & $\mathrm{V}$ & $\mathrm{Nb}$ & $\mathrm{Mo}$ & $\mathrm{N}$ & $\mathrm{Mn}$ & $\mathrm{Ni}$ & $\mathrm{Ti}$ \\
\hline $\begin{array}{c}\text { ASME } \\
\text { standard }\end{array}$ & $\begin{array}{c}7.90- \\
9.60\end{array}$ & $\begin{array}{c}0.06- \\
0.15\end{array}$ & $\begin{array}{c}0.16- \\
0.27\end{array}$ & $\begin{array}{c}0.05- \\
0.11\end{array}$ & $\begin{array}{c}0.80- \\
1.10\end{array}$ & $\begin{array}{c}0.025- \\
0.080\end{array}$ & $\begin{array}{c}0.25- \\
0.66\end{array}$ & $\begin{array}{c}0.43 \\
(\text { max })\end{array}$ & $\begin{array}{c}0.01 \\
(\text { max })\end{array}$ \\
\hline $\begin{array}{c}\text { Gr.91 } \\
\text { Baseline }\end{array}$ & 8.75 & .10 & .215 & .08 & .95 & .05 & - & - & - \\
\hline $\begin{array}{c}\text { Simulation } 4 \\
\text { (S-4) }\end{array}$ & 8.75 & .10 & .27 & .08 & .95 & .05 & - & - & - \\
\hline $\begin{array}{c}\text { Simulation 5 } \\
\text { (S-5) }\end{array}$ & 8.75 & .10 & .215 & .11 & .95 & .05 & - & - & - \\
\hline $\begin{array}{c}\text { Simulation 6 } \\
\text { (S-6) }\end{array}$ & 8.75 & .10 & .215 & .08 & .95 & .025 & - & - & - \\
\hline
\end{tabular}

Table 5 shows the modified version of Gr.91 under the combined elements of Mn, $\mathrm{Ni}$, and $\mathrm{Ti}$ while also optimizing the $\mathrm{V}, \mathrm{Nb}$, and $\mathrm{N}$ concentrations. More specifically, under the modified version of $\mathrm{Gr} .91$ the $\mathrm{Mn}, \mathrm{Ni}, \mathrm{Ti}, \mathrm{V}$, and $\mathrm{Nb}$ will be at its maximum allowed concentrations while concentrations of $\mathrm{N}$ will be at its minimum. The reason for this is to establish how the stability of each secondary phase changes in accordance to the results of previous simulations made in Table 3 and Table 4. 
Table 5. Modified version of Gr.91 under the combined elements of Mn, Ni, and Ti while also optimizing the $\mathrm{V}, \mathrm{Nb}$, and $\mathrm{N}$ concentrations.

\begin{tabular}{|c|c|c|c|c|c|c|c|c|c|}
\hline $\begin{array}{c}\text { Elements } \\
\text { (wt.\%) }\end{array}$ & $C r$ & $C$ & $V$ & $N b$ & $M o$ & $N$ & $M n$ & $N i$ & $T i$ \\
\hline $\begin{array}{c}\text { ASME } \\
\text { standard }\end{array}$ & $\begin{array}{c}7.90- \\
9.60\end{array}$ & $\begin{array}{c}0.06- \\
0.15\end{array}$ & $\begin{array}{c}0.16- \\
0.27\end{array}$ & $\begin{array}{c}0.05- \\
0.11\end{array}$ & $\begin{array}{c}0.80- \\
1.10\end{array}$ & $\begin{array}{c}0.025- \\
0.080\end{array}$ & $\begin{array}{c}0.25- \\
0.66\end{array}$ & $\begin{array}{c}0.43 \\
(\max )\end{array}$ & $\begin{array}{c}0.01 \\
(\max )\end{array}$ \\
\hline $\begin{array}{c}\text { Modified } \\
\text { Gr.91 }\end{array}$ & 8.75 & .10 & .27 & .11 & .95 & .025 & .66 & .43 & .01 \\
\hline
\end{tabular}




\section{CHAPTER 5}

\section{RESULTS AND DISCUSSION}

\subsection{Gr.91 Based System}

A baseline simulation was done for the Gr.91 under the composition seen in Table 2. The purpose of this baseline study is to provide the necessary fundamental thermodynamic information which is not abundant when compared with other studies. Therefore, in order to address this issue, the first half of the results section has provided some basic simulated studies on the stability of $\mathrm{M}_{23} \mathrm{C}_{6}, \mathrm{MX}$, and Z-phase formation. This includes isopleth diagrams, Ac temperature changes, mole and site fraction analysis, scheil vs. equilibrium graphs, and threshold temperatures of various secondary phases.

\subsubsection{Isopleth Diagrams}

Both Figure 20 and Figure 21 shows the isopleth diagrams of Gr.91 based system with respect to the change of wt.\% of C [81]. More specifically, Figure 20 is the isopleth diagram in the range from $0.0-0.20 \mathrm{wt} . \% \mathrm{C}$ at temperatures between $600^{\circ} \mathrm{C}-1600^{\circ} \mathrm{C}$ whereas Figure 21 is under $0.0-0.15 \mathrm{wt} . \% \mathrm{C}$ at $700^{\circ} \mathrm{C}-1000^{\circ} \mathrm{C}$. Here, in both figures, it clearly shows the phase stability for ferrite $(\alpha)$ and austenite $(\gamma)$ phases along with the threshold temperatures of secondary phases, including $\mathrm{MX}$ phase, $\mathrm{M}_{23} \mathrm{C}_{6}$ phase, and the $\mathrm{Z}$ phase.

As mentioned before, the MX phase has the same crystal structure (FCC) as the austenite phase. However, under the Gibbs energy minimization at each composition, there is a clear indication that at least two different MX phases with different compositions may 
form at elevated temperatures, which has been observed in other previous experiments [10, $15,48,82,83]$. The notation used in both diagrams decribes the MX phase as a two sublattice solution phase: $(\mathrm{V}, \mathrm{Nb})(\mathrm{C}, \mathrm{N})$ where vanadium $(\mathrm{V})$ and niobium $(\mathrm{Nb})$ can occupy the first sublattice while carbon $(\mathrm{C})$ and nitrogen $(\mathrm{N})$ can occupy the second. Here, MX1 is used to decribe the MX phase which has higher site fraction of $\mathrm{N}$ than $\mathrm{C}$ in the second sublattice. MX2 is used to describe when the site fraction of $\mathrm{C}$ is higher than $\mathrm{N}$ in the second sublattice.

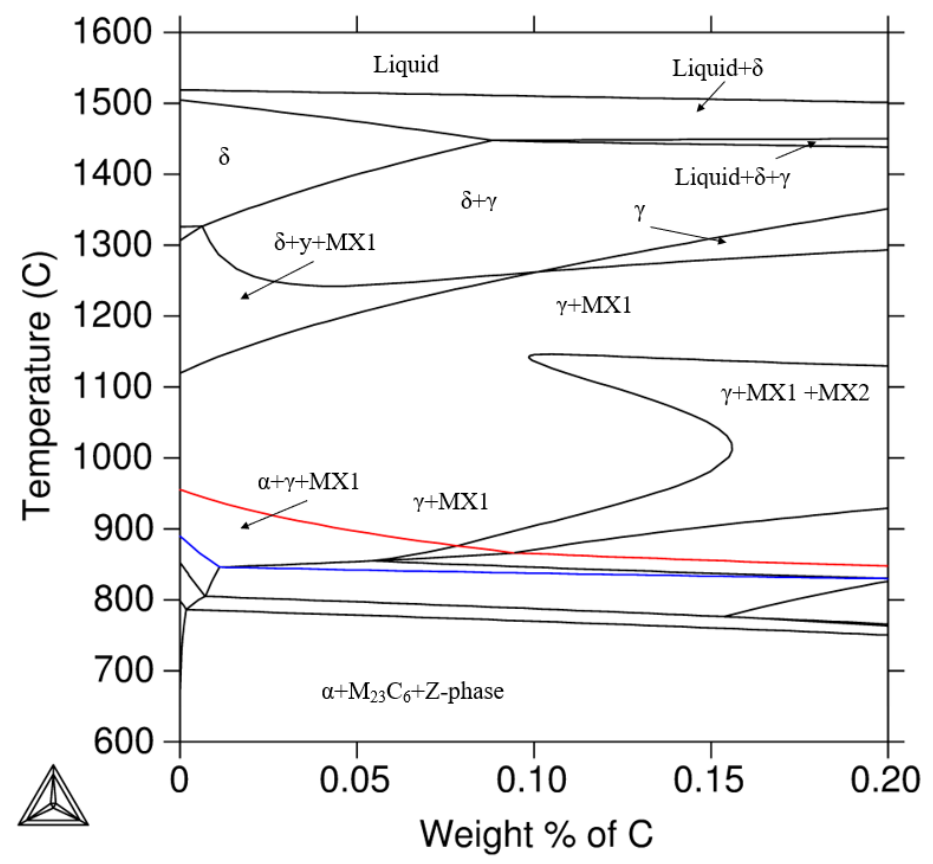

Figure 20. Overall isopleth diagram of Gr.91 based system for temperature ranges of $600^{\circ} \mathrm{C}-1600^{\circ} \mathrm{C}$ at a range of $0-0.2 \mathrm{wt} . \% \mathrm{C}[81]$.

At $0.05 \mathrm{wt} . \% \mathrm{C}$, the first secondary phases that are precipitated out in the temperature region between $896^{\circ} \mathrm{C}$ and $1243^{\circ} \mathrm{C}$ is the MX1 phase. Below the Ac3 temperature $\left(896^{\circ} \mathrm{C}\right), \gamma$ phase starts to transform into the $\alpha$ phase. Further down, the other two secondary phases, i.e. $\mathrm{M}_{23} \mathrm{C}_{6}$ phase and Z-phase become stable. 


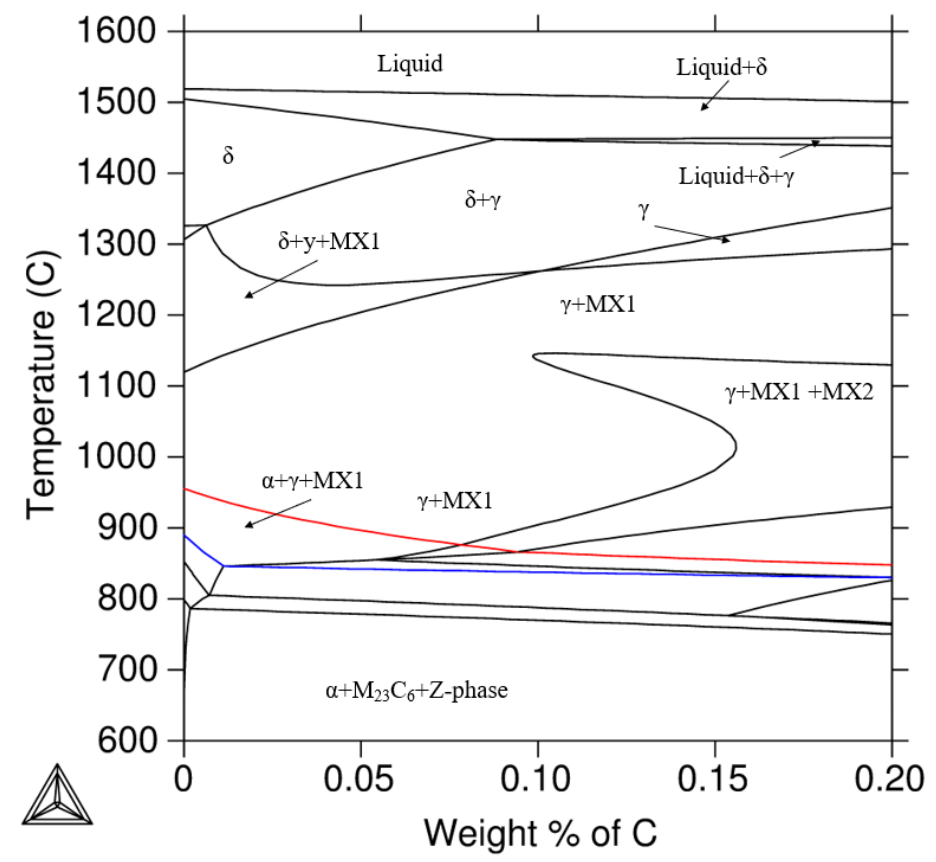

Figure 21. Close up of phase diagram at temperature ranges of $700^{\circ} \mathrm{C}-1000^{\circ} \mathrm{C}$ and 0 0.15 wt. \% C [81].

At higher $\mathrm{C}$ concentrations of $0.1 \mathrm{wt} . \%$, multiple $\mathrm{MX}$ phases become stable due to the miscibility gap. For instance at $1000^{\circ} \mathrm{C}$ seen in Figure $20, \gamma+\mathrm{MX} 1$ changes into $\gamma+\mathrm{MX} 1+\mathrm{MX} 2$ at around $0.155 \mathrm{wt} . \% \mathrm{C}$. As for $\mathrm{M}_{23} \mathrm{C}_{6}$, which is described as $(\mathrm{Cr}, \mathrm{Fe}, \mathrm{Mo})_{23} \mathrm{C}_{6}$, does not change much in terms of composition where $\mathrm{Cr}$ is the most dominate element in the first sublattice and starts to form at lower temperature regions. Z-phase, described as $\mathrm{Cr}(\mathrm{V}, \mathrm{Nb}) \mathrm{N}$, forms at even lower tmeperature regions than the $\mathrm{M}_{23} \mathrm{C}_{6}$ phase, in which case composition does not change much with $\mathrm{V}$ always being the dominant element in the second sublattice. 


\subsubsection{Ac1 and Ac3 Temperature Change}

Ac1 and Ac3 are critical to understanding the phase stabilities and also the changes to the microstructure inside the heat-affected-zone (HAZ). Essentially, Ac3 defines the boundary between the Fine Grain HAZ (FGHAZ) and Intercritical HAZ (ICHAZ) while Ac1 defines the boundary between ICHAZ with over tempered region. This is primarily due to the thermal gradient caused by the welding processes of the material. Figure 22 and Figure 23 shows the results of Ac1 and Ac3 temperatures changes of the Gr.91 base system when compared with a binary FE-C phase diagram [81].

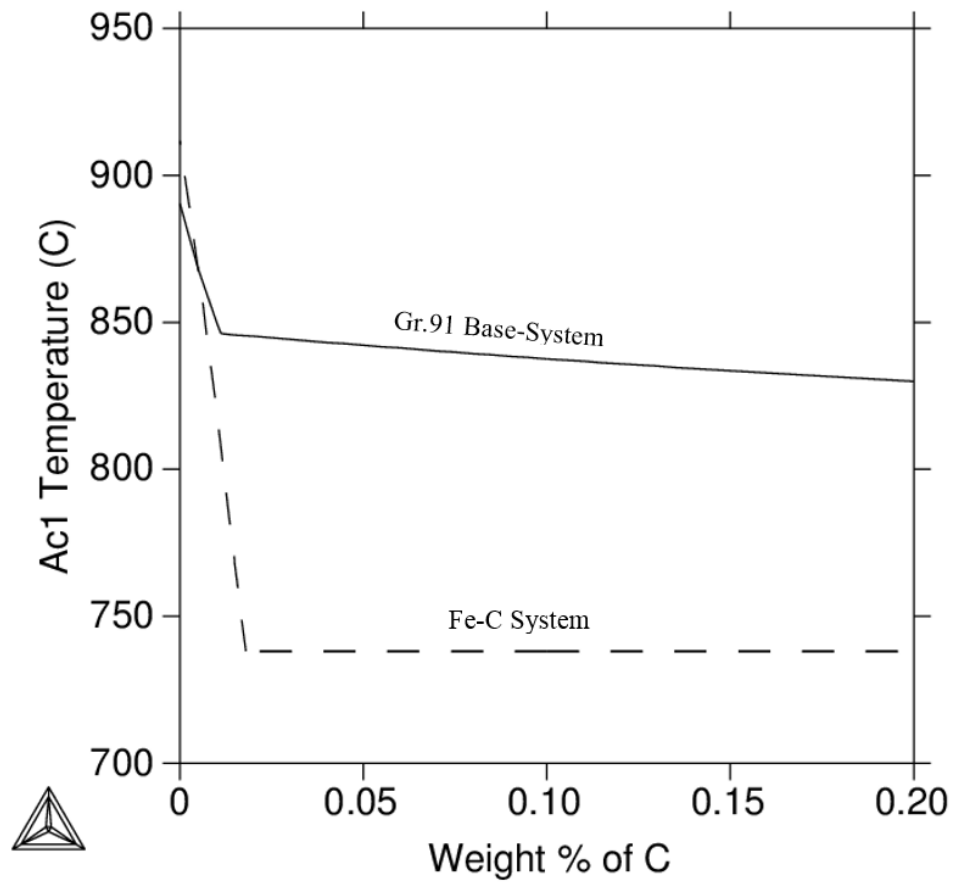

Figure 22. Ac1 temperature $\left({ }^{\circ} \mathrm{C}\right)$ vs. wt. $\%$ of $\mathrm{C}$ for $\mathrm{Gr} .91$ based system simulation (solid line) while comparing with the Fe-C binary system Ac temperatures (dash line) [81].

In Figure 22, Ac1 temperature of Gr.91 based system drops from $890^{\circ} \mathrm{C}$ to $830^{\circ} \mathrm{C}$ where the biggest difference happens in the beginning up to $0.01 \mathrm{wt} . \% \mathrm{C}$ and then gradually decreases afterwards. As for the FE-C binary system, the same can be said, however the 
sudden change happens at a slightly higher $\mathrm{C}$ concentration and it dropped from $910^{\circ} \mathrm{C}$ to $738^{\circ} \mathrm{C}$. The sudden changes in both Ac1 and Ac3 temperatures seen in both Figure 22 and Figure 23, are due to the phase transformation in both systems. From Figure 22, this dramatic shift of Ac1 temperatures indicates that alloying elements other than $\mathrm{C}$ greatly increase the Ac1 temperature.

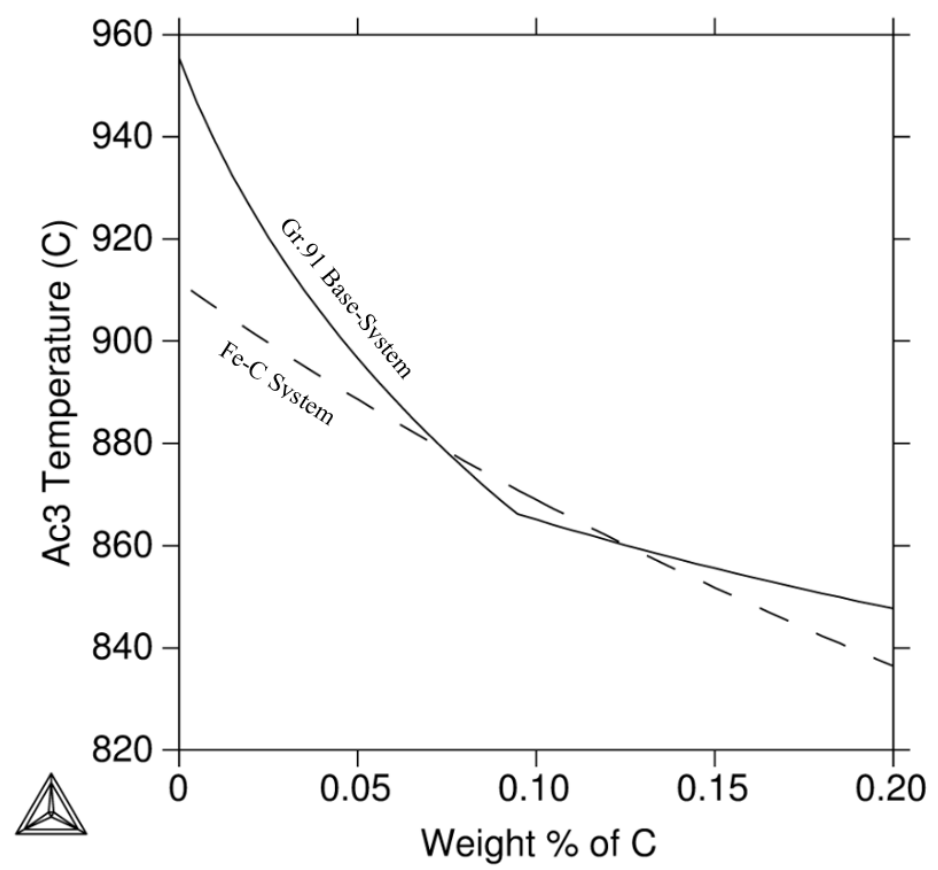

Figure 23. Ac3 temperature $\left({ }^{\circ} \mathrm{C}\right)$ vs. wt. $\%$ of $\mathrm{C}$ for Gr.91 based system simulation (solid line) while comparing with the $\mathrm{Fe}-\mathrm{C}$ binary system Ac temperatures (dash line) [81].

Figure 23 shows that the $\mathrm{Ac} 3$ temperature drops from $960^{\circ} \mathrm{C}$ at $0 \mathrm{wt} . \% \mathrm{C}$ to $850^{\circ} \mathrm{C}$ at $0.2 \mathrm{wt} . \% \mathrm{C}$ for $\mathrm{Gr} .91$ based-system whereas it drops from $910^{\circ} \mathrm{C}$ to $840^{\circ} \mathrm{C}$ for the $\mathrm{Fe}-\mathrm{C}$ system. Similar in Figure 22, the slope changes in Figure 23 for Gr.91 based-system at around $0.08 \mathrm{wt} . \% \mathrm{C}$ represent a phase transformation from $\alpha+\gamma+\mathrm{MX} 1+\mathrm{MX} 2+\mathrm{M}_{23} \mathrm{C}_{6}$ to $\alpha+\gamma+\mathrm{MX} 1+\mathrm{M}_{23} \mathrm{C}_{6}$. A linear relationship is seen with the FE-C system which represents that no phase transformation has occurred within this temperature region. In general, Figure 
23 shows that Ac3 temperatures have a smaller influence in terms of increased concentration of $\mathrm{C}$ wt.\%.

\subsubsection{Gibbs Energy of FCC Structure ( $\gamma$ phase and MX phase)}

Figure 24 below shows the results of the Gibbs energy of various phases with facecenter cubic (fcc) crystal structures which means that $\gamma, \mathrm{MX} 1$, and MX2 are included [81]. Under the CALPHAD approach, one Gibbs energy is typically used to describe the phases sharing the same crystal structure. As mentioned, the MX phase is considered a good phase within the system due to its very low coarsening rate when compared with $\mathrm{M}_{23} \mathrm{C}_{6}$ under short term applications [26], which can hinder the creep strength of the alloy.

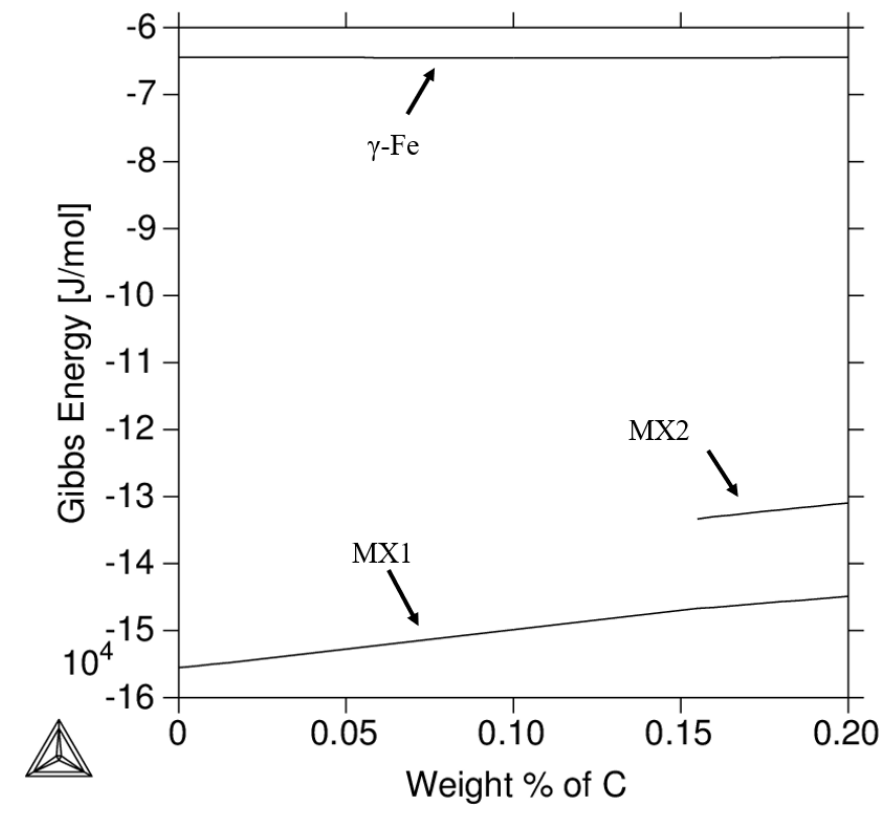

Figure 24. The Gibbs energy of $\gamma$ phase, MX1 phase, and MX2 phase in the Gr.91 based system at $1000^{\circ} \mathrm{C}$ from $0 w t . \%-0.20 \mathrm{wt} . \% \mathrm{C}$ [81].

Figure 24 shows the Gibbs energies of the $\gamma, \mathrm{MX} 1$, and $\mathrm{MX} 2$ at $1000^{\circ} \mathrm{C}$ were plotted. It is clearly noted that three energies have appeared corresponding to the three 
different fcc phases, even though they share the same crystal structure. In the region with less than $0.15 \mathrm{wt} . \% \mathrm{C}, \gamma$ and MX1 are the only stable phases, while MX2 becomes stable in the higher $\mathrm{C}$ concentration region. This clearly indicates a miscibility gap and phase transformation observed in Figure 20 at $1000^{\circ} \mathrm{C}$.

\subsubsection{Mole Fraction of Secondary Phases under Equilibrium Condition}

Figure 25 shows the mole fraction of the secondary phases in the temperature range between $600^{\circ} \mathrm{C}$ and $1400^{\circ} \mathrm{C}$ under which it shows the stability of $\mathrm{M}_{23} \mathrm{C}_{6}, \mathrm{MX} 1, \mathrm{MX} 2$, and Z-phase [81]. In this case, the $\mathrm{M}_{23} \mathrm{C}_{6}$ phase is the dominant secondary phase in the system and it reaches the maximum amount at $600^{\circ} \mathrm{C}$ after which it then drops dramatically from $837^{\circ} \mathrm{C}$ and becomes completely unstable at $870^{\circ} \mathrm{C}$. This dramatic drop for the $\mathrm{M}_{23} \mathrm{C}_{6}$ phase is primarily due to the presence of austenite $\gamma$ phase which becomes a stable phase, leading to a multiphase region of both $\gamma$ and $\alpha$ phases. In addition, this zone $\left(837^{\circ} \mathrm{C}-865^{\circ} \mathrm{C}\right)$ is also considered to be the ICHAZ due to the temperatures being between Ac1 and Ac3 where type IV cracks are likely observed.

Confirming what was seen in Figure 20 is the presence of MX1 and MX2. For MX1 phase, the stable temperature region was simulated between $770^{\circ} \mathrm{C}$ and $1260^{\circ} \mathrm{C}$ and much more dominate, while very limited amount of MX2 phase only show up briefly between $847^{\circ} \mathrm{C}-890^{\circ} \mathrm{C}$ (Ac3 temperature zone). Z-phase is stable until about $770^{\circ} \mathrm{C}$ then becomes unstable after reaching $790^{\circ} \mathrm{C}$ which is likely because of the appearance of $\mathrm{V}$ rich $\mathrm{MX} 1$ phase in this temperature region. 


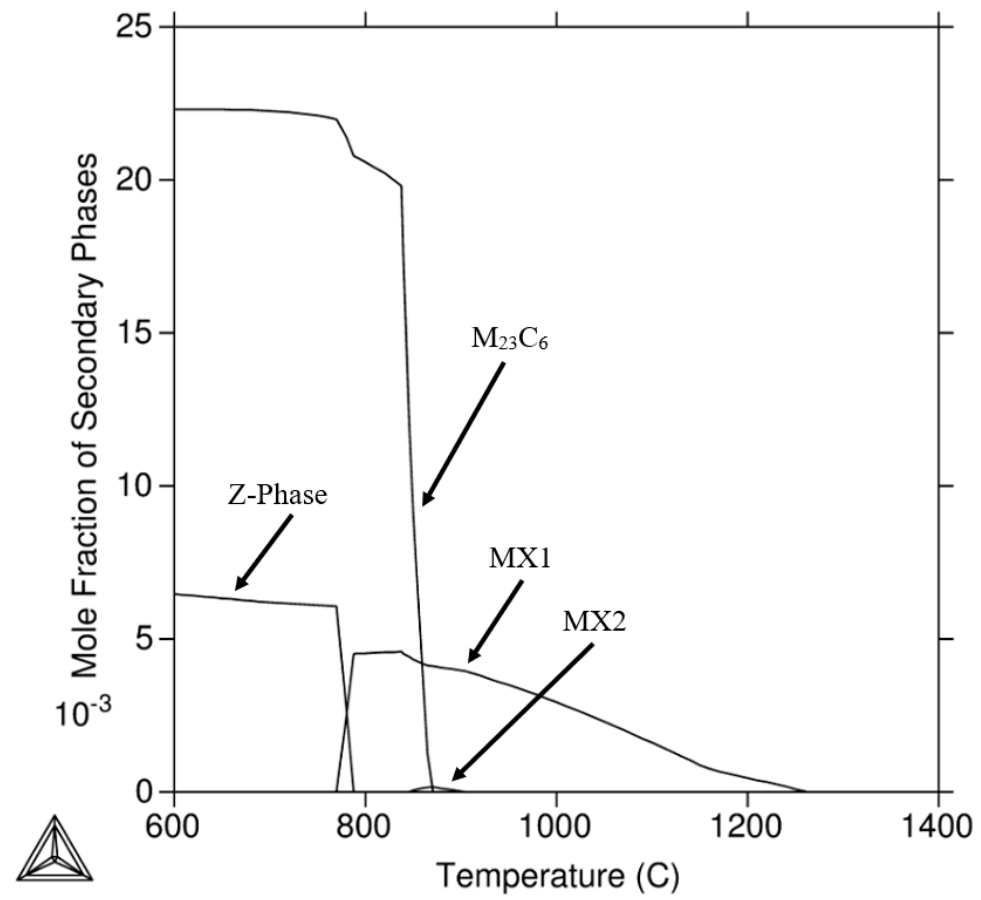

Figure 25. Mole fraction of secondary phases in Gr.91 based system [81].

\subsubsection{Site Fraction of MX Phase under Equilibrium Condition}

Figure 26 through Figure 29 establishes the site fraction of $\mathrm{Nb}, \mathrm{V}, \mathrm{C}$, and $\mathrm{N}$ concentrations for MX1 and MX2 during the temperature range from $800^{\circ} \mathrm{C}$ to $1200^{\circ} \mathrm{C}$ [81]. More specifically, Figure 26 and Figure 27 represents the elemental composition changes for both sublattices of MX1 whereas, Figure 28 and Figure 29 are for MX2. For MX1, Figure 26 shows that the dominant element in the first sublattice is gradually shifting from $\mathrm{Nb}$ to $\mathrm{V}$ with the decrease of temperature while $\mathrm{N}$ is always the dominant element in the second sublattice. The complete shift from $\mathrm{Nb}$ rich to $\mathrm{V}$ rich in the first sublattice happens at about $1100^{\circ} \mathrm{C}$. For MX2 phase, $\mathrm{Nb}$ will be the dominant element in the first sublattice, while $\mathrm{C}$ has higher site fraction than $\mathrm{N}$ in the second sublattice. 


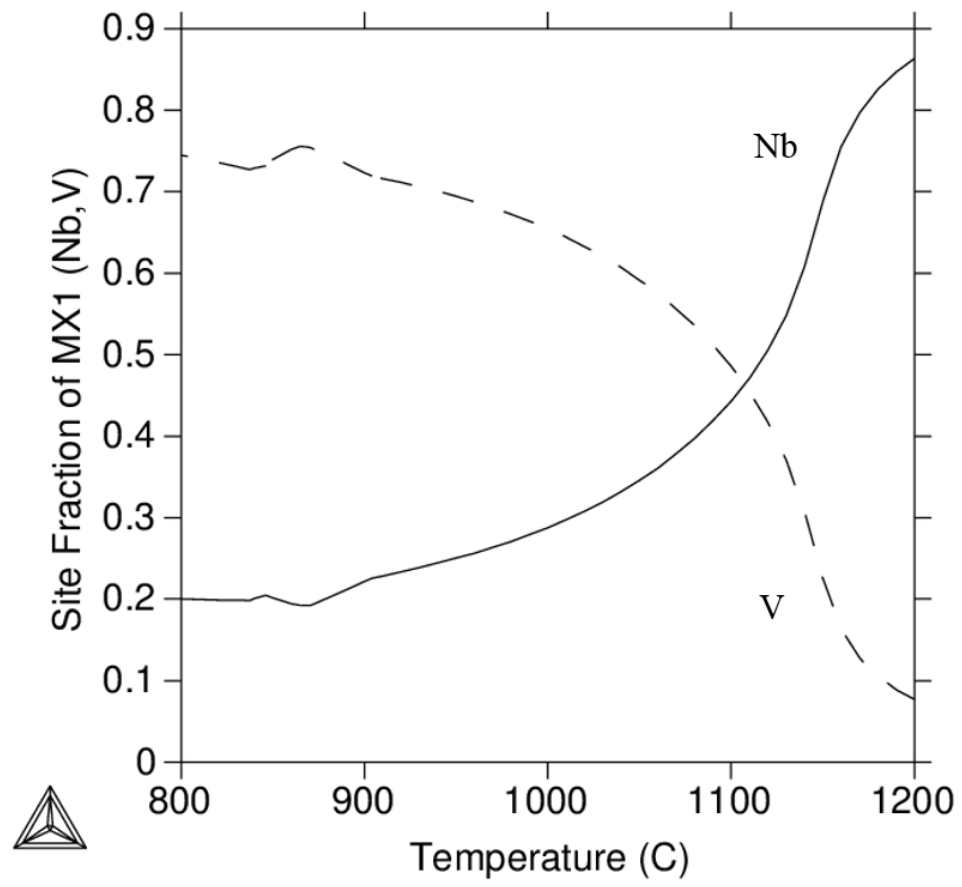

Figure 26. Site Fraction of MX1 for $\mathrm{Nb}$ and $\mathrm{V}$ concentrations under the first sublattice of the crystal [81].

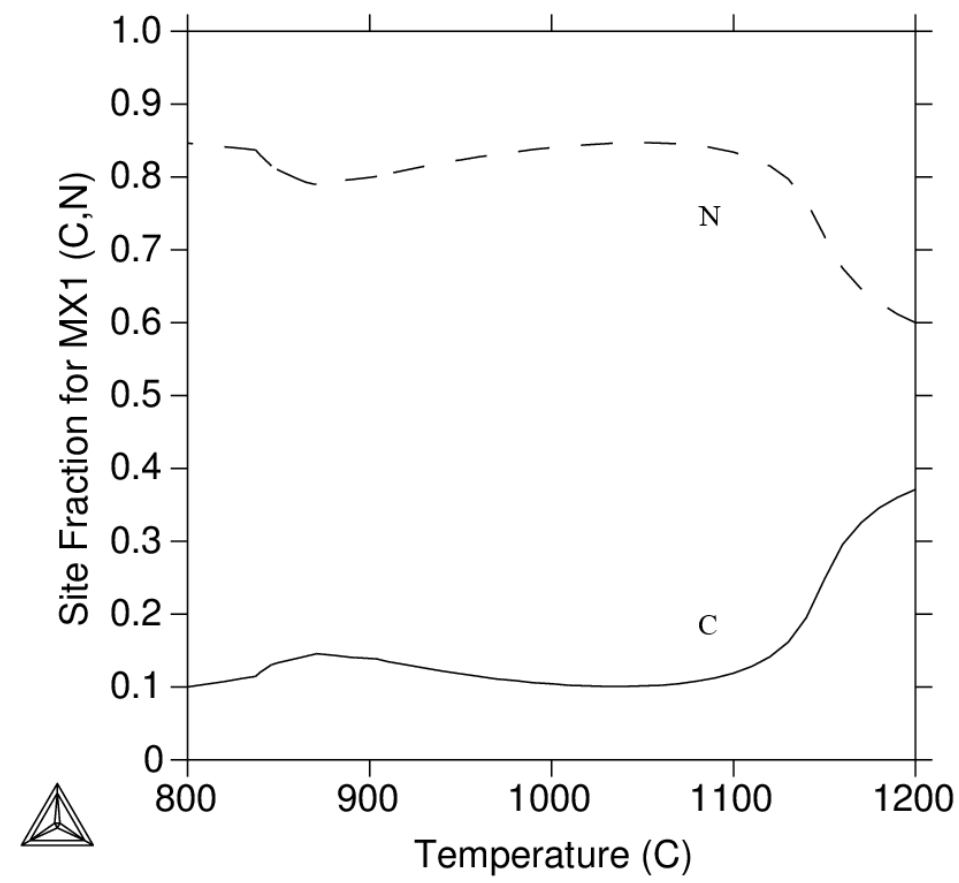

Figure 27. Site Fraction of MX1 for $\mathrm{C}$ and $\mathrm{N}$ concentrations under the second sublattice of the crystal structure [81]. 


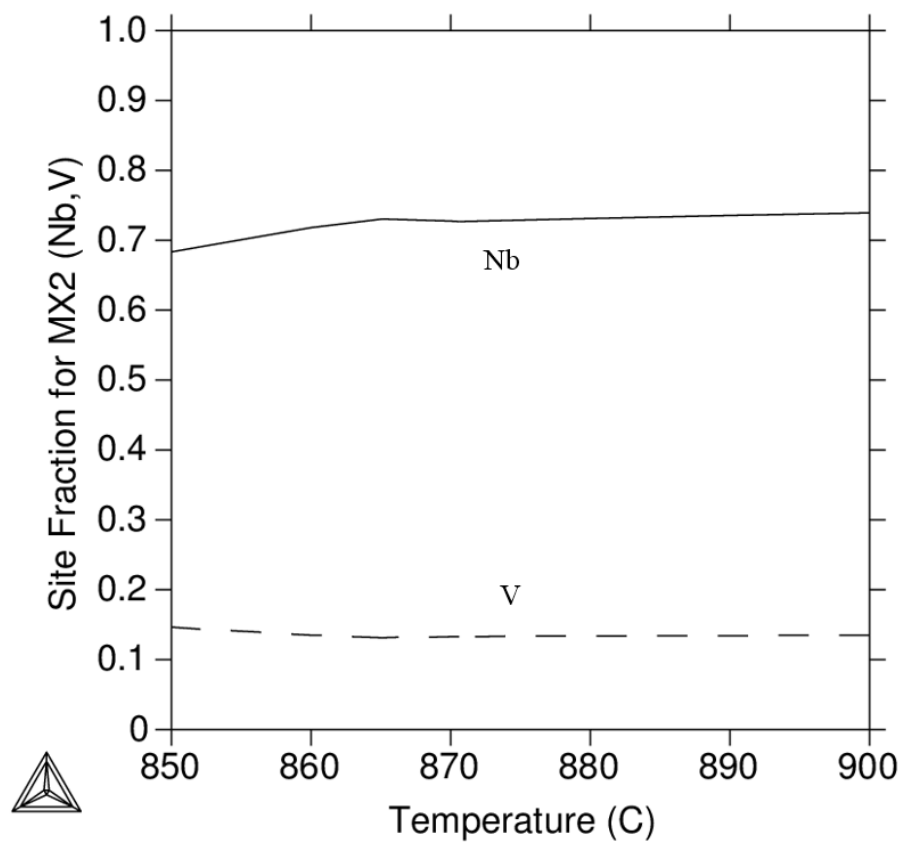

Figure 28. Site Fraction of MX2 for $\mathrm{Nb}$ and $\mathrm{V}$ concentrations under the first sublattice of the crystal structure [81].

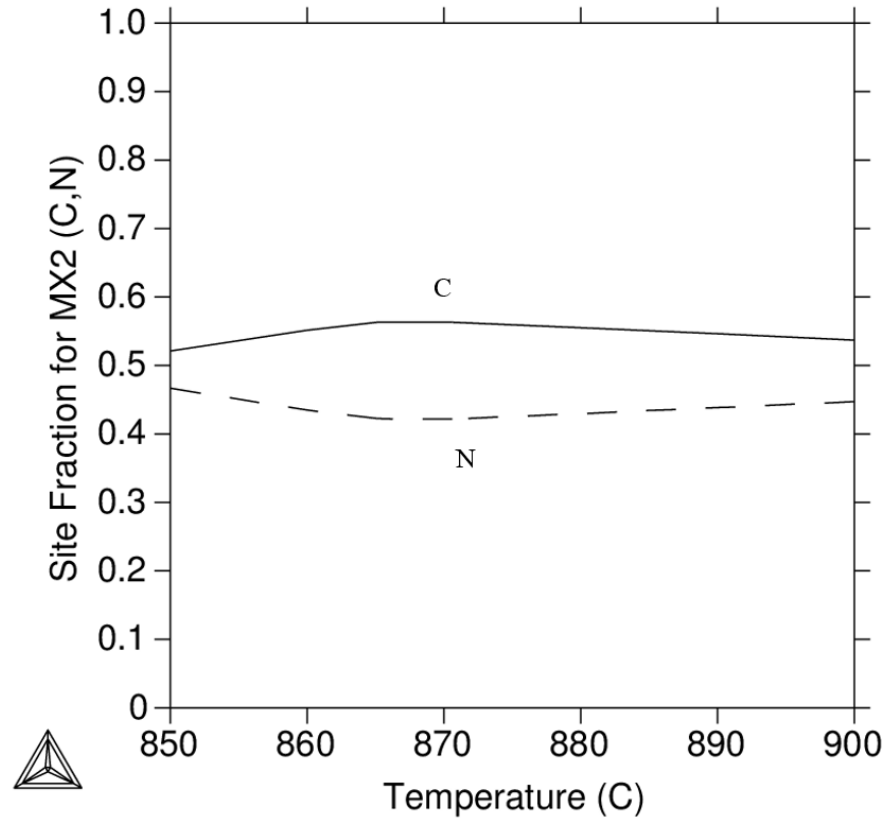

Figure 29. Site Fraction of MX2 for $\mathrm{C}$ and $\mathrm{N}$ concentrations under the second sublattice of the crystal structure [81]. 


\subsubsection{Equilibrium Cooling and Scheil Simulations}

Scheil simulations are very important in understanding the boundary conditions of various secondary phases within the Gr.91 base system. For example, under typical cooling conditions, the alloy does not always reach equilibrium at each temperature, therefore Scheil is necessary to understanding the phase stabilities under the real cooling conditions. The assumptions made for the equilibrium cooling is for the whole system at an infinitely slow cooling process while the Scheil simulation is typically adopted to simulate fast cooling conditions.

Under the Scheil simulation, there are two major assumptions: 1) No diffusion occurs in solid phases once they are formed and 2) the liquid phase is homogeneous all the time. These assumptions result in two cooling simulations and are treated as the boundary conditions, while the real cooling process of the material is somewhere in-between these two extreme conditions. In this case, it is easier to both visualize and comprehend how the stability of the secondary phases changes over the course of the materials' life cycle instead of extensive kinetic simulations. 


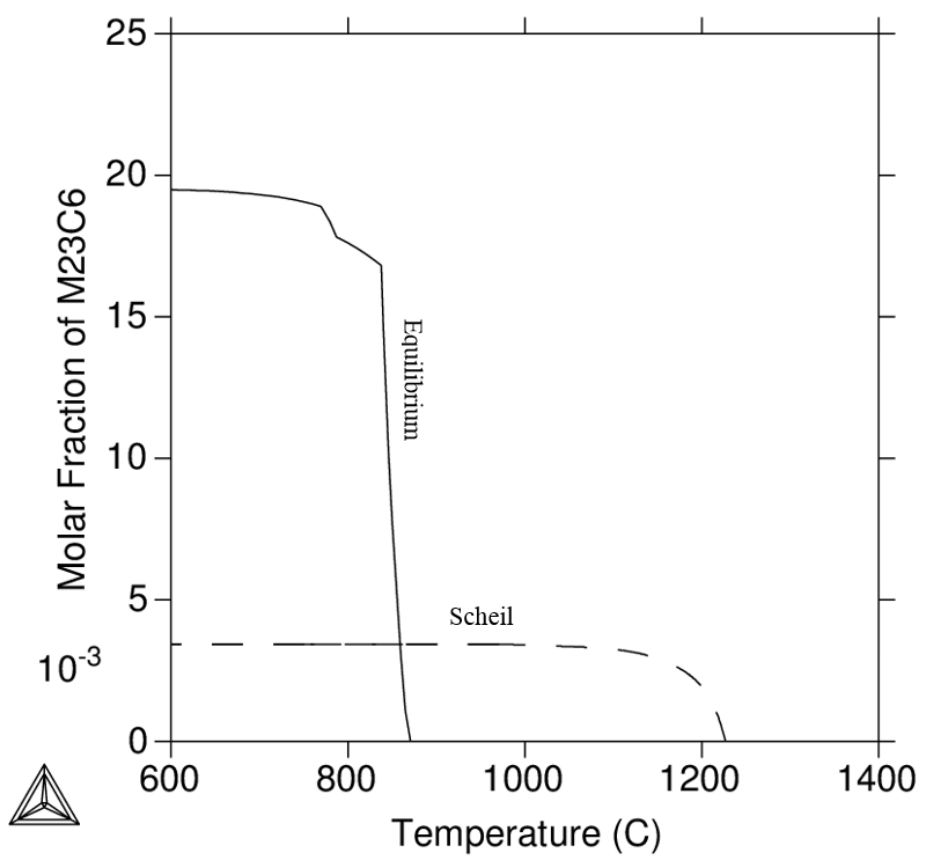

Figure 30. Scheil (dash line) and equilibrium (solid line) cooling simulations results for molar fraction for $\mathrm{M}_{23} \mathrm{C}_{6}$ [81].

Figure 30 shows the results of the equilibrium and Scheil simulations of the $\mathrm{M}_{23} \mathrm{C}_{6}$ carbides within the Gr.91 base system [81]. The results show that the $\mathrm{M}_{23} \mathrm{C}_{6}$ phase will precipitate out at $870^{\circ} \mathrm{C}$ under equilibrium cooling condition, while it can form at $1225^{\circ} \mathrm{C}$ under the Scheil simulation under a lower molar fraction. This indicates that the Gr.91 alloy forms much more $\mathrm{M}_{23} \mathrm{C}_{6}$ phases during the annealing/operation condition at elevated temperatures which explains why much more $\mathrm{M}_{23} \mathrm{C}_{6}$ phase are observed in the Gr.91 samples during higher temperature testing conditions. 


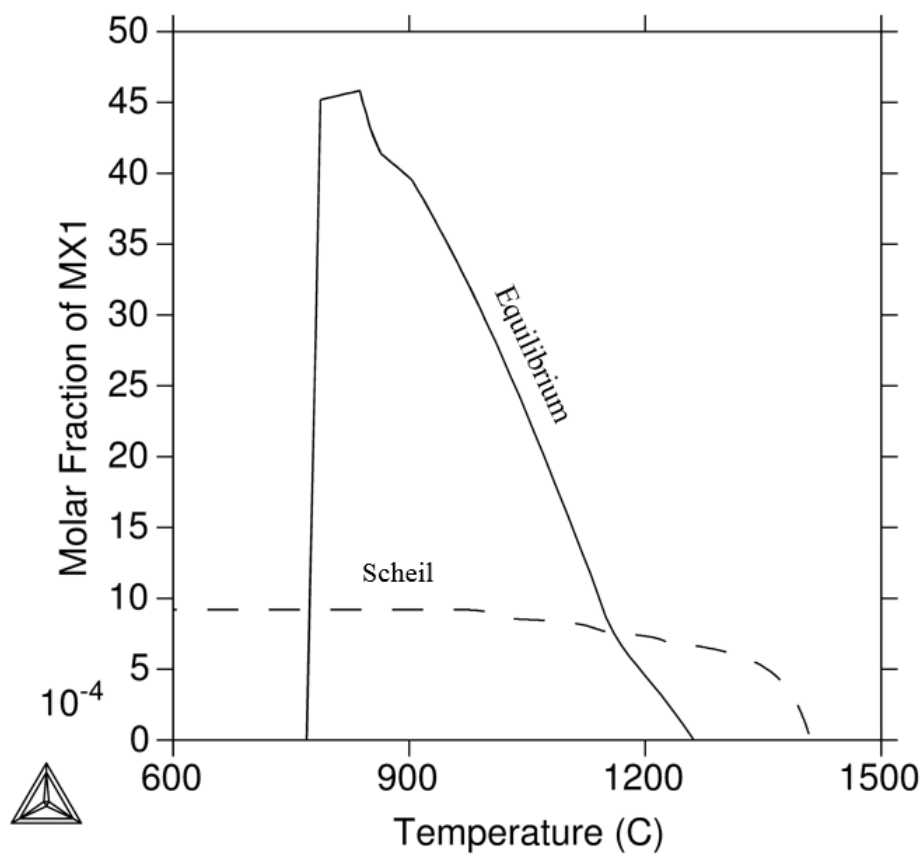

Figure 31.Scheil (dash line) and equilibrium (solid line) cooling simulations results for molar fraction for MX1 [81].

Figure 31 shows the results of the equilibrium and Scheil simulations of MX1 phase within the Gr.91 base system [81]. Similar in the case of $\mathrm{M}_{23} \mathrm{C}_{6}$, the MX1phase will form at a much greater amount under the equilibrium conditions than within the Scheil cooling simulation. Here, $\mathrm{MX} 1$ phase will form at $1260^{\circ} \mathrm{C}$ during the equilibrium cooling and then become completely unstable lower than $770^{\circ} \mathrm{C}$, while under the Scheil simulation, the phase will form at $1410^{\circ} \mathrm{C}$. This indicates that not only is this phase in a metastable state at room temperature, but also has the tendency to disappear under the high temperature operation condition. 


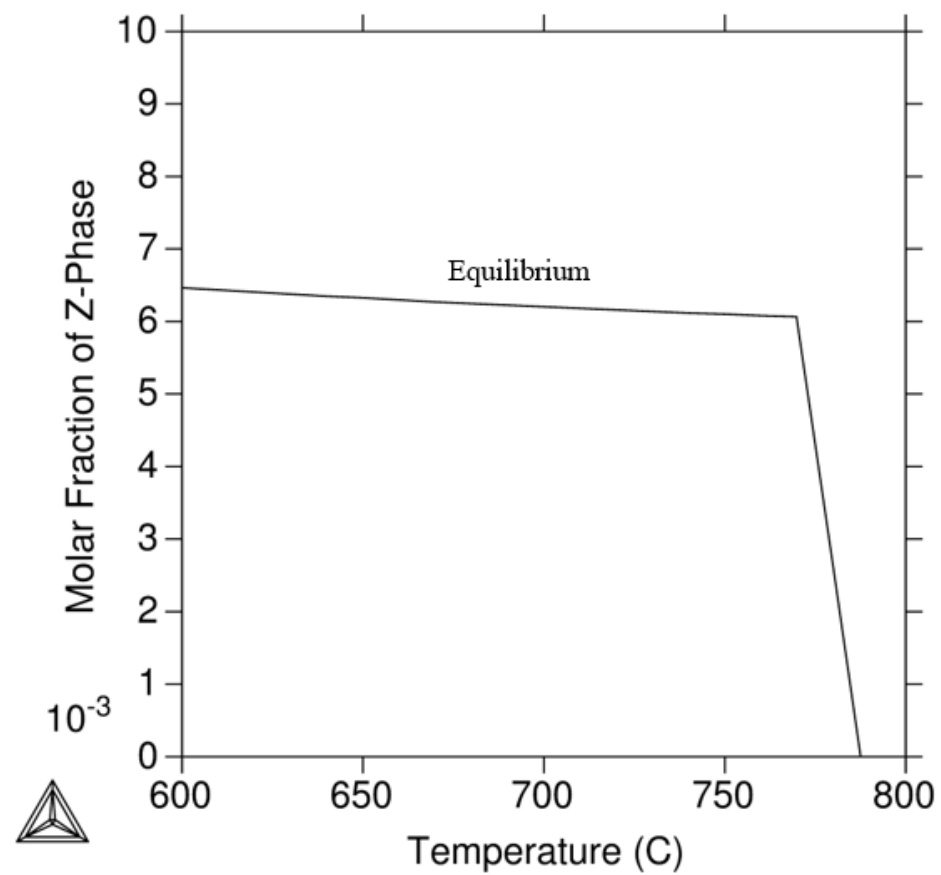

Figure 32. Equilibrium (solid line) simulations results for molar fraction for Z-phase. No Scheil simulations were added due to its nature to being stable after long-term operational use [81].

Figure 32 shows that Z-phase is a stable phase under equilibrium cooling conditions, while its formation temperature is lower than from $\mathrm{M}_{23} \mathrm{C}_{6}$ and $\mathrm{MX}$ phase [81]. However, due to how long it takes to stabilize, this resulted in no formation of Z-phase during fast cooling and therefore no Scheil simulation is seen in this figure. This explains very well why Z-phase is not observed in the initial microstructure and why it gradually shows up and "eats away" the MX phase under low temperature operation condition. 


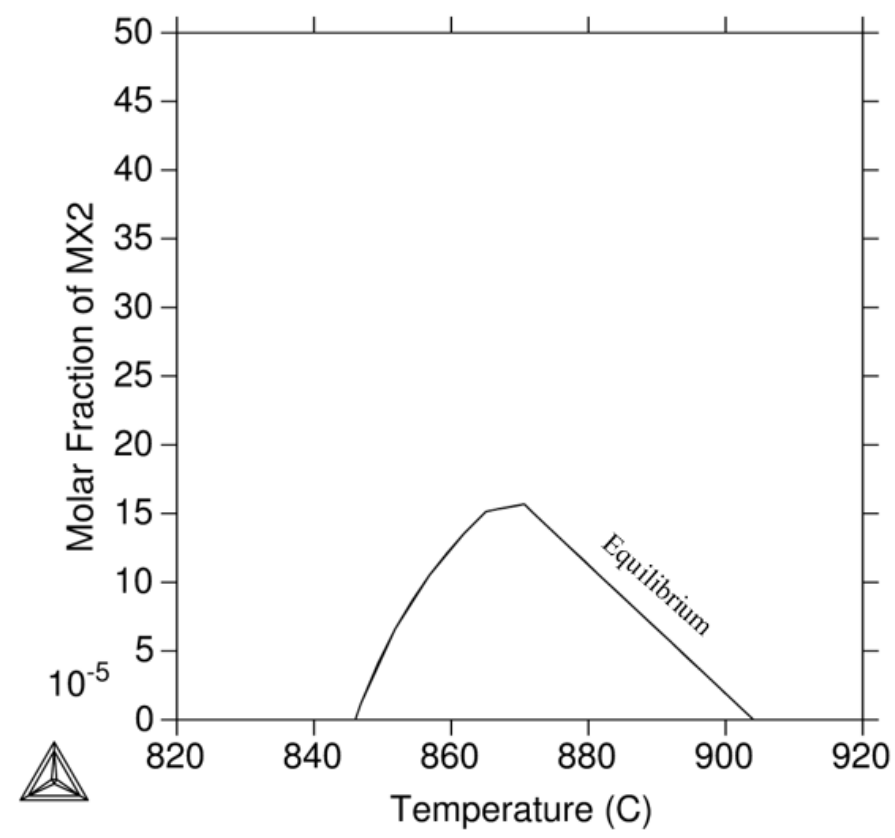

Figure 33. Equilibrium (solid line) simulation results for molar fraction for MX2. No Scheil simulations were added due to a small amount that was simulated during equilibrium [81].

The last graph seen here in Figure 33, shows the equilibrium and Scheil simulations of MX2. Much like the Z-phase, very little is formed during equilibrium as well as within a short temperature range, therefore no Scheil simulation is shown. It is very likely that MX2 no MX2 phase can form and its stability will greatly depend on the cooling behavior and the alloy compositions.

\subsubsection{Threshold Temperatures}

Figure 34 below shows the threshold temperatures for $\mathrm{M}_{23} \mathrm{C}_{6}$, Z-phase, Ac1, and Ac3 temperatures [81]. The purpose of this graph is to establish the stability conditions under the Gr.91 base system for the two critical phases that degraded the alloys creep resistance at both the short-term and long-term applications. This is also used to establish what has been explained in section 3.2 about improving the alloys creep resistance by 
lowering the threshold temperatures of both $\mathrm{M}_{23} \mathrm{C}_{6}$ and Z-phases through Ac temperatures. For example, $\mathrm{M}_{23} \mathrm{C}_{6}$ (black solid line) is only stable below this line and is only increased after an increase in $\mathrm{C}$ concentration within the material, which can be seen at $797^{\circ} \mathrm{C}$ with $0.5 \mathrm{wt} . \% \mathrm{C}$ and then at $904^{\circ} \mathrm{C}$ with $1.5 \mathrm{wt} . \% \mathrm{C}$. This indicates that the increase of $\mathrm{C}$ concentration in Gr.91 steels is harmful to the creep resistance at high temperatures if $\mathrm{M}_{23} \mathrm{C}_{6}$ coarsening is the dominant mechanism. This observation can also be seen with a decrease in Z-phase stability (dash line) at the same $\mathrm{C}$ concentration under long-term applications. However, in this case, the stability of Z-phase with respect to increase in C concentration, its threshold temperature does not change much, which indicates that the increase of C concentration will only slightly lower the Z-phase stability. Therefore, it is important to observe the effects of each secondary phase stability when under lower Ac temperatures.

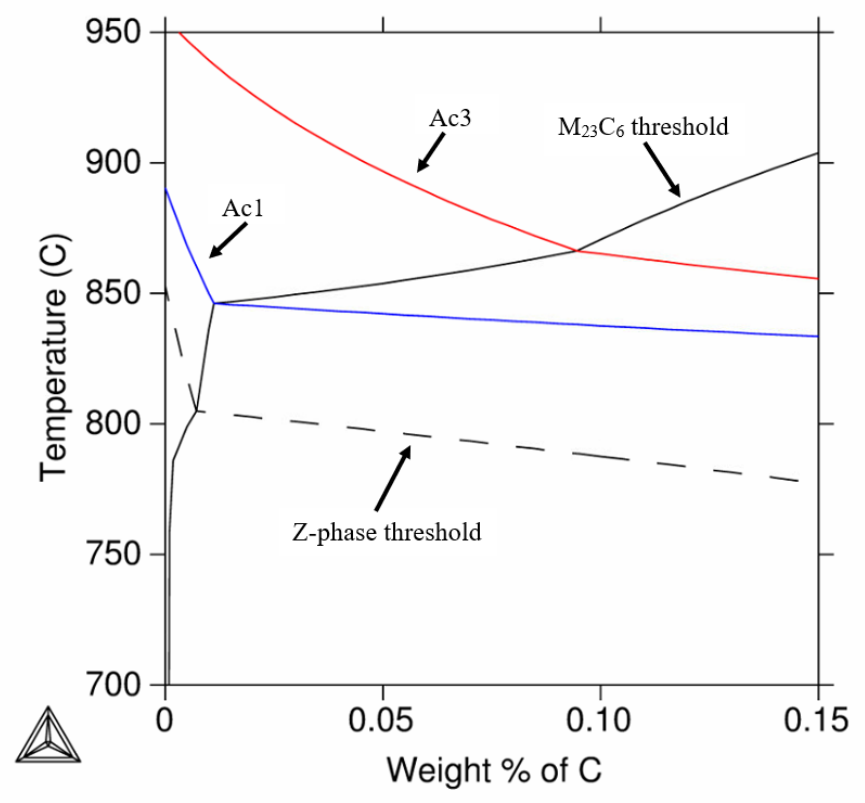

Figure 34. Threshold temperatures of $\mathrm{M}_{23} \mathrm{C}_{6}$ (solid line), Z-phase (dotted line), Ac1 (blue), and Ac3 (red) temperatures under the Gr.91 base system [81]. 


\subsection{Modified Gr.91 System}

The second half of the results pertain to the additional alloying elements that were simulated and compared with the baseline Gr.91 system. The specific compositions can be seen in Table 3, Table 4, and Table 5. The purpose of this is to simulate the effects of various alloying elements that have been observed to suppress $\mathrm{M}_{23} \mathrm{C}_{6}$, and Z-phase formation which corresponds to the short-term and long-term creep failure of the material. The results include the effects of manganese $(\mathrm{Mn})$, nickel $(\mathrm{Ni})$, and titanium (Ti) have on the stability of $\mathrm{M}_{23} \mathrm{C}_{6}$ and $\mathrm{MX}$ phases as well as the compositional changes of nitrogen $(\mathrm{N})$, vanadium $(\mathrm{V})$, and niobium $(\mathrm{Nb})$.

\subsubsection{Effects of Manganese (Mn) and Nickle (Ni) with Stability of $M_{23} C_{6}$ Phase}

Figure 35 below shows the simulated results of S-1 and S-2 compositions while compared with the baseline Gr.91 system. The exact composition of S-1 and S-2 can be seen in Table 3. Specifically, S-1 represents the added alloying element manganese (Mn) at 0.66 wt. \% whereas $\mathrm{S}-2$ is for nickel $(\mathrm{Ni})$ at $0.43 \mathrm{wt} . \%$. Both compositions in this case are for compositions that include the maximum amount of $\mathrm{Mn}$ and $\mathrm{Ni}$ that can be added to Gr.91 under ASME standards [23] in order to characterize the effects they have on $\mathrm{M}_{23} \mathrm{C}_{6}$ precipitates under equilibrium conditions. The overall goal in this case is to destabilize the $\mathrm{M}_{23} \mathrm{C}_{6}$ carbides to minimize the coarsening effects under short-term operational conditions. Recall that the main observed mechanism for short-term creep failure for Gr.91 steel is the Oswalt Ripening Effect for $\mathrm{M}_{23} \mathrm{C}_{6}$ carbides which can cause premature failure. 


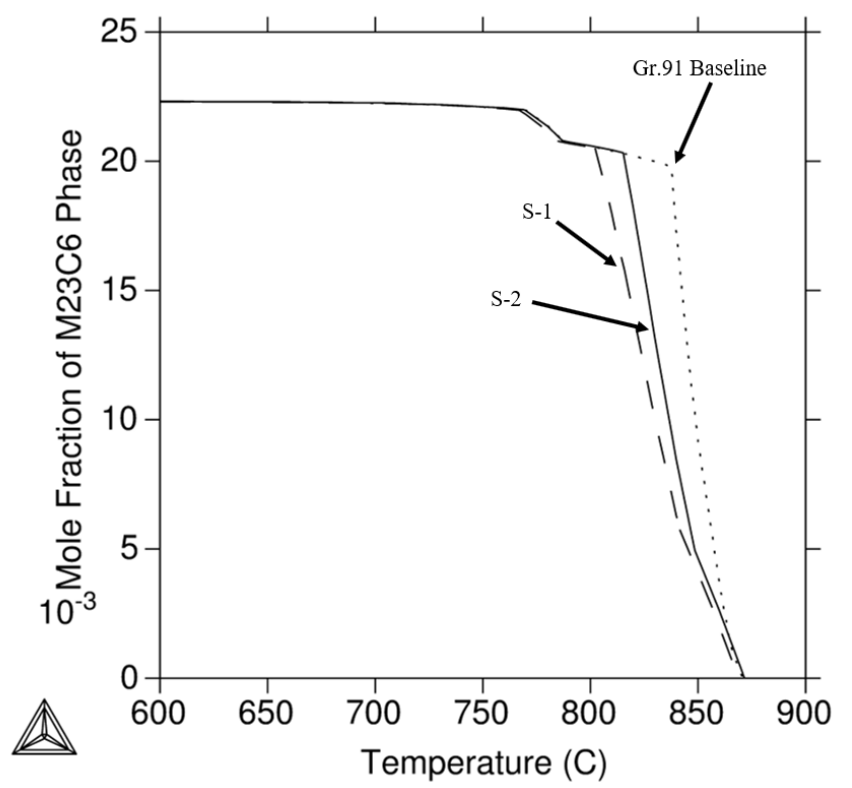

Figure 35. The effects of added concentrations of Mn and Ni to the Gr.91 Baseline System. S-1 represents the simulation for added $0.66 \mathrm{Wt} . \% \mathrm{Mn}$ and S-2 represents 0.43 wt. $\%$ Ni. Both are the maximum allowed wt.\% under ASME standards [23].

Here it can be plainly seen that concentrations of $0.66 \mathrm{wt} . \% \mathrm{Mn}$ have more of an effect on both the mole fraction and stability of $\mathrm{M}_{23} \mathrm{C}_{6}$ carbides than $0.43 \mathrm{wt} . \% \mathrm{Ni}$. For example, under S-1 simulation, the destabilization of $\mathrm{M}_{23} \mathrm{C}_{6}$ carbides starts at $802.2^{\circ} \mathrm{C}$ which is $35.5^{\circ} \mathrm{C}$ smaller than the destabilization temperature at the baseline Gr.91 system, however under $\mathrm{S}-2$, the destabilization of $\mathrm{M}_{23} \mathrm{C}_{6}$ starts at $814.9^{\circ} \mathrm{C}$ which is only $22.8^{\circ} \mathrm{C}$ smaller. The same can be seen for the mole fraction, in which case, the most defining drop can be seen between temperatures of $802.2^{\circ} \mathrm{C}$ and $837.7^{\circ} \mathrm{C}$ when compared to both simulations. At higher temperatures above $850^{\circ} \mathrm{C}$, the effects of both concentrations become less critical and the overall stability of $\mathrm{M}_{23} \mathrm{C}_{6}$ phase does not change. This can be noted at the convergent point of all 3 curves at $870^{\circ} \mathrm{C}$ which is the maximum stability temperature of $\mathrm{M}_{23} \mathrm{C}_{6}$. 


\subsubsection{Mole and Composition Change of Titanium (Ti) with of MX1 Phase}

Figure 36 shows the stability changes of MX1 under the added effects of 0.01wt.\%Ti (S-3) while compared to the baseline Gr.91 system. In this case, the MX2 phase was omitted due to a very small change under this simulation. Since the MX phases within Gr.91 are very thermally stable and with little to no coarsening during the entire annealing process, it is worth a look into increasing their stability.

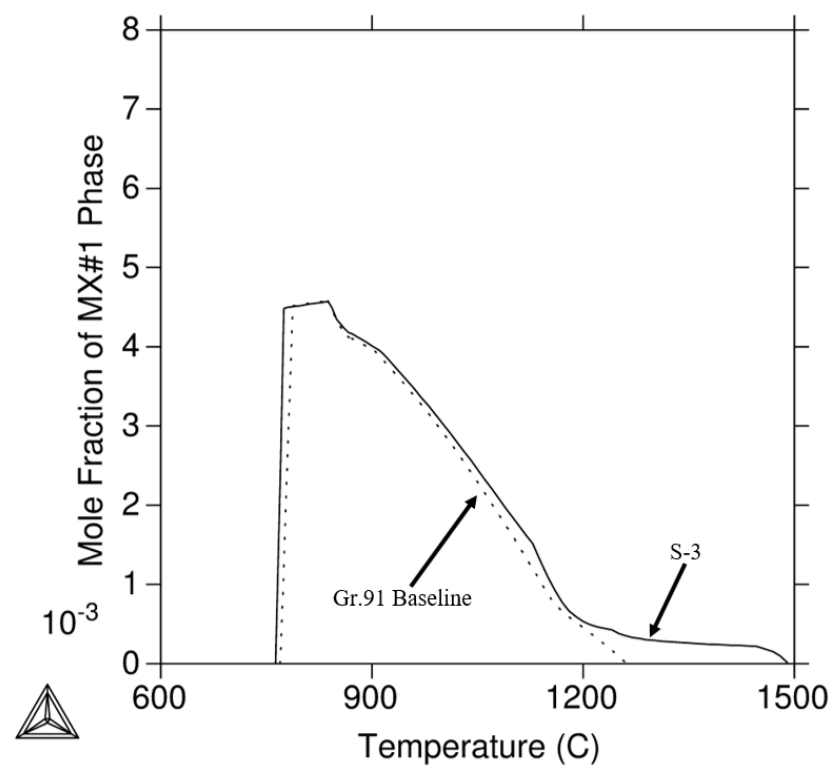

Figure 36. Added concentrations of Ti while compared to the Gr.91 Baseline System. S-3 represents the mole fraction of added $0.01 \mathrm{wt}$. $\% \mathrm{Ti}$ added to the baseline.

The results seen here are for the S-3 simulation where maximum concentration of $0.01 \mathrm{wt} . \% \mathrm{Ti}$ was introduced to the material. Here we can see the effects that Ti have on the MX1 phase. Recall that MX1 is the stable phase formed during the baseline in which $\mathrm{N}$ is greater than $\mathrm{C}$ within the crystals second sublattice. Overall, it can be clearly seen that $\mathrm{Ti}$ plays an important role in increasing both MX1 molar volume and stability at higher temperature regions. The entire profile of the baseline MX1 stays consistent with the S-3 
curve with little increases in molar fraction at temperatures between $761.2^{\circ} \mathrm{C}$ to $1200^{\circ} \mathrm{C}$, after which the S-3 curve starts to deviate. The entire stable temperature profile of S-3 ranges between $761.2^{\circ} \mathrm{C}$ at the starting temperature to its maximum temperature of $1489.88^{\circ} \mathrm{C}$. The stable temperature range for MX1 under the baseline was between $770^{\circ} \mathrm{C}$ and $1260^{\circ} \mathrm{C}$, making the total temperature stability difference of about $230^{\circ} \mathrm{C}$ under the addition of $0.01 \mathrm{wt} . \% \mathrm{Ti}$.

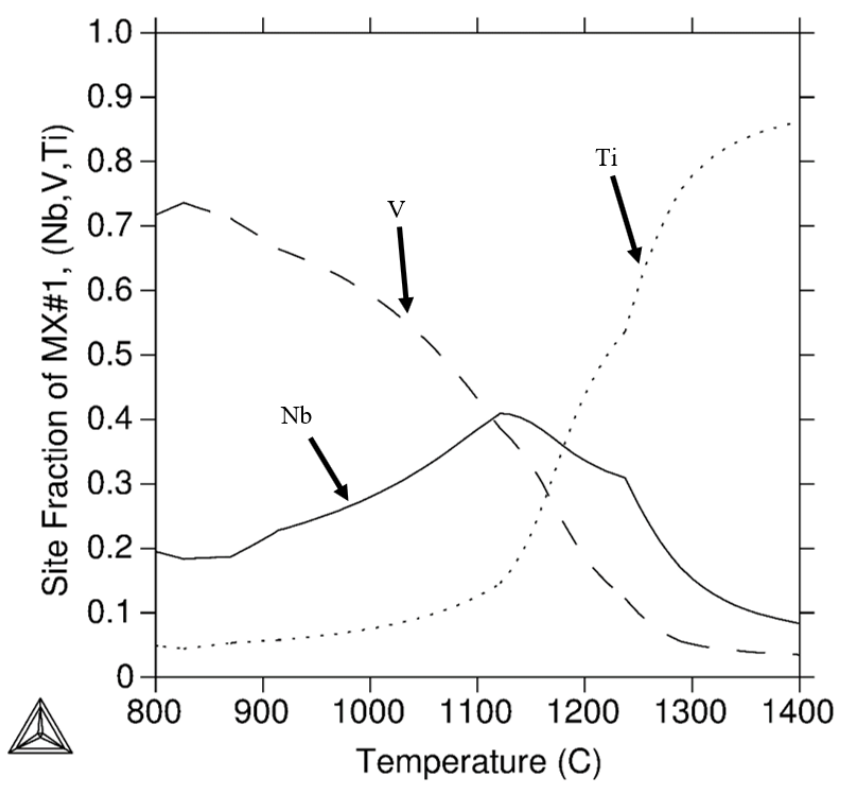

Figure 37. Site Fraction of MX1 for first sublattice under S-3 simulation which contains the alloying elements titanium $(\mathrm{Ti})$, niobium $(\mathrm{Nb})$, and vanadium $(\mathrm{V})$. 


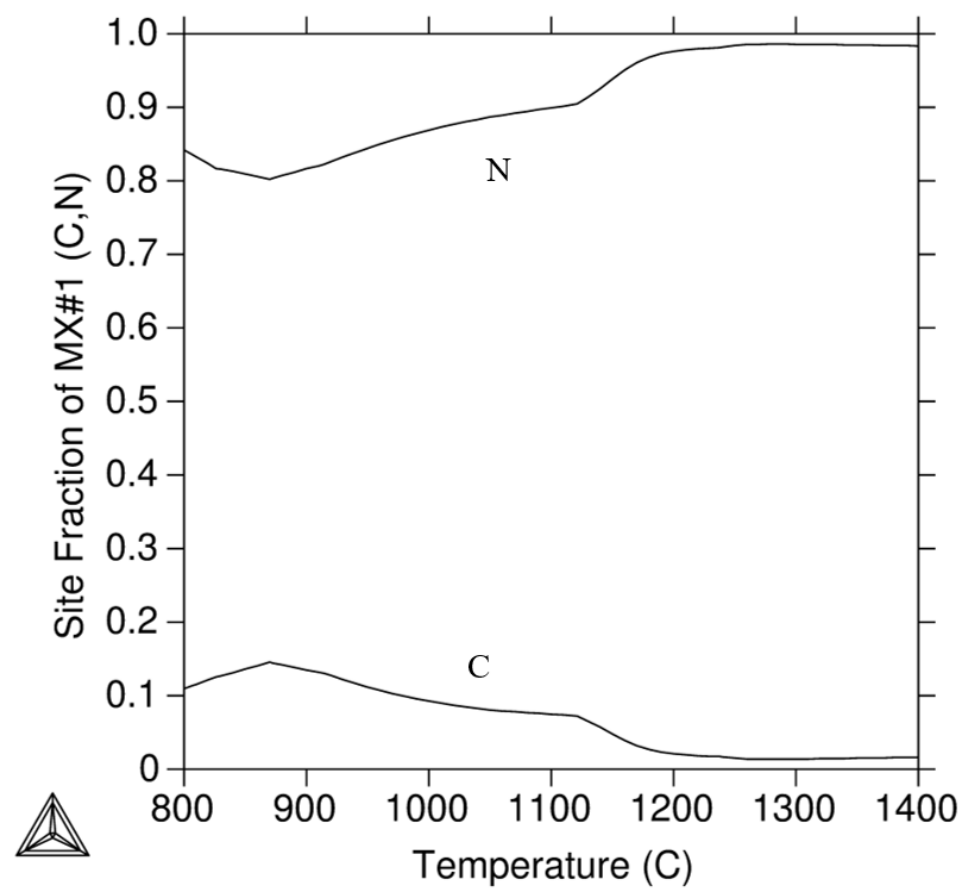

Figure 38. Site Fraction of MX1 for second sublattice under S-3 simulation which contains the alloying elements carbon $(\mathrm{C})$ and nitrogen $(\mathrm{N})$.

Figure 37 and Figure 38 both show the results of the site fraction changes of MX1under vanadium $(\mathrm{V})$, niobium $(\mathrm{Nb})$, titanium $(\mathrm{Ti})$, carbon $(\mathrm{C})$, and nitrogen $(\mathrm{N})$ contents. Recall that MX phase is a two sublattice FCC crystal structure, under which in S-3 simulation can contain $\mathrm{V}, \mathrm{Nb}$, or Ti under the first sublattice for Figure 37, and $\mathrm{C}$ or $\mathrm{N}$ in the second for Figure 38. In this case, both $\mathrm{Ti}$ and $\mathrm{N}$ are the most likely metallic element to form within the temperature range of $1180.9^{\circ} \mathrm{C}-1489.88^{\circ} \mathrm{C}$ of the $\mathrm{MX} 1$ phase. This can be followed by $1113.96^{\circ} \mathrm{C}-1180.92^{\circ} \mathrm{C}$ for $\mathrm{NbN}$, and $761.2^{\circ} \mathrm{C}-1113.96^{\circ} \mathrm{C}$ for $\mathrm{VN}$ at lower temperature regions. From this, it is clearly seen that MX nitrites $(M(N))$ are far more easily stable than carbides within the profile of MX1 under this simulation. 


\subsubsection{Scheil Simulations for $M_{23} C_{6}$ and $M X 1$ Phases for $S-1, S-2$, and $S-3$}

Similar to what was done to the Gr.91 baseline in Figure 30 and Figure 31 for $\mathrm{M}_{23} \mathrm{C}_{6}$ and MX1 phases, Figure 39 represents the scheil simulation results of S-1 and S-2 for concentrations of $0.66 \mathrm{wt} . \% \mathrm{Mn}$ and $0.43 \mathrm{wt} . \% \mathrm{Ni}$ for $\mathrm{M}_{23} \mathrm{C}_{6}$ while Figure 40 shows the scheil results of S-3 for $0.01 \mathrm{wt} . \% \mathrm{Ti}$ while compared with the Gr.91 baseline system. It is clear on Figure 39 that the results provided indicated that little change has occurred under S-1 and S-2 for the overall stability and volume change of $\mathrm{M}_{23} \mathrm{C}_{6}$ precipitates. Under S-1 for $0.66 \mathrm{wt} . \% \mathrm{Mn}$ the maximum molar fraction appears to be .0036 at lower temperature regions below $1000^{\circ} \mathrm{C}$. Compared with the $\mathrm{S}-2$ at $0.43 \mathrm{wt} . \% \mathrm{Ni}$, the molar fraction is at .0035 which is still higher than the Gr.91 baseline system. From these results, high concentrations of Mn lower the overall stability, though very small changes, going from $1225^{\circ} \mathrm{C}$ for the baseline to $1216^{\circ} \mathrm{C}$ under S-1, however no changes appear to have happened under high concentrations of $\mathrm{Ni}$ for S-2. 


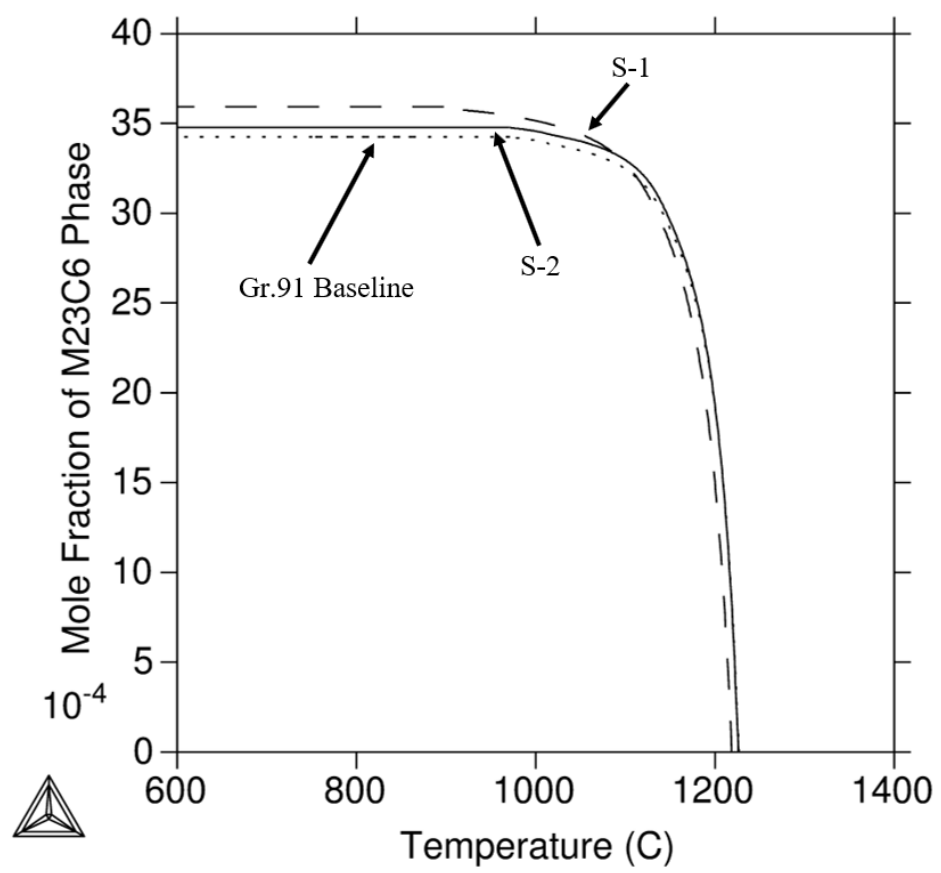

Figure 39. Scheil simulation results of $0.66 \mathrm{wt} . \% \mathrm{Mn} \mathrm{S}-1$ (dash line), $0.43 \mathrm{wt} . \% \mathrm{Ni}$ S-2 (solid line), and Gr.91 baseline system (dotted line) for $\mathrm{M}_{23} \mathrm{C}_{6}$ phase.

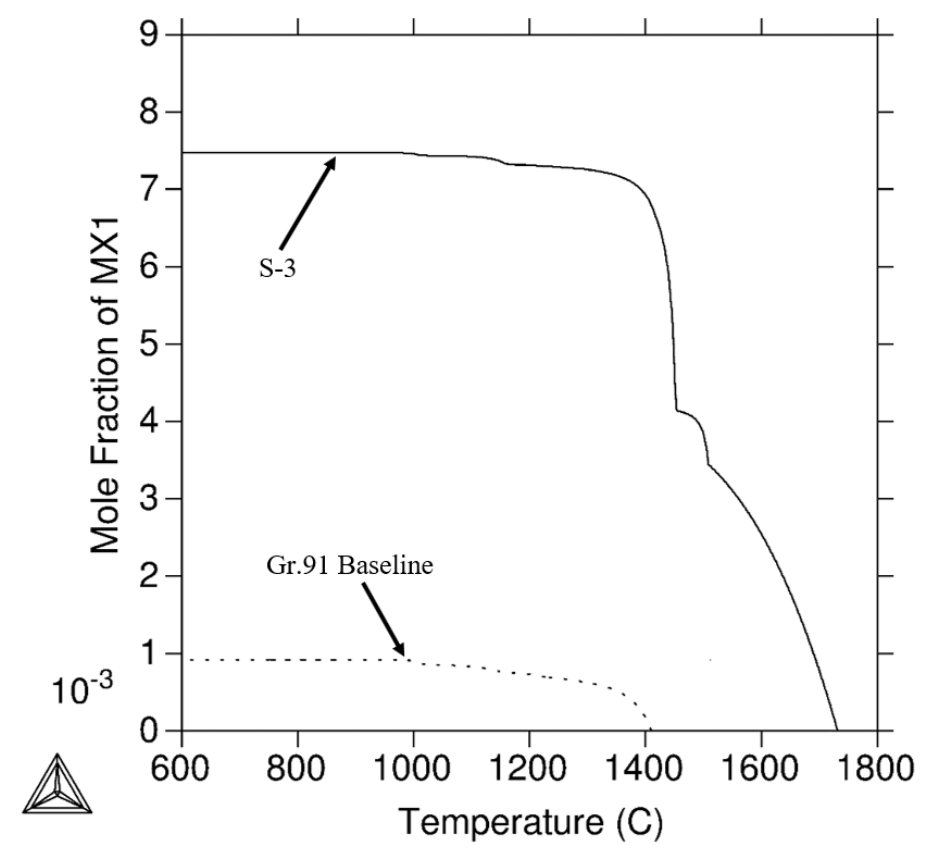

Figure 40. Scheil simulation results of 0.01wt.\% Ti (S-3) and Gr.91 baseline system for MX1 phase. 
From Figure 40 it is clear that concentrations of Ti greatly increase the stability of MX1 phases, which supports the results in Figure 36. At 0.01wt.\% Ti (S-3), the overall stability increases from $1410^{\circ} \mathrm{C}$ for the baseline to $1733^{\circ} \mathrm{C}$, while increasing its molar fraction serval times over from .0009 to .0074 .

\subsubsection{Mole Fraction and Composition of New MX3 Phase under S-3 Simulation}

Figure 41 shows the results of the molar fraction of a new MX phase under the S-3 simulation called MX3, while Figure 42 and Figure 43 are the compositional analysis of the site fraction for first and second sublattice of MX3. As it is well understood from Figure 36 , the added addition of $0.01 \mathrm{wt} . \% \mathrm{Ti}$ has greatly increased the stability of MX1, however it has also stabilized a new MX phase (MX3) to form under lower temperature regions. In this case, $\mathrm{MX} 3$ is stable between temperatures of $600^{\circ} \mathrm{C}-777^{\circ} \mathrm{C}$ while its molar fraction barely reaches above $25^{-5}$. Under this situation, it is unlikely that this MX phase will form under short-term or long-term conditions, depending on the concentrations of the material. However, it does provide important information that high concentrations of Ti based MX phases are stable within the lower temperature regions where Z-phase is stable which under previous studies have shown to improve creep strength [34, 59]. 


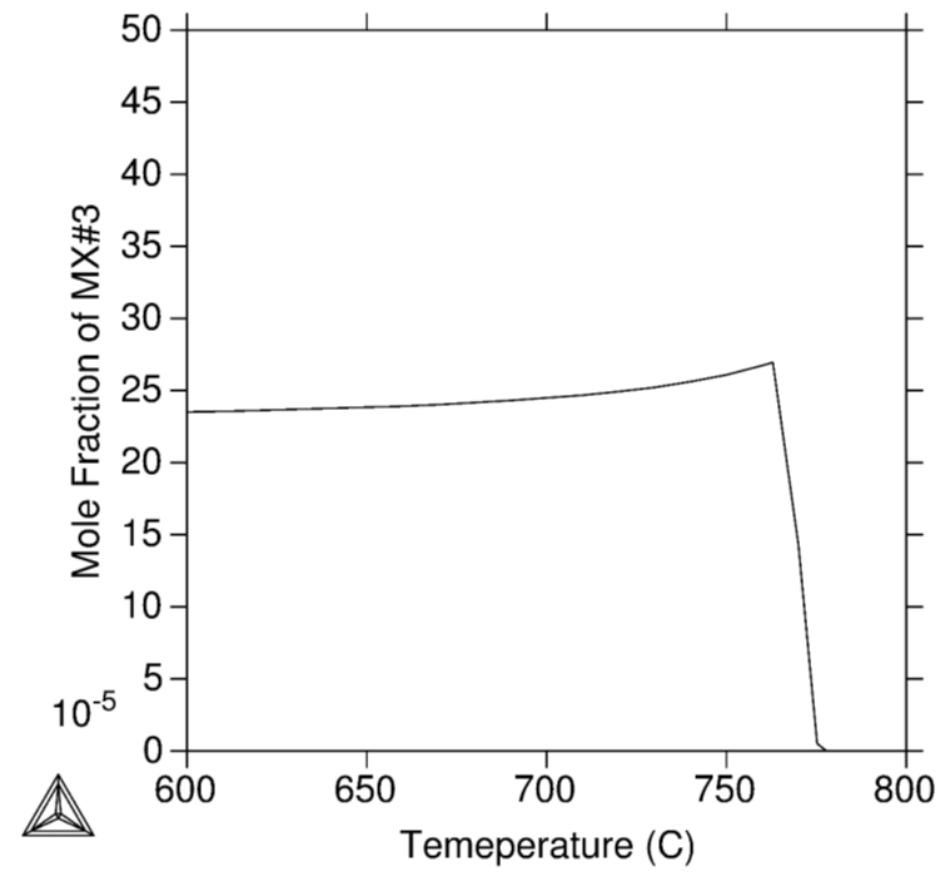

Figure 41. Results of mole fraction of a new MX phase under the S-3 simulation called MX3.

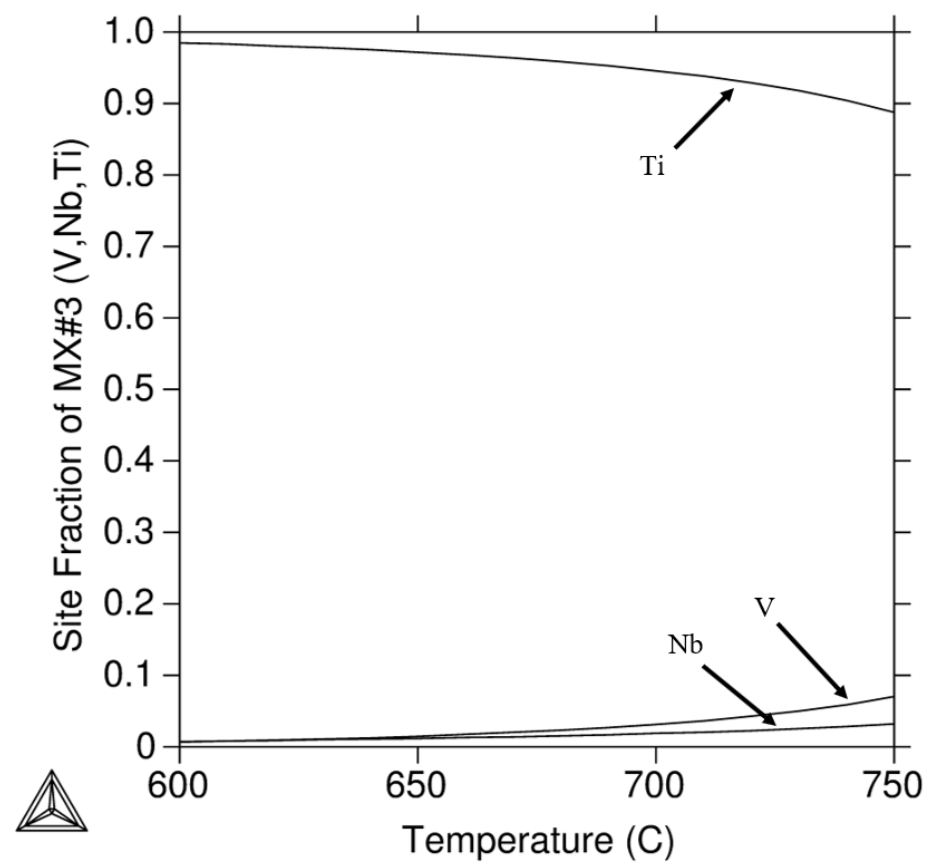

Figure 42. Composition of MX3 which contains results for the site fraction of the first sublattice results for vanadium $(\mathrm{V})$, niobium $(\mathrm{Nb})$, and titanium $(\mathrm{Ti})$. 


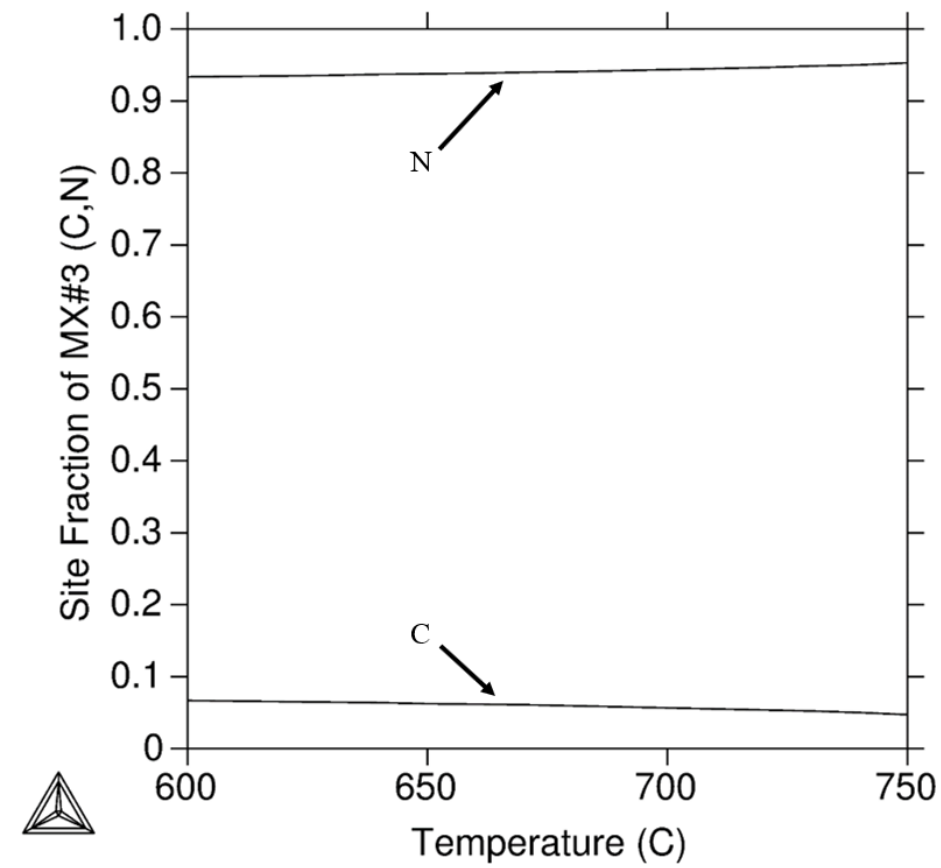

Figure 43. Composition of MX3 which contains results for the site fraction of the second sublattice results for carbon $(\mathrm{C})$, and nitrogen $(\mathrm{N})$.

\subsubsection{Z-phase Stability Changes Under Different Compositions}

Figure 44 shows the results for the molar fraction and stability changes under three different compositions of Gr.91. In this case, the results show a characterization of various changes to the baseline system of Gr.91 including $0.27 \mathrm{wt} . \% \mathrm{~V}(\mathrm{~S}-4), 0.11 \mathrm{wt} . \% \mathrm{Nb}(\mathrm{S}-5)$, and $0.025 \mathrm{wt} . \% \mathrm{~N}(\mathrm{~S}-6)$ while excluding concentrations of $\mathrm{Mn}, \mathrm{Ni}$, and Ti. The reason for this is to show which element was the most effective in reducing the stability of Z-phase. Recall that the empirical formula for the modified Z-phase is $(\mathrm{Cr}, \mathrm{Fe})(\mathrm{V}, \mathrm{Nb}) \mathrm{N}$, and while it is unwise to reduce or change the concentrations of $\mathrm{Cr}$ within the material due to its properties as having a strong resistance to corrosive environments, the option was left to change concentrations of $\mathrm{V}, \mathrm{Nb}$, and $\mathrm{N}$. 


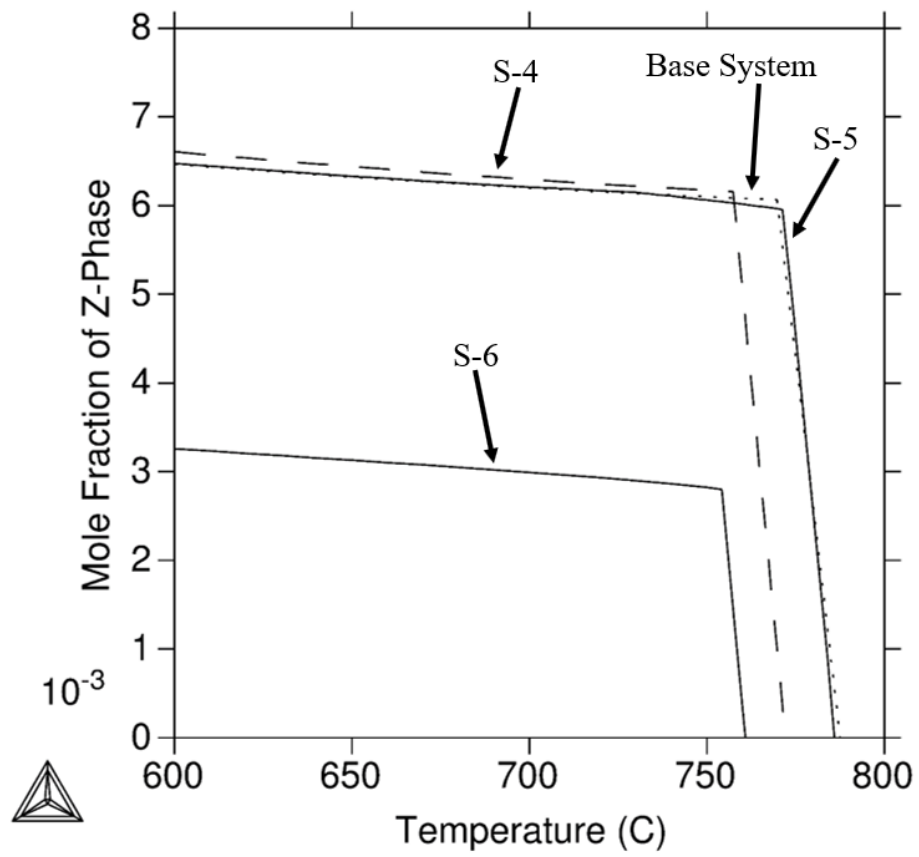

Figure 44. Mole Fraction of Z-phase under three different simulations. S-4 represents the added concentrations of $0.27 \mathrm{wt} . \% \mathrm{~V}, \mathrm{~S}-5$ is for the added concentrations of $0.11 \mathrm{wt} . \% \mathrm{Nb}$, and S-6 is the lower concentrations of $0.025 \mathrm{wt} . \% \mathrm{~N}$ while compared with Gr.91 baseline.

It is clear from the results that low concentrations of $\mathrm{N}(\mathrm{S}-6)$ have the most effect on the stabilization of Z-phase cutting nearly in half the volume amount that can be precipitated out under equilibrium conditions when compared with increased $\mathrm{V}$ and $\mathrm{Nb}$ concentrations for S-4 and S-5. For S-6, the maximum temperature in which Z-phase is stable reaches $760.6^{\circ} \mathrm{C}$ where for S-4, it is at $771.5^{\circ} \mathrm{C}$. Minimal changes for Z-phase stability were seen for $\mathrm{S}-5$ for maximum $\mathrm{Nb}$ concentrations. When compared with the results for the baseline Gr.91 system the temperatures are $29.4^{\circ} \mathrm{C}$ and $18.5^{\circ} \mathrm{C}$ below the baseline for S-6 and S-4 respectively.

\subsubsection{Mole Fraction and Threshold Temperatures of the new modified Gr.91}

Figure 45 and Figure 46 show the properties of the secondary phases within the new modified Gr.91 steel. The composition in this case is the combination of all simulated 
results given from S-1 to S-5. Specifically, this means that the alloy composition includes $\max \mathrm{Mn}, \mathrm{Ni}, \mathrm{Ti}, \mathrm{V}$, and $\mathrm{Nb}$ and minimum $\mathrm{N}$ concentrations as seen in Table 5.

In Figure 45, the results show the molar fraction of all secondary phases within the system including the $\mathrm{M}_{23} \mathrm{C}_{6}, \mathrm{MX} 1, \mathrm{MX} 2, \mathrm{MX} 3$, and Z-phases. First, MX1 has shown a dramatic decrease in both stable temperatures and in molar amount whereas MX2 has increased overall. The maximum stable temperature in this case, for the modified version for $\mathrm{MX} 1$, is $1045.6^{\circ} \mathrm{C}$ which is $214.4^{\circ} \mathrm{C}$ below the baseline. In the case of MX2, the stable temperature range has increased from a range seen in the baseline of $847^{\circ} \mathrm{C}-890^{\circ} \mathrm{C}$ to a range of $600^{\circ} \mathrm{C}-1290^{\circ} \mathrm{C}$ within the modified system. The dramatic decrease in MX1 can be explained by the lack of $\mathrm{N}$ concentration within the modified system, which is the primary element to form MX carbonitrides $(\mathrm{M}(\mathrm{C}, \mathrm{N}))$ and nitrides $(\mathrm{MN})$. Nevertheless, the modified Gr.91 system contains two MX phases (MX2 and MX3), both within the stability temperature range of $600^{\circ} \mathrm{C}-740.5^{\circ} \mathrm{C}$ where Z-phase is stable. Elemental analysis was done to both MX2 and MX3 which resulted in MX2 phase primary forming NbC and TiN for MX3 under these lower temperatures. This conclusion indicates that a promotion of MX carbides or higher concentrations of Ti to form very stable MX phases within Gr.91 could dramatically increase the creep life of this alloy. 


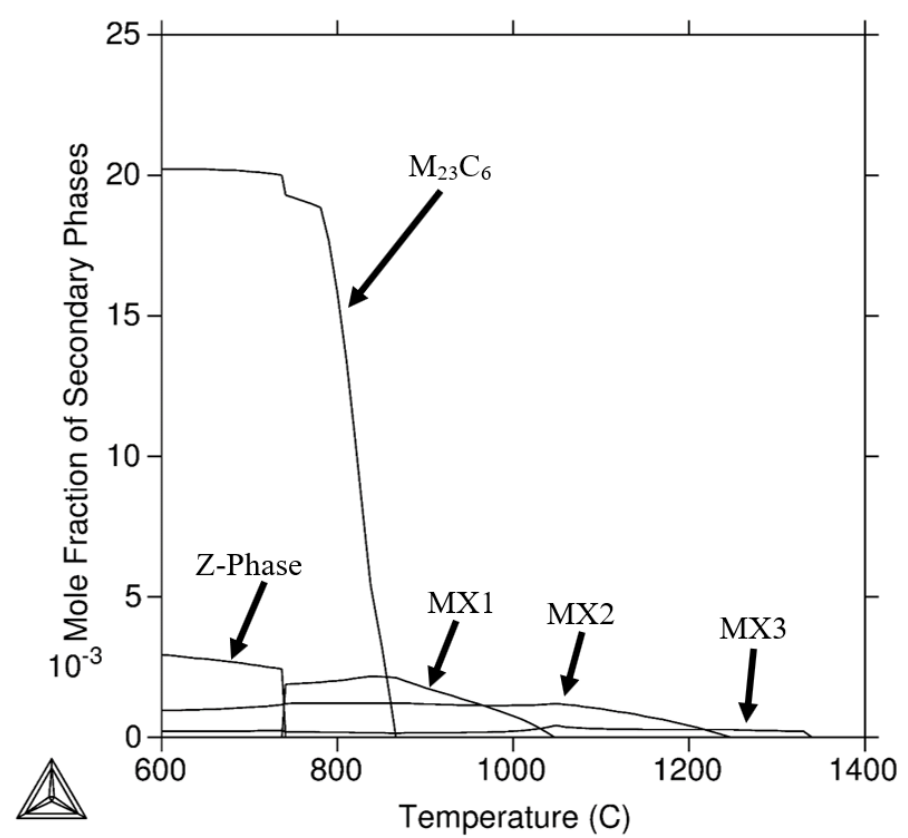

Figure 45. Mole Fraction of secondary phases for the modified Gr.91 including $\mathrm{M}_{23} \mathrm{C}_{6}$, MX1, MX2, MX3, and Z-phases.

In the case of $\mathrm{M}_{23} \mathrm{C}_{6}$, it can clearly still be considered the most dominate secondary phase within the modified system. Its maximum reaches at $600^{\circ} \mathrm{C}$ and then dramatically decreases from $780^{\circ} \mathrm{C}$ to becoming completely unstable at $867^{\circ} \mathrm{C}$ which is similar to the profile seen in Figure 25 but at higher temperatures. A slight decrease in molar amount can be noticed as well when compared with Figure 25. A proposed solution to this can be made by increasing the $\mathrm{C}$ concentrations within the steel.

Figure 46 shows the threshold temperatures of the modified Gr.91 including the Ac1 (blue), Ac3 (red), $\mathrm{M}_{23} \mathrm{C}_{6}$ (black solid line), and $\mathrm{Z}$-phase (dash line) under the composition seen in Table 5. Similarly, in Figure 34, the $\mathrm{M}_{23} \mathrm{C}_{6}$ threshold temperature represents the line below which $\mathrm{M}_{23} \mathrm{C}_{6}$ carbides are stable much like the Z-phase threshold temperature. Under lower Ac temperatures between Ac1 and Ac3, which indicates the ICHAZ, the entire threshold temperature profile for $\mathrm{M}_{23} \mathrm{C}_{6}$ shifts downwards when 
compared with the baseline Gr.91 threshold temperatures. This indicates that lowering Ac temperatures does decrease the stability of $\mathrm{M}_{23} \mathrm{C}_{6}$ at this temperature region which can mean lower concentrations of the carbide can appear under certain heat treatment conditions. The overall stability temperature threshold profile of $\mathrm{M}_{23} \mathrm{C}_{6}$ indicates, similarly to Figure 34, that under an increase of $\mathrm{C}$ concentration, the $\mathrm{M}_{23} \mathrm{C}_{6}$ threshold temperature will greatly increase. Other small changes can also be noted. For example, the stability of $\mathrm{M}_{23} \mathrm{C}_{6}$ does decrease slightly at lower temperatures below $750^{\circ} \mathrm{C}$ staying at a constant .001 wt. \% C above which it becomes unstable.

In the case of Z-phase, while at higher concentrations of $\mathrm{C}$ above $.001 \mathrm{wt} . \%$ at around $750^{\circ} \mathrm{C}$ does indicate that the phase starts to decrease in stability slowly, however at higher concentrations of $\mathrm{C}$ at the same point, it shows the phase dramatically increasing in stability going to as high as $938^{\circ} \mathrm{C}$ at very low concentrations of $\mathrm{C}$. This verifies what is shown in Figure 34, which indicates that while increasing the amount of $\mathrm{C}$ within the system can decrease the stability of Z-phase and therefore increase the creep strength of the material, at very low concentrations under this modified Gr.91, it could also dramatically decrease its creep strength due to the increase in stability. 


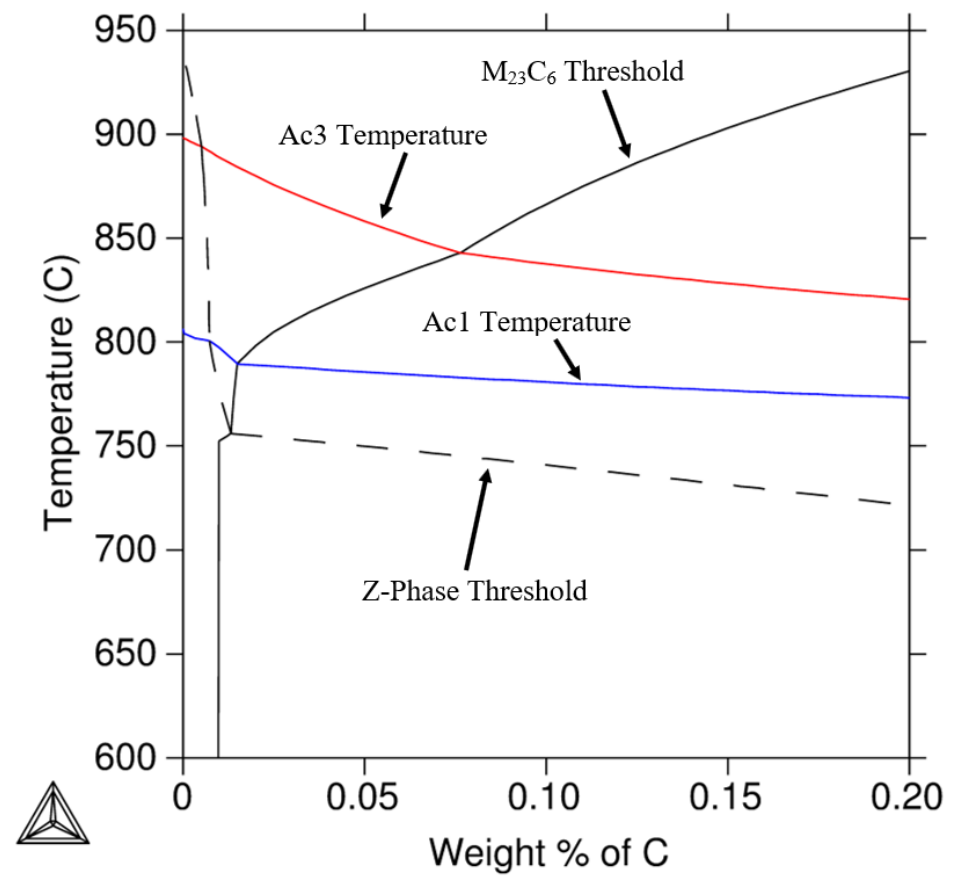

Figure 46. The new threshold temperatures of the modified Gr.91 including the Ac1 (blue), Ac3 (red), $\mathrm{M}_{23} \mathrm{C}_{6}$ (black solid line), and Z-phase (dash line). 


\section{CHAPTER 6}

\section{CONCLUSIONS}

1. Two different creep mechanisms at different conditions that have been observed to contribute to type IV crack propagation were discussed: 1.) Under short-term conditions where higher stress and temperatures can occur within the steel, $\mathrm{M}_{23} \mathrm{C}_{6}$ coarsening can be seen as the observed failure mechanism and 2.) Under long-term or lower stress and testing temperatures, Z-phase can form at the expense of MX phases.

2. In order to increase the creep strength of Gr.91, a proposed method of lowering both the Ac1 and Ac3 temperatures would contribute to two different factors: 1.) decrease the stability of $\mathrm{M}_{23} \mathrm{C}_{6}$, and 2.) increase the stability and concentration of MX phases.

3. The CALPHAD approach was utilized to simulate two different sets of results. First, a baseline fundamental thermodynamic understanding of the Gr.91 steel which included the material as having a Fe-Cr-C-V-Nb-N alloy composition. The second, established a thermodynamic profile in which $\mathrm{Mn}, \mathrm{Ni}$, and $\mathrm{Ti}$ alloying elements as well as variations of $\mathrm{V}, \mathrm{Nb}$, and $\mathrm{N}$ concentrations were added and compared with the baseline results.

4. For the baseline, two different MX phases, named MX1 and MX2 became stable. Site fraction analysis showed that MX1 had a higher concentration of $\mathrm{N}$ within the second sublattice of the FCC crystal making them nitrides (MN) whereas MX2 were mostly carbides (MC). 
5. S-1 and S-2 simulations showed the results of high concentrations of manganese (Mn), and separately nickel (Ni) had on the stability of $\mathrm{M}_{23} \mathrm{C}_{6}$ carbides. The results show that $0.66 w t . \% \mathrm{Mn}(\mathrm{S}-1)$ had more of an effect of destabilizing the carbides than 0.43 wt. $\% \mathrm{Ni}(\mathrm{S}-2)$ at temperatures between $802.2^{\circ} \mathrm{C}$ and $837.7^{\circ} \mathrm{C}$. At higher temperatures, the effects became less critical and therefore did not decrease its maximum stability temperature of $870^{\circ} \mathrm{C}$ which was noted as the convergent point of all three curves.

6. Under $0.01 \mathrm{wt} . \% \mathrm{Ti}$ for S-3 simulation, showed results in both an increase in concentration and volume amount for MX1. Site fraction analysis gave the profile of MX1 in which $\mathrm{TiN}, \mathrm{NbN}$, and $\mathrm{VN}$ metallic FCC structures are most likely to appear within its stable temperature range.

7. The results for $\mathrm{S}-4, \mathrm{~S}-5$, and $\mathrm{S}-6$, which correspond with changes to the vanadium $(\mathrm{V})$, niobium $(\mathrm{Nb})$, and nitrogen $(\mathrm{N})$ concentrations of the baseline Gr.91 system, revealed that small concentrations of $0.025 \mathrm{wt} . \% \mathrm{~N}$ (S-6), could dramatically decrease the volume amount and stability of Z-phase precipitates. Under S-4 for $0.27 \mathrm{wt} . \% \mathrm{~V}$ and S-5 for $0.11 \mathrm{wt} \% \mathrm{Nb}$, were observed to have little or no changes to molar fraction of Z-phase, however S-4 did effectively lower the maximum stability temperature for this phase.

8. Scheil simulations for $\mathrm{M}_{23} \mathrm{C}_{6}$ and $\mathrm{MX} 1$ phases were simulated. More specifically, S-1 and S-2 for $\mathrm{M}_{23} \mathrm{C}_{6}$ and S-3 for MX1 were compared with the baseline scheil simulations. The results concluded very small changes for S-1 and S-2, overall indicating that high concentrations of $\mathrm{Mn}$ and $\mathrm{Ni}$ do not change the stability nor molar fractions of $\mathrm{M}_{23} \mathrm{C}_{6}$ phases under fast cooling conditions. However, for $\mathrm{S}-3$ 
for $0.01 \mathrm{wt} . \% \mathrm{Ti}$ was observed to not only increase the stability of MX1 phases, moving the maximum stability temperature of $1410^{\circ} \mathrm{C}$ for the baseline to $1733^{\circ} \mathrm{C}$, but also increasing its molar fraction serval times over from .0009 to .0074.

9. A new modified Gr.91 composition was simulated. The specific composition seen in Table 5 is the combined simulated compositions seen in S-1 through S-6. The modified Gr.91 resulted in not only lowering the Z-phase precipitates within the system, but also increased MX phase stability in lower temperature regions where Z-phase is stable. However, due to the low concentrations of N, the MX1 phase seen previously as the most dominate MX phase under baseline simulations, was lowered both in molar fraction and in stability at higher temperature regions. MX2 was observed to have the greatest effect. Site fractional analysis showed that $\mathrm{NbC}$ were the leading MX2 carbides to be stable at lower temperatures, indicating that a promotion of MX carbides to form very stable MX phases within Gr.91 could dramatically increase the creep life of this alloy.

10. Threshold temperatures for the modified Gr.91 concluded similar properties with the baseline results. For example, increased concentration of $\mathrm{C}$ in both the baseline and modified Gr.91 increased the stability of $\mathrm{M}_{23} \mathrm{C}_{6}$ while decreasing the Z-phase. However, under the modified Gr.91 a slightly higher concentration of C, above $.001 \mathrm{wt} . \% \mathrm{C}$, is required to stabilize $\mathrm{M}_{23} \mathrm{C}_{6}$ within this system. Also, Z-phase stability was observed to increase from about $850^{\circ} \mathrm{C}$ under the baseline results to $938^{\circ} \mathrm{C}$ at concentrations lower than $.001 \mathrm{wt} . \% \mathrm{C}$. However, overall the stability of $\mathrm{M}_{23} \mathrm{C}_{6}$ was simulated to be lower between the $\mathrm{Ac} 1$ and $\mathrm{Ac} 3$ temperature region as 
well as the Z-phase under lower temperature regions when compared with the baseline results.

11. Overall, the results from both the baseline Gr.91 system and simulations of added alloying elements have concluded that certain alloying elements added, such as $\mathrm{Mn}$, $\mathrm{Ni}$, and $\mathrm{N}$, to the Gr.91 system can dramatically change the stability of the secondary phases. Under this compositional change the suppression of both $\mathrm{M}_{23} \mathrm{C}_{6}$ and Z-phases is possible which in turn can both increase the creep life of the material under short-term and long-term operational temperatures, as well as possibly changing the microstructure of the HAZ during welding. This can lead to possible type IV mechanisms that have not been previously observed before and in turn lead to better understanding of type IV failures in future high Cr martensitic structural steels. 


\section{CHAPTER 7}

\section{FUTURE WORK}

1. Experimental creep work which observes the effects of the secondary phases under the various compositional changes seen in this thesis must be done. This includes both short-term and long-term operational use of the material.

2. Additional simulations can be completed under different austenite stabilizers including palladium (Pd), rhodium (Rh), Platinum (Pt), and Iridium (Ir), which has been concluded to strengthen these families of steels $[84,85]$.

3. For $\mathrm{M}_{23} \mathrm{C}_{6}$, additional simulations which have been observed to affect the coarsening rate of these precipitates can be done including small additions of boron (B) $[31,48,86,87]$, and high concentrations of tungsten (W) [88].

4. Additional elements have also been observed to increase the creep strength for high $\mathrm{Cr}$ ferritic steels including aluminum (Al) [89], high concentrations of both tungsten (W) and cobalt (Co) [90, 91], and copper (Cu) [92].

5. Focus must be done to include increased amount of MX carbonitrides or carbides which could increase the creep strength under long-term use. Additionally, lower concentrations of nitrogen $(\mathrm{N})$ within Gr.91 must also be prioritized to lower the stability and molar fraction of Z-phase precipitates as seen in Figure 44. 


\section{REFERENCES}

[1] F. Abe, H. Okada, S. Wanikawa, M. Tabuchi, T. Itagaki, K. Kimura, K. Yamaguchi, and M. Igarashi, Proceedings of the Seventh Liege Conference on Materials for Advanced Power Engineering, Liege, Belgium (2002) 1397.

[2] K. Laha, K.S. Chandravathi, P. Parameswaran, K.B.S. Rao, and S.L. Mannan, "Characterization of Microstructures across the Heat-Affected Zone of the Modified 9Cr1Mo Weld Joint to Understand Its Role in Promoting Type IV Cracking", Metallurgical and Materials Transactions A 38(1) (2007) 58-68.

[3] X. Yu, "Multi-Scale Characterization of Heat-Affected Zone in Martensitic Steels", Graduate Program in Welding Engineering, The Ohio State University, 2012, p. 291.

[4] J.A. Francis, W. Mazur, and H.K.D.H. Bhadeshia, "Type IV cracking in ferritic power plant steels", Materials Science and Technology 22(12) (2013) 1387-1395.

[5] A. Orlova, J. Bursik, K. Kucharova, and V. Sklenicka, "Microstructural Stability of Creep Resistance Alloys for High Temperature Plant Applications", The Institute of Materials, London, 1998.

[6] K. Suzuki, S. Kumai, H. Kushima, K. Kimura, and F. Abe, "Precipitation of Z-phase and Precipitation Sequence during Creep Deformation of Mod.9Cr-1Mo Steel", Tetsu-toHagane 89(6) (2003) 691-698.

[7] F. Abe, "Creep rates and strengthening mechanisms in tungsten-strengthened $9 \mathrm{Cr}$ steels", Materials Science and Engineering A 319-321 (2001) 770-773.

[8] X. Yu, S.S. Babu, H. Terasaki, Y. Komizo, Y. Yamamoto, and M.L. Santella, "Correlation of precipitate stability to increased creep resistance of $\mathrm{Cr}-\mathrm{Mo}$ steel welds", Acta Materialia 61(6) (2013) 2194-2206.

[9] M. Santella, "Improving the Proformence Creep Strength-Enhanced Ferritic Steels", pp. 1-7.

[10] N. Dudova, A. Plotnikova, D. Molodov, A. Belyakov, and R. Kaibyshev, "Structural changes of tempered martensitic $9 \% \mathrm{Cr}-2 \% \mathrm{~W}-3 \%$ Co steel during creep at $650^{\circ} \mathrm{C}$ ", Materials Science and Engineering: A 534 (2012) 632-639. 
[11] F. Abe, T. Horiuchi, M. Taneike, and K. Sawada, "Stabilization of martensitic microstructure in advanced 9Cr steel during creep at high temperature", Materials Science and Engineering: A 378(1-2) (2004) 299-303.

[12] R. Agamennone, W. Blum, C. Gupta, and J.K. Chakravartty, "Evolution of microstructure and deformation resistance in creep of tempered martensitic 9-12\% Cr2\%W-5\%Co steels", Acta Materialia 54(11) (2006) 3003-3014.

[13] B. Sonderegger, S. Mitsche, and H. Cerjak, "Martensite laths in creep resistant martensitic 9-12\% Cr steels - Calculation and measurement of misorientations", Materials Characterization 58(10) (2007) 874-882.

[14] D. Rojas, J. Garcia, O. Prat, L. Agudo, C. Carrasco, G. Sauthoff, and A.R. KaysserPyzalla, "Effect of processing parameters on the evolution of dislocation density and subgrain size of a $12 \% \mathrm{Cr}$ heat resistant steel during creep at $650^{\circ} \mathrm{C} "$, Materials Science and Engineering: A 528(3) (2011) 1372-1381.

[15] A. Kipelova, R. Kaibyshev, A. Belyakov, and D. Molodov, "Microstructure evolution in a 3\%Co modified P911 heat resistant steel under tempering and creep conditions", Materials Science and Engineering: A 528(3) (2011) 1280-1286.

[16] D.J. Abson, and J.S. Rothwell, "Review of Type IV Cracking of Weldments in 9$12 \%$ Cr Creep Strength Enhanced Ferritic Steels", International Materials Reviews 58(8) (2013) 437-473.

[17] K. Laha, K.S. Chandravathi, P. Parameswaran, and K. Bhanu Sankara Rao, "Type IV Cracking Susceptibility in Weld Joints of Different Grades of Cr-Mo Ferritic Steel", Metallurgical and Materials Transactions A 40(2) (2008) 386-397.

[18] D.J. Gooch, and S.T. Kimmins, "A study of Type IV cracking in 1/2\%CrMoV/2 1/4 CrMo weldments", Proceedings of the Third International Conference: Creep \& Fracture of Engineering Materials \& Structures, (1987 of Conference) pp. 689-703.

[19] S.T. Kimmins, M.C. Coleman, and D.J. Smith, "An overview of creep failure associated with heat affected zones of ferritic weldments", Proceedings of the Fifth International Conference: Creep \& Fracture of Engineering Materials \& Structures, (1993) 681-694. 
[20] S.T. Kimmins, and D.J. Smith, "Relaxation of interface stresses during creep of ferritic steel weldments", The Journal of Strain Analysis for Engineering Design 33(3) (1998) 195-206.

[21] F.V. Ellis, and R. Viswanathan, "Review of Type IV cracking in pipe welds", International Conference on Integrity of High Temperature Welds, London (1998 of Conference) pp. 125-134.

[22] N. Nishimura, K. Iwamoto, M. Yamauchi, F. Masuyama, T. Imamoto, and T. Yokoyama, "Development of life assessment system for high energy piping in fossil power boilers", The 4th International Conference on Reliability, Maintenance, and Safety Engineering, Shanghai (1999 of Conference).

[23] K. Coleman, and J. Parker, "Guidelines and Specifications for High-Reliability Fossil Power Plants", 3420 Hillview Avenue Palo Alto, CA 94304-1338 USA, 2011.

[24] J.D. Holloman, and L.D. Jaffe, "Time-Temperature Relations In Tempering of Steel", Advances in Mechanical Engineering 162 (1945) 223-229.

[25] H.C. Peter Mayr, Claus Jochum, and Jerzy Pasternak, "LONG-TERM CREEP BEHAVIOUR OF E911 HEAT RESISTANT 9\% CR STEEL WELDMENTS FABRICATED WITH FILLER METALS OF DIFFERENT CREEP STRENGTH", Proceedings of CREEP8 Eight International Conference on Creep and Fatigue at Elevated Temperatures, San Antonio, Texas (2007) 675-680.

[26] R.L. Klueh, "Elevated Temperature Ferritic and Martensitic Steels and their Application to Future Nuclear Reactors", International Materials Reviews 50(5) (2013) 287-310.

[27] R.P. Chen, H. Ghassemi Armaki, K. Maruyama, and M. Igarashi, "Long-term microstructural degradation and creep strength in Gr.91 steel", Materials Science and Engineering: A 528(13-14) (2011) 4390-4394.

[28] H.C.a.P. Mayr, "Creep strength of welded joints of ferritic steels", Woodhead Publishing Limited and CRC Press LLC, 6000 Broken Sound Parkway, NW, Suite 300, Boca Raton, FL 33487, USA, 2008.

[29] A. Grybėnas, V. Makarevičius, A. Baltušnikas, I. Lukošiūtė, and R. Kriūkienė, "Correlation between structural changes of $\mathrm{M}_{23} \mathrm{C}_{6}$ carbide and mechanical behaviour of 
P91 steel after thermal aging", Materials Science and Engineering: A 696 (2017) 453460.

[30] T. Horiuchi, M. Igarashi, and F. Abe, "Improved Utilization of Added B in 9Cr Heat-Resistant Steels Containing W", ISIJ International 42 (2002) S67-S71.

[31] F. Abe, T. Horiuchi, and K. Sawada, "High-Temperature Annealing for Maximization of Dissolved Boron in Creep-Resistant Martensitic 9Cr Steel", Materials Science Forum 426-432 (2003) 1393-1398.

[32] T. Shrestha, S. Alsagabi, I. Charit, G. Potirniche, and M. Glazoff, "Effect of Heat Treatment on Microstructure and Hardness of Grade 91 Steel", Metals 5(1) (2015) 131149.

[33] V. Foldyna, Z. Kubon, V. Vodarek, and J. Purmensky, Proceedings from the Thrid International Conference (EPRI) on Advanced Materials Technology for Fossil Plants, Llandysul, Ceredigion, UK, Gomer Press (2001 of Conference) pp. 89-98.

[34] F. Abe, M. Taneike, and K. Sawada, "Alloy design of creep resistant 9Cr steel using a dispersion of nano-sized carbonitrides", International Journal of Pressure Vessels and Piping 84(1-2) (2007) 3-12.

[35] H.K. Danielsen, and J. Hald, "A thermodynamic model of the Z-phase Cr(V, Nb)N", Calphad 31(4) (2007) 505-514.

[36] H.K. Danielsen, M.A.J. Somers, and J. Hald, "Z-phase in 9-12\% Cr Steels", Technical University of Denmark (DTU), Kongens Lyngby, Denmark, 2007.

[37] K. Sawada, H. Kushima, K. Kimura, and M. Tabuchi, "Z-phase formation and its effect on long-term creep strength in 9-12\%Cr creep resistant steels", Transactions of The Indian Institute of Metals 63(2-3) (2010) 117-122.

[38] J. Hald, "Materials for Advanced Power Engineering", Proceedings of the Eighth Liege Conference on Materials for Advanced Power Engineering, Forshungszentrum, Jülich GmbH, Jülich (2006). 
[39] K. Kimura, K. Sawada, H. Kushima, and Y. Toda, "Influence of Chemical Composition and Heat Treatment on Long-term Creep Strength of Grade 91 Steel", Procedia Engineering 55 (2013) 2-9.

[40] M. HaÈttestrand, and H.-O. AndreÂn, "Evaluation of particle size distributions of precipitates in a $9 \%$ chromium steel using energy filtered transmission electron microscopy", Micron 32 (2001) 789 - 797.

[41] J. Hald, "Metallurgy and creep properties of new 9-12\%Cr steels", STEEL RESEARCH 67(9) (1996) 369-374.

[42] V. Knezevic, G. Sauthoff, J. Vilk, G. Inden, A. Singheiser, R. Agamennone, W. Blum, Y. Wang, A. Scholz, C. Berger, J. Ehlers, and L. Singheiser, "Martensitic/Ferritic Super Heat-resistant $650^{\circ} \mathrm{C}$ Steels-Design and Testing of Model Alloys", ISIJ International 42(12) (2002) 1505-1514.

[43] O. Prat, J. Garcia, D. Rojas, G. Sauthoff, and G. Inden, "The role of Laves phase on microstructure evolution and creep strength of novel $9 \% \mathrm{Cr}$ heat resistant steels", Intermetallics 32 (2013) 362-372.

[44] J. Nutting, "Advanced Heat Resistant Steel for Power Generation", London Institute of Materials, 1999.

[45] K. Kuo, Transactions of the Iron and Steel Institute of Japan 173 (1953) 363.

[46] W. Crafts, and J.L. Lamont, Transactions of the American Institute of Mining and Metallurgical Engineers 185 (1949) 957.

[47] H.J.G. Schmidt, Transactions of the Iron and Steel Institute of Japan 160 (1948) 345.

[48] I. Fedorova, A. Kostka, E. Tkachev, A. Belyakov, and R. Kaibyshev, "Tempering behavior of a low nitrogen boron-added 9\%Cr steel", Materials Science and Engineering: A 662 (2016) 443-455.

[49] "ASM Handbook: Heat Treating", 10 ed., ASM International1991. 
[50] J.H.a.Z. Kubon, "Microstructural development and stability in high chromium ferritic power plant steels", London, Institute of Materials, 1997.

[51] M.S.a.H.-O.A.n. M. Hattestrand, "Advanced Heat Resistant Steel for Power Generation", London, Institute of Materials, 1999.

[52] A.M. Barnes, "Microstructural stability of creep resistant alloys for high temperature plant applications", London, Institute of Materials, 1998.

[53] P. Bianchi, P. Bontempi, A. Benvenuti, and N. Ricci, "Microstructural stability of creep resistant alloys for high temperature plant applications", London, Institute of Materials, 1998.

[54] A. Strang, and V. Vodarek, "Microstructural development and stability in high chromium ferritic power plant steels", London, Institute of Materials, 1997.

[55] T.K.a.Y.M. K. Hayashi, "Advanced Heat Resistant Steel for Power Generation", London, Institute of Materials, 1999.

[56] M.L. Santella, R.W. Swindeman, R.W. Reed, and J.M. Tanzosh, "Martensite formation in $9 \mathrm{Cr}-1$ Mo steel weld metal and its effect on creep behavior", in: O.R. Oak Ridge National Laboratory, Tennessee 37831 (Ed.) Babcock \& Wilcox Company, Barberton, Ohio 44203.

[57] S. Kobayashi, K. Toshimori, K. Nakai, Y. Ohmori, H. Asahi, and T. Muraki, "Effects of Boron Addition on Tempering Processes in an Fe-9Cr-O .1 C Alloy Martensite ", ISIJ International 42(Supplement) (2002) S72-S76.

[58] M. Kondo, M. Tabuchi, S. Tsukamoto, F. Yin, and F. Abe, "Suppressing type IV failure via modification of heat affected zone microstructures using high boron content in 9Cr heat resistant steel welded joints", Science and Technology of Welding and Joining 11(2) (2013) 216-223.

[59] M. Taneike, N. Fujitsuna, and F. Abe, "Improvement of creep strength by fine distribution of TiC in 9Cr ferritic heat resistant steel", Materials Science and Technology 20(11) (2013) 1455-1461. 
[60] C.R. Brinkman, V.K. Sikka, J.A. Horak, and M.L. Santella, "Long-Term CreepRupture Behavior of Modified 9Cr-1Mo Steel Base and Weldment Behavior", Oak Ridge National Laboratory, 1987, pp. 1-90.

[61] J. Hald, "Microstructure and long-term creep properties of 9-12\% Cr steels", International Journal of Pressure Vessels and Piping 85(1-2) (2008) 30-37.

[62] H.K. Danielsen, and J. Hald, Energy Materials 1 (2006) 49-57.

[63] C.G. Panait, W. Bendick, A. Fuchsmann, A.F. Gourgues-Lorenzon, and J. Besson, "Study of the microstructure of the Grade 91 steel after more than 100,000 h of creep exposure at $600{ }^{\circ} \mathrm{C} "$, International Journal of Pressure Vessels and Piping 87(6) (2010) 326-335.

[64] E.E. E. Cerri, S. Spigarelli, and P. Bianchi, "Evolution of microstructure in a modified 9Cr-1Mo steel during short term creep", Materials Science and Engineering A 245(2) (1998) 285-292.

[65] W.N.S.a.K.S.T. Smith D J, "Type IV creep cavity accumulation and failure in steel welds", International Journal of Pressure Vessels and Piping 80(9) (2003) 617-627.

[66] J.S. Lee, K. Maruyama, I. Nonaka, and T. Ito, "Mechanism of type IV failure in weldment of a mod 9Cr-1Mo steel", Creep deformation and fracture, design and life extension (MS\&T), Warrendale, PA (2005) 139-148.

[67] J.A. FRANCIS, W. MAZUR, and H.K.D.H. BHADESHIA, "Estimation of Type IV Cracking Tendency in Power Plant Steels", ISIJ International 44(11) (2004) 1966-1968.

[68] V.S. Agueev, V.N. Bykov, A.M. Dvoryashin, V.N. Golovanov, E.A. Medvendeva, V.V. Romaneev, V.K. Sharmardin, and A.N. Vorobiev, "14th international symposium on 'Effects of radiation on materials'", ASTM STP 1046, Philadelphia, PA, 1989.

[69] P.J. Maziasz, R.L. Klueh, and J.M. Vitek, "Helium effects on void formation in 9Cr$1 \mathrm{MoVNb}$ and 12Cr-1MoVW irradiated in HFIR", Journal of Nuclear Materials 141-143 (1986) 929-937. 
[70] R.L. Klueh, J.J. Kai, and D.J. Alexander, "Microstructure-mechanical properties correlation of irradiated conventional and reduced-activation martensitic steels ", Journal of Nuclear Materials 225 (1995) 175-186.

[71] E.A. Little, and L.P. Stoter, "11th Conference on 'Effects of Irradiation on Materials'", ASTM STP 782, Philadelphia, PA, 1982.

[72] D.S. Gelles, and L.E. Thomas, "Proceedings of Topical Conference on 'Ferritic Alloys for Use in Nuclear Energy Technologies'", Metallurgical Society of AIME, Warrendale, PA, 1984.

[73] H.K. Danielsen, and J. Hald, "A thermodynamic model of the Z-phase Cr(V, Nb)N ", Department of Manufacturing Engineering and Management, Technical University of Denmark, 2007, p. 146.

[74] F. Abe, "Analysis of creep rates of tempered martensitic 9\% Cr steel based on microstructure evolution", Materials Science and Engineering: A 510-511 (2009) 64-69.

[75] Y. Zhong, K. Ozturk, J.O. Sofo, and Z. Liu, "Contribution of first-principles energetics to the $\mathrm{Ca}-\mathrm{Mg}$ thermodynamic modeling", Journal of Alloys and Compounds 420 (2006) 98-106.

[76] M. Asadikiya, C. Rudolf, C. Zhang, B. Boesl, A. Agarwal, and Y. Zhong, "Thermodynamic modeling and investigation of the oxygen effect on the sintering of B4C", Journal of Alloys and Compounds 699 (2017) 1022-1029.

[77] M. Asadikiya, C. Zhang, C. Rudolf, B. Boesl, A. Agarwal, and Y. Zhong, "The effect of sintering parameters on spark plasma sintering of $\mathrm{B}_{4} \mathrm{C}$ ", Ceramics International 43(14) (2017) 11182-11188.

[78] M. Asadikiya, and Y. Zhong, "Oxygen ion mobility and conductivity prediction in cubic yttria-stabilized zirconia single crystals", Journal of Materials Science 53(3) (2017) 1699-1709.

[79] M. Asadikiya, H. Sabarou, M. Chen, and Y. Zhong, "Phase diagram for a nanoyttria-stabilized zirconia system. ", RSC Advances 6(21) (2016) 438-445. 
[80] M. Asadikiya, C. Rudolf, C. Zhang, B. Boesl, and Y. Zhong, "The Role of Calphad Approach in the Sintering of $\mathrm{B}_{4} \mathrm{C}$ with SIC as a Sintering Aid by Spark Plasma Sintering Technique", in: K. Shimamura, S. Kirihara, J. Akedo, T. Ohji, M. Naito (Eds.), Additive Manufacturing and Strategic Technologies in Advanced Ceramics: Ceramic Transactions, John Wiley \& Sons, Inc., Hoboken, NJ, USA, 2016.

[81] A. Smith, M. Asadikiya, M. Yang, and Y. Zhong, "Investigation of the Stabilities of Secondary Phases in Grade 91 Steels Through CALPHAD Approach", Metallurgical and Materials Transactions A (2018).

[82] A.Y. Kipelova, A.N. Belyakov, V.N. Skorobogatykh, A. Shchenkova, and R.O. Kaibyshev, "Tempering-induced structural changes in steel 10Kh9K3V1M1FBR and their effect on the mechanical properties", Metal Science and Heat Treatment 52 (2010) 100-110.

[83] A. Fedoseeva, N. Dudova, and R. Kaibyshev, "Creep strength breakdown and microstructure evolution in a 3\%Co modified P92 steel", Materials Science and Engineering: A 654 (2016) 1-12.

[84] P.D. Clarke, P.F. Morris, N. Cardinal, and M.J. Worrall, Parsons 2003, engineering issues in turbine machinery, power plant and renewables: Proceedings of the Sixth International Charles Parsons Turbine Conference, London (2003) 334-345.

[85] F. Abe, M. Igarashi, N. Fujitsuna, K. Kimura, and S. Muneki, "Advanced Heat Resistant Steel for Power Generation", London Institute of Materials, 1999.

[86] S. Kobayashi, K. Toshimori, K. Nakai, Y. Ohmori, H. Ashi, and T. Muraki, "Effects of Boron Addition on Tempering Processes in an Fe-9Cr-0.1C Alloy Martensite", ISIJ International 42 (2002) S72-S76.

[87] M. Klimenkov, E. Materna-Morris, and A. Möslang, "Boron effect on the microstructure of $9 \% \mathrm{Cr}$ ferritic-martensitic steels", Journal of Nuclear Materials $\mathbf{4 6 2}$ (2015) 280-288.

[88] Y. Hasegawa, M. Ohgahi, and Y. Okamura, Advances in Material Technology for Fossil Power Plants: Proceedings of the 3rd International Conference, University of Wales, Swansea (2001 of Conference) pp. 457-466. 
[89] J. Parker, "Factors affecting Type IV creep damage in Grade 91 steel welds", Materials Science and Engineering: A 578 (2013) 430-437.

[90] M. Igarashi, S. Muneki, H. Hasegawa, K. Yamada, and F. Abe, "Creep Deformation and Microstructural Evolution the Corresponding in High-Cr Ferritic Steel", ISIJ International 41(4) (2001) S101-109.

[91] K. Kimura, K. Seki, Y. Toda, and F. Abe, "Developmentof High Strength $15 \mathrm{Cr}$ Ferritic Creep Resistant Steel with Addition of Tungsten and Cobalt", ISIJ International 41(4) (2001) S121-129.

[92] A. Iseda, A. Natori, Y. Sawaragi, K. Ogawa, F. Masuyama, and T. Yokoyama, Thermal and Nuclear Power Engineering Society 45(8) (1994) 900-909. 